\title{
Abundance variations in the globular cluster M71 (NGC 6838)
}

\author{
A. Alves-Brito ${ }^{1}$, R. P. Schiavon ${ }^{2}$, B. Castilho ${ }^{3}$, and B. Barbuy ${ }^{1}$ \\ 1 Universidade de São Paulo, IAG, Rua do Matão 1226, Cidade Universitária, São Paulo 05508-900, Brazil \\ e-mail: abrito@astro.iag.usp.br, barbuy@astro.iag.usp.br \\ 2 Department of Astronomy, University of Virginia, P.O. Box 3818, Charlottesville, VA 22903-0818. \\ e-mail: rps7v@mail .astro.virginia.edu \\ 3 Laboratório Nacional de Astrofísica/MCT, CP 21, Itajubá, MG, 37500-000, Brazil \\ e-mail: bruno@lna.br \\ 2007
}

\begin{abstract}
Context. Abundance variations in moderately metal-rich globular clusters can give clues about the formation and chemical enrichment of globular clusters.

Aims. $\mathrm{CN}, \mathrm{CH}, \mathrm{Na}, \mathrm{Mg}$ and $\mathrm{Al}$ indices in spectra of 89 stars of the template metal-rich globular cluster M71 are measured and implications on internal mixing are discussed.

Methods. Stars from the turn-off up to the Red Giant Branch $(0.87<\log g<4.65)$ observed with the GMOS multi-object spectrograph at the Gemini-North telescope are analyzed. Radial velocities, colours, effective temperatures, gravities and spectral indices are determined for the sample.

Results. Previous findings related to the $\mathrm{CN}$ bimodality and $\mathrm{CN}-\mathrm{CH}$ anticorrelation in stars of $\mathrm{M} 71$ are confirmed. We also find a $\mathrm{CN}-\mathrm{Na}$ correlation, and $\mathrm{Al}-\mathrm{Na}$, as well as an $\mathrm{Mg}_{2}-\mathrm{Al}$ anticorrelation.

Conclusions. A combination of convective mixing and a primordial pollution by AGB or massive stars in the early stages of globular cluster formation is required to explain the observations.
\end{abstract}

Key words. globular clusters : general - globular cluster : individual : M71 - stars : abundances

\section{Introduction}

Globular Clusters (GCs) provide important information on the early chemical and dynamical evolution of the Milky Way.

Star-to-star abundance variations of light elements - Li, C, $\mathrm{N}, \mathrm{O}, \mathrm{Na}, \mathrm{Mg}$, and $\mathrm{Al}$ - are extensively reported in the literature (Gratton et al. 2004 and references therein). Li variations among turnoff (TO) stars and a Li-Na anticorrelation have been reported; among giant stars, $\mathrm{C}$ and $\mathrm{N}$ abundances, as well as the pairs $\mathrm{O}: \mathrm{Na}$ and $\mathrm{Al}: \mathrm{Mg}$ are also found to be anticorrelated. Such anomalies have not been obtained for heavier elements. These abundance variations have been reported in the literature over the past two decades, but their origin is still widely debated.

Some of the abundance variations seen in globular-cluster giants can be explained by evolutionary mixing with migration of processed material through the CNO cycle to the surface of giant stars (Iben 1964; Charbonnel 1994), whereas a primordialenrichment scenario, which requires early contamination of intracluster material, is claimed by some authors (e.g. Smith 1987; Kraft 1994).

With a moderately high metallicity $(\langle[\mathrm{Fe} / \mathrm{H}]\rangle=-0.73$, Harris 1996), and an old age of 10-12 Gyr (Grundahl et al. 2002; Meissner \& Weiss 2006), M71 is often regarded as a prototype of northern metal-rich globular clusters and considered as a suitable globular cluster to study abundance variations. It is located near the Galactic plane $\left(b=-4.6^{\circ}\right)$ and has a reddening of $E(B-$ $\mathrm{V})=0.27 \pm 0.05$ and an apparent distance modulus of $(\mathrm{m}-\mathrm{M})_{\mathrm{V}}$ $=13.60 \pm 0.10$ (Geffert \& Maintz 2000). Dinescu et al. (1999) have obtained space velocities for a set of Galactic globular clus-

Send offprint requests to: A. Alves-Brito ters. For M71 they determined velocity components $(\mathrm{U}, \mathrm{V}, \mathrm{W})=$ $(77 \pm 14,-58 \pm 10,-2 \pm 14) \mathrm{km} / \mathrm{s}$ and a low eccentricity orbit, which characterizes M71, kinematically, as a thick-disk cluster.

Chemical abundances were discussed in several previous studies of this cluster, including DDO photometry of giant stars (Hesser et al. 1977; Briley et al. 2001) and low- and highresolution analysis of stars in different evolutionary stages from the Main-Sequence (MS) TO to the Red Giant Branch (RGB) tip (Cohen 1980; Smith \& Norris 1982; Leep et al. 1987; Smith \& Penny 1989; Penny et al. 1992; Sneden et al. 1994; Cohen 1999; Ramirez \& Cohen 2002; Lee et al. 2004; Lee 2005; Boesgaard et al. 2005; Yong et al. 2006). Many of these studies show a CN bimodality, with $\mathrm{CN}-\mathrm{CH}$ anticorrelation, $\mathrm{Na}-\mathrm{O}$ anticorrelation and variations in $\mathrm{Al}$ abundance.

In this paper we present the main results of an analysis of high $\mathrm{S} / \mathrm{N}$, medium resolution, Gemini/GMOS spectra of a large number of M 71 stars, from the main-sequence turnoff to the tip of the giant branch. Our goals are twofold: to improve the statistics on abundance variations in M71 stars; and to study the behaviour of 14 spectral indices for the sample stars in order to shed light on the main astrophysical processes leading to the observed star-to-star abundance variations. We estimate the $\mathrm{C}$ and $\mathrm{N}$ abundances of one $\mathrm{CN}$-strong and one $\mathrm{CN}$-weak giant from spectrum synthesis, based on state-of-the-art model photospheres and an up-to-date line list. A comparison of our results with those based on recent high-resolution abundance analysis is also presented.

This paper is structured as follows. The observations and data reductions are described in Sect. 2. The analysis of radial velocities, photometry, atmospheric parameters and line indices 
is presented in Sect. 3. In Sect. 4 the results are shown, and in Sec. 5 they are discussed and contrasted with previous studies. Our conclusions are summarized in Sect. 6.

\section{Observations and data reduction}

Imaging and spectroscopy of M71 stars were obtained with the Gemini Multi-Object Spectrograph (GMOS; see, for example, Hook et al. 2004 for more details) in the MOS mode on the $8 \mathrm{~m}$ Frederick C. Gillett Telescope (Gemini-North).

On July 18, 2002, the pre-imaging required to build four GMOS masks was obtained. It superposes a GMOS-North field over 5.5 arcmin x 5.5 arcmin. The image of the M71 field was obtained using the r_G0303 filter, with an effective wavelength of $6300 \AA$ and wavelength coverage of 5620-6980 A. Exposures of $4 \times 180$ s were taken, with the CCD detector operating at 4 electrons/DN and a readout noise of 6.6 electrons. The mean airmass during the pre-imaging observation was 1.157 . Thus, using a finding-chart available in Cudworth (1985), 145 M71 stars were identified in the GMOS image and selected for spectroscopic observations.

Spectroscopic data were collected on August 5, 2002, using the B600+_G5303 (600 lines/mm) grating and adopting arcsecwide slits. The CCDs were binned in a 2 x 2 mode (along both the spatial and dispersion axes). This configuration achieved a spectral resolution $\mathrm{R} \sim 2,000$ at $5100 \AA$ with a dispersion of $0.0917 \mathrm{~nm} /$ pix, covering from 3500 to $7000 \AA$.

The 145 target stars were selected in order to give appropriate sampling of the colour magnitude diagram (CMD). The maximum time for each individual exposure was constrained by the bright red giants of the cluster. Short exposures were taken in order to avoid saturation and a number of these exposures for the faintest stars of the turn-off were co-added. The total integration time was defined by our desire to achieve $\mathrm{S} / \mathrm{N} \sim 150$ at $\lambda \sim$ $4000 \AA$ A Finally, spectra of the spectrophotometric standard star EG 131 were obtained using a 1-arcsec longslit, with the same instrumental set up as adopted for the science observations.

Science and standard star data were both reduced using the GEMINI GMOS Data Reduction Package within the IRAF package. Bias frames, flat-fields and $\mathrm{CuAr}$ images were taken as part of the GEMINI base calibrations. At this point, the reduction process comprised bias-subtraction and flat-fielding, using GCAL flats which were previously co-added and normalized. Cosmic rays were then cleaned. The wavelength calibration was carried out with solutions obtained from the $\mathrm{CuAr}$ arc exposures, which provided typical residuals of $0.2 \AA$. Spectra were then sky-subtracted and extracted into a series of 1D spectra. All spectra were extinction-corrected using the mean extinction coefficients obtained for Mauna Kea. As a result of the location of the slits with respect to the mask-bisector, the wavelength coverage varies from star to star. In addition, two gaps corresponding to $0.5 \mathrm{~mm}$ between CCDs are also present in the final spectra.

\section{Analysis}

\subsection{Heliocentric radial velocities}

Heliocentric radial velocities for the sample stars were obtained using both rvidlines and fxcor IRAF procedures. The former measures radial velocities from spectra by determining the wavelength shift in spectral lines relative to specified rest wavelengths and the measured velocities are corrected to a heliocentric frame of reference. We derived a mean heliocentric radial velocity of
$-12 \pm 46 \mathrm{~km} / \mathrm{s}(\mathrm{N}=145$ stars $)$. The task fxcor, on the other hand, performs a Fourier cross-correlation between lists of input object and template spectra. A set of 77 spectral templates with stellar parameters given by: $[\mathrm{Fe} / \mathrm{H}]=-1.00,[\alpha / \mathrm{Fe}]=0.00,4250$ $\leq \mathrm{T}_{\text {eff }} \leq 5750 \mathrm{~K}$ and $0.00 \leq \operatorname{logg} \leq 5.0$ dex were taken from the library of synthetic stellar spectra by Coelho et al. (2005). Measurements of 142 stars led to a mean heliocentric radial velocity of $11 \pm 49 \mathrm{~km} / \mathrm{s}$.

The mean difference between the heliocentric radial velocities as measured in two ways $\left(\mathrm{v}_{\mathrm{fxcor}}^{\mathrm{h}}-\mathrm{v}_{\text {rvidlines }}^{\mathrm{h}}\right)$ is $23 \mathrm{~km} / \mathrm{s}$. For comparison, Harris (1996) gives a mean heliocentric radial velocity of $-22.8 \pm 0.2 \mathrm{~km} / \mathrm{s}$ for M71. As the sample spectra have a resolution $\mathrm{R} \sim 2000$, we expect a theoretical accuracy of around $(1 / 10)(\mathrm{c} / 2000)=15 \mathrm{~km} / \mathrm{s}$, which is in good agreement with the scatter obtained above. Individually, the higher values in the measurements of the heliocentric radial velocities could be explained in part based on the low-resolution of the spectra. We found a nearly Gaussian distribution of the radial velocitites with a dispersion of $\sim 45 \mathrm{~km} / \mathrm{s}$, and we believe that this finding reflects the uncertainty in the determination of the radial velocity itself at this spectral resolution. The accuracy in the heliocentric radial velocities measurements is also wavelengthcalibration dependent; in our case the GMOS calibration lamps were rather poor. Given the high velocity-dispersion obtained, the radial velocities were used to shift the sample spectra to rest wavelengths rather than a star membership selection criterion.

\subsection{Photometry}

As reported in the GEMINI/GMOS web sit巴, up to September 12,2006 there was a large ( 5") offset in the optical positions (RA and DEC) in GMOS-North images. A FORTRAN code was applied in order to take these offsets into account and find out the correct identification of the sample stars from previous photometric catalogs of M71. Using the SkyCat tool we plotted all 145 observed stars on the Gemini-North preimaging and created our own finding chart of M71 following the identification as given in each GMOS mask. Optical photometry for M71 from the literature was adopted by selecting CCD photometry able to give us crucial information like completeness and membership probability. Two papers fulfilled these requirements: (i) Cudworth (1985) presents proper motions and visual photometry for 350 M 71 stars down to a limit of $\mathrm{V}=16$. Cudworth (2006, priv. comm.) gives proper motions and photometry for fainter stars (V > 16), amounting to 1522 stars. (ii) Geffert \& Maintz (2000) and Geffert (2002, priv. comm.) present B,V CCD observations for around 4450 stars (limited to $V=18.5 \mathrm{mag}$ ) covering a field of $20 \times 20$ arcminutes of M71.

The colour-magnitude diagram (CMD) of M71, using the photometry from Cudworth $(1985,2006)$ and marking the sample stars is displayed in Figure 1. Overplotted is a Yonsei-Yale isochrone (Kim et al. 2002) with parameters $[\mathrm{Fe} / \mathrm{H}]=-0.68 \mathrm{dex}$, $[\alpha / \mathrm{Fe}]=0.00 \mathrm{dex}$, age $=12 \mathrm{Gyr}$. The isochrone has been shifted by $(\mathrm{m}-\mathrm{M})_{\mathrm{V}}=13.60 \mathrm{mag}$ and $\mathrm{E}(\mathrm{B}-\mathrm{V})=0.27 \mathrm{mag}($ Geffert $\&$ Maintz 2000). The stars' designations, positions, membership probabilities, colours, along with bolometric magnitudes, gravities and temperatures are shown in Table 1

\subsubsection{Temperatures}

Effective temperatures $\left(\mathrm{T}_{\mathrm{eff}}\right)$ for the sample were obtained by employing the empirical calibrations of Alonso et al. (1996;

\footnotetext{
${ }^{1}$ http://www.gemini.edu/sciops/instruments/gmos/gmosIndex.html
} 

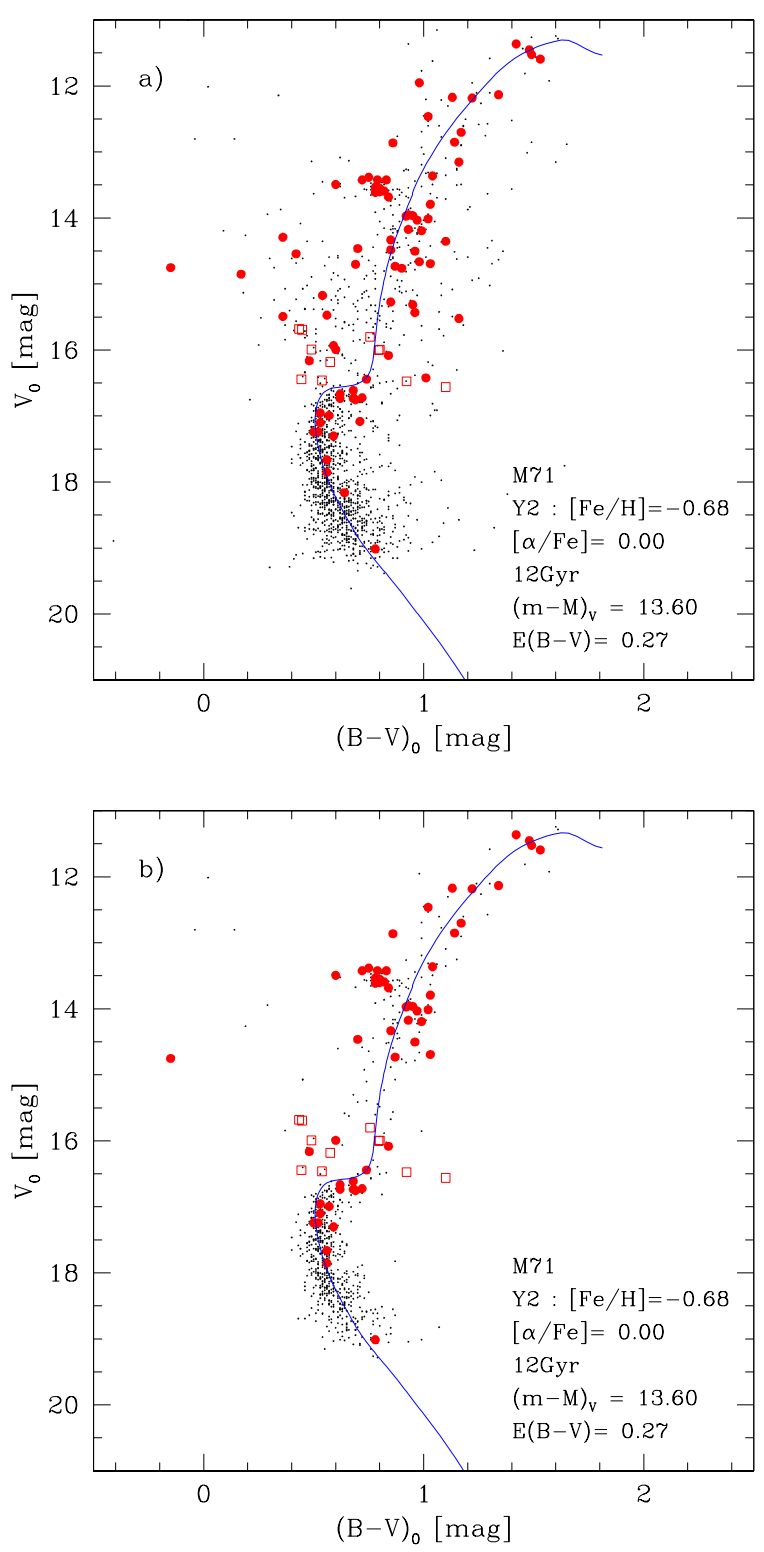

Fig. 1. The optical V,B-V CMD of M71. Top: dots: Cudworth $(1985,2006)$ photometry; filled circles: sample stars; open squares: stars identified in Geffert \& Maintz (2000). Bottom: stars with membership probability $\mathrm{P} \geq 80 \%$ (symbols are the same as above). A Yonsei-Yale isochrone by Kim et al. (2002) with parameters as indicated is overplotted.

1999; 2001) for dwarfs and giants stars. The intrinsic colours $(\mathrm{B}-\mathrm{V})_{\mathrm{o}}$ were determined by adopting $\mathrm{E}(\mathrm{B}-\mathrm{V})=0.27$ (Geffert \& Maintz 2000) and mean $[\mathrm{Fe} / \mathrm{H}]=-0.73$ (Harris 1996). The uncertainty in the effective temperatures $\mathrm{T}(\mathrm{B}-\mathrm{V})$ derived using Alonso et al.'s calibrations is typically $150 \mathrm{~K}$ (within $1 \sigma$ ).

\subsubsection{Surface gravities}

Photometric gravities for all stars were obtained in the classical way, using the $\mathrm{T}_{\text {eff }} \mathrm{S}$ described in the previous section and adopting $\mathrm{M}_{*}=0.80 \mathrm{M}_{\odot},(\mathrm{m}-\mathrm{M})_{\mathrm{V}}=13.60, \mathrm{E}(\mathrm{B}-\mathrm{V})=0.27($ Geffert \& Maintz 2000), with bolometric corrections taken from Alonso et al. (1999). Input solar values adopted were: $\mathrm{T}_{\odot}=5780 \mathrm{~K}$, $\mathrm{M}_{\mathrm{bol} \odot}=4.75$, and $\log g=4.44$. The error in $\mathrm{M}_{\mathrm{bol}}$ is mostly due to the $\mathrm{M}_{\mathrm{V}}$ value and total extinction $\mathrm{A}_{\mathrm{V}}$, the latter with an uncertainty around $\pm 0.05 \mathrm{mag}$. For $\mathrm{M}_{\mathrm{V}}$, adopting an error in distance as large as $30 \%$, we get $\sigma_{\mathrm{M}_{\mathrm{bol}}} \sim 0.30 \mathrm{mag}$, which leads to an error on the adopted photometric gravities of \pm 0.30 dex. For stars fainter than $\mathrm{V}=17.5$, the surface gravities were derived from Yonsei-Yale $12 \mathrm{Gyr}$ isochrones of $\mathrm{Z}=0.0040, \mathrm{Y}=0.24$ and $[\mathrm{Fe} / \mathrm{H}]=-0.70$ (Kim et al. 2002).

\subsubsection{Spectral indices}

The ability to analyze individual spectra of cluster members can provide knowledge on the spectral properties of stellar populations, placing constraints on stellar population synthesis. In medium-resolution spectra the measurement and analysis of spectral indices is widely employed to interpret the chemical evolution history of stellar populations in galaxies.

Absorption line indices were measured using the LECTOR program, by A. Vazdekis, which measures line strengths in 1-D spectra (Vazdekis et al. 2003). Besides measuring the Lick/IDS absorption-line indices (Worthey et al. 1994; Worthey $\&$ Ottaviani 1997) we modified LECTOR in order to measure the line indices recently defined by Serven et al. (2005). In this paper, the only index from the latter list we will discuss is Al3953, which was shown by Serven et al. to be very sensitive to the abundance of aluminium.

For the uncertainties on the indices we initially considered those provided by LECTOR (see Cardiel et al. 1998 for details). These Poisson-based uncertainties on the indices are underestimated. Thus, the uncertainties were also estimated from the standard deviation of the measurements for each index on the individual spectra, and hereafter these latest uncertainties will preferentially be shown.

In Table 2 are presented the index passband definitions where wavelengths are given in angstroms. Tables 3,4 and 5 show the results and Poisson uncertainties in the total-passband net counts for the indices $\mathrm{CN}_{1}$ [mag], $\mathrm{CN}_{2}$ [mag], Ca4227 [ $\AA$ ], G4300:CH [mag], $\mathrm{Fe} 4383[\AA], \mathrm{H}_{\beta}[\AA], \mathrm{Mg}_{1}$ [mag], $\mathrm{Mg}_{2}$ [mag], $\mathrm{Mgb}[\AA]$,

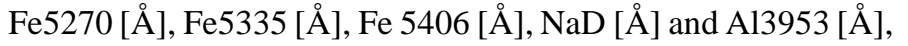
while Figure 2 shows one of the final flux-calibrated spectra of the sample with some features labeled.

\section{Results}

The final sample adopted consists of stars with a membership probability higher than $80 \%$ and magnitudes $\mathrm{V} \leq 15.5 \mathrm{mag}$. In addition, each spectrum was individually inspected by the region of the index passbands. Below we present the main results.

\section{1. $\mathrm{CN}$ and $\mathrm{CH}$}

The Lick CN indices measure the strength of the $\mathrm{CN} 4150 \AA$ bandhead. Although we have measured $\mathrm{CN}_{1}$ and $\mathrm{CN}_{2}$, we chose to work with $\mathrm{CN}_{1}$ more extensively. Both indices are similar in definition with a slight difference in their blue pseudocontinuum definition.

Figures 3 a,b present the $\mathrm{CN}_{1}$ index vs. V-band magnitude and $(\mathrm{B}-\mathrm{V})_{0}$ colours for M71 selected stars. Stellar IDs are also marked. The distribution of the data points in these two plots is clearly bi-modal, with two families of stars with strong and weak $\mathrm{CN}$ bands at fixed colour and/or magnitude. The dividing line between $\mathrm{CN}$-strong stars, it the top half, and $\mathrm{CN}$-weak stars in the bottom half of the plots runs diagonally from the lower left to the top right of both plots. This is because in both families of 
Table 2. Index definition.

\begin{tabular}{lccc}
\hline \hline $\begin{array}{l}\text { Index } \\
(1)\end{array}$ & $\begin{array}{c}\text { Blue Pseudocontinuum } \\
(2)\end{array}$ & $\begin{array}{c}\text { Feature } \\
(3)\end{array}$ & $\begin{array}{c}\text { Red Pseudocontinuum } \\
(4)\end{array}$ \\
\hline $\mathrm{CN}_{1}$ & 4081.3754118 .875 & 4143.3754178 .375 & 4245.3754285 .375 \\
$\mathrm{CN}_{2}$ & 4085.1254097 .625 & 4143.3754178 .375 & 4245.3754285 .375 \\
$\mathrm{Ca} 4227$ & 4212.2504221 .000 & 4223.5004236 .000 & 4242.2504252 .250 \\
$\mathrm{G} 4300$ & 4267.6254283 .875 & 4282.6254317 .625 & 4320.1254336 .375 \\
$\mathrm{Fe} 4383$ & 4360.3754371 .625 & 4370.3754421 .625 & 4444.1254456 .625 \\
$\mathrm{H} \_$beta & 4827.8754847 .875 & 4847.8754876 .625 & 4876.6254891 .625 \\
$\mathrm{Mg}_{1}$ & 4895.1254957 .625 & 5069.1255134 .125 & 5301.1255366 .125 \\
$\mathrm{Mg}_{2}$ & 4895.1254957 .625 & 5154.1255196 .625 & 5301.1255366 .125 \\
$\mathrm{Mgb}$ & 5142.6255161 .375 & 5160.1255192 .625 & 5191.3755206 .375 \\
$\mathrm{Fe} 5270$ & 5233.1505248 .150 & 5245.6505285 .650 & 5285.6505318 .150 \\
$\mathrm{Fe} 5335$ & 5304.6255315 .875 & 5312.1255352 .125 & 5353.3755363 .375 \\
$\mathrm{Fe} 5406$ & 5376.2505387 .500 & 5387.5005415 .000 & 5415.0005425 .000 \\
$\mathrm{NaD}$ & 5862.3755877 .375 & 5878.6255911 .125 & 5923.8755949 .875 \\
$\mathrm{Al3953}$ & 3937.6003967 .400 & 3921.3003935 .500 & 3969.5003987 .000 \\
\hline
\end{tabular}

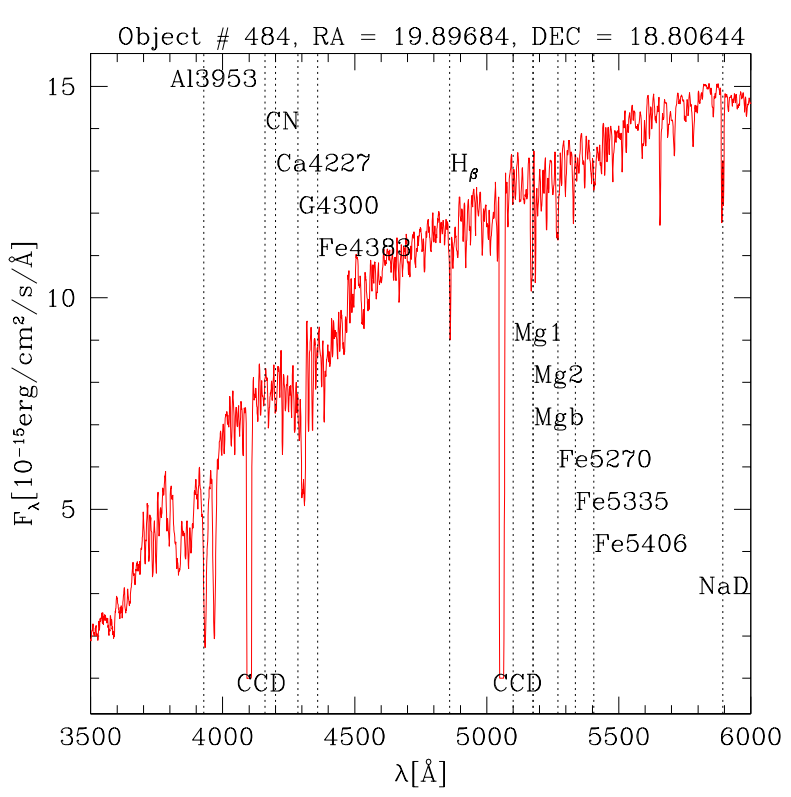

Fig. 2. Spectrum of the star $484(1-55, \mathrm{~V}=14.26)$ observed in the Mask \# 2. Gaps are due to the 3 CCD configuration of the detector. Central wavelengths of studied indices are indicated.

stars, $\mathrm{CN}$ is a strong function of temperature, so that $\mathrm{CN}$-bands become stronger for lower temperatures in both the $\mathrm{CN}$-strong and CN-weak groups. It is interesting that stars 291, 390 and 526 are AGB members, and they show a higher $\mathrm{N}$ enhancement.

Concerning stars 1351,1556 and 640, their CN measurements were slightly affected by the presence of the 2 CCD gaps around their red passband. For the $\mathrm{CN}$-strong stars, showing nitrogen excesses, we found $\langle\mathrm{CN}\rangle=0.19 \pm 0.04(\mathrm{~N}=8$ stars $)$, whereas for the $\mathrm{CN}$-weak stars $\langle\mathrm{CN}\rangle=0.04 \pm 0.04(\mathrm{~N}=20$ stars). Note that stars 1351,1556 and 640 were not taken into consideration in computing the mean $\mathrm{CN}$-weak value.

In Fig. 4 we show the location of $\mathrm{CN}$-strong and $\mathrm{CN}$-weak stars in the CMD, for $\mathrm{V}<15.5$. Stars weaker than $\mathrm{V}>15.5$ are also plotted, with no distinction between $\mathrm{CN}$ intensities, given the lower $\mathrm{S} / \mathrm{N}$ of the spectra. In Fig. 5 the $\mathrm{CN}_{1}$ index vs. $\mathrm{T}_{\text {eff }}$ is shown for the giants, where the bimodality of CN-strength is found among both RGB and Asymptotic Giant Branch (AGB) stars. Fig. 6 shows $\mathrm{CN}_{1}$ vs. $\log \mathrm{g}$ for all stars, illustrating the clear separation between $\mathrm{CN}$-strong and $\mathrm{CN}$-weak giants, whereas for dwarfs, the bimodality is not so clear, partly due to the lower $\mathrm{S} / \mathrm{N}$ of our dwarf-star spectra, and partly because the differences between $\mathrm{CN}$-strong and $\mathrm{CN}$-weak spectra are more subtle, given that $\mathrm{CN}$-bands are weak overall in the spectra of warm turnoff stars. Recall however that Cohen (1999) has found a bimodality for main sequence (MS) stars of M71.

The G-band at $4300 \AA$ includes a $\mathrm{CH}$ bandhead and can be used to derive the carbon abundance. Its behaviour along the main sequence, subgiant and red giant sequences can give important clues on mixing processes along stellar evolution. In Fig. 7 we plot the $\mathrm{G}$ band indices as a function of $\mathrm{V}$ magnitude. The symbols are the same as used in Figs. 3 $\mathrm{a}, \mathrm{b}$, where the $\mathrm{CN}$-strong and $\mathrm{CN}$-weak sequences are represented by filled and open circles. One can see that $\mathrm{CN}$-strong stars tend to present lower $\mathrm{CH}$ values, while the $\mathrm{CN}$-weak stars appear to show higher values of $\mathrm{CH}$. This general trend confirms the well-known $\mathrm{CN}-\mathrm{CH}$ anticorrelation in giant stars reported in past decades for many Galactic globular clusters (e.g., Dickens et al. 1979; Smith 1987; Kraft 1994; Gratton et al. 2004 and references therein). Note, however, that despite their high membership probabilities, stars 2001, 458, 505 and 7498 present lower G-band strengths than other CN-weak stars of the sample. Stars 2001, 458 and 505 are HB members, and this suggests that we also detect a bimodal distribution in the HB. Figure 8 plots an example of CN-bimodality and $\mathrm{CN}-\mathrm{CH}$ anticorrelation for two M71 stars of similar V magnitude and $\mathrm{T}_{\text {eff }}$. The $\mathrm{CN}$-strong giant $390(\mathrm{~T}=4435 \mathrm{~K}: \mathrm{CN}=$ $0.24: \mathrm{CH}=6.18$ ) presents a stronger $\mathrm{CN}$ band and a weaker $\mathrm{CH}$ band strength than star $399(\mathrm{~T}=4419: \mathrm{CN}=0.04: \mathrm{CH}=6.62)$.

\subsection{Iron and magnesium indices}

We measured spectral indices sensitive to the abundances of iron (Fe4383, Fe5270, Fe5335, and Fe5406) and magnesium $\left(\mathrm{Mg}_{1}\right.$, $\mathrm{Mg}_{2}$ and $\mathrm{Mgb}$ ) in all our spectra. We henceforth focus on an average $\mathrm{Fe}$ index, defined as $\langle\mathrm{Fe}\rangle=(\mathrm{Fe} 4383+\mathrm{Fe} 5270+\mathrm{Fe} 5335$ $+\mathrm{Fe} 5406) / 4$ and $\mathrm{Mg}_{2}$. All these indices are of widespread use in stellar population studies in galaxies and stellar clusters. Figure 9 plots the behaviour of $\mathrm{Mg}_{2}$ as a function of $\mathrm{CN}$ and $\mathrm{T}_{\text {eff }}$, respectively. In this figure we see that both $\mathrm{CN}$-weak and $\mathrm{CN}$-strong sequences correspond to $\mathrm{Mg}_{2} \geq 0.05 \mathrm{mag}$ and $\mathrm{Mg}_{2}$ tends to be higher for cooler stars $\left(\mathrm{T}_{\text {eff }} \leq 4300 \mathrm{~K}\right)$. Therefore, $\mathrm{Mg}_{2}$ is weaker in $\mathrm{CN}$-strong stars, and this seems to indicate that besides a $\mathrm{Mg}$ $\mathrm{Al}$ anticorrelation (Fig. 14), and a weak Al-CN anticorrelation (Fig. 13), we found some evidence for a $\mathrm{Mg}-\mathrm{N}$ anticorrelation (see Gratton et al. 2004). 

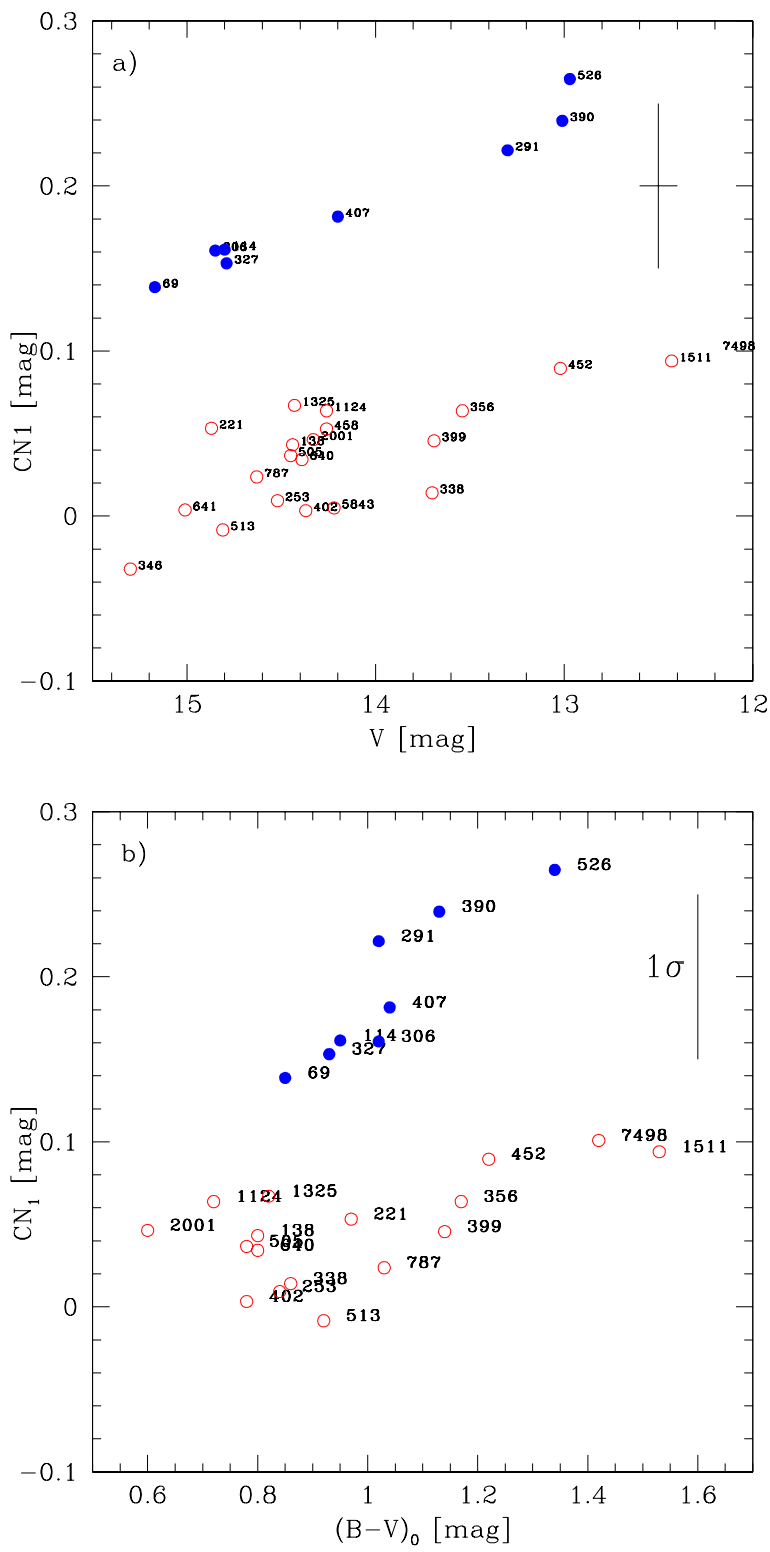

Fig. 3. $a$ ): $\mathrm{CN}_{1}$ plotted against $\mathrm{V}$, and $b$ ): $\mathrm{CN}_{1}$ vs. $(\mathrm{B}-\mathrm{V})_{0}$ for the M71 sample stars, where the locus $\mathrm{CN}$-strong (filled circles) and $\mathrm{CN}$-weak (open circles) are seen. Error bars quoted correspond to the rms on all measurements available.

\section{3. $\mathrm{Ca} 4227$}

This index is widely used in stellar population studies in galaxies, where $\mathrm{Ca}$ is considered as a representative $\alpha$-element (e.g. Thomas et al. 2003; Prochaska et al. 2005). We found $\langle\mathrm{Ca} 4227\rangle$ $=1.25 \pm 1.00 \AA$ for 32 stars in the range $12 \leq \mathrm{V} \leq 15.5$ and with a membership probability higher than $80 \%$.

Figures 10 and 11 show the behaviour of $\mathrm{Ca} 4227$ as a function of $\mathrm{T}_{\text {eff }}$ and the metallicity indicators $\langle\mathrm{Fe}\rangle$ and $\mathrm{Mg}_{2}$ indices, respectively. By comparing Fig. 9 with Fig. 10, a similarity between the general behaviour of $\mathrm{Ca} 4227$ and $\mathrm{Mg}_{2}$ indices with $\mathrm{T}_{\text {eff }}$ is seen. This explains the behaviour presented between $\mathrm{Ca} 4227$ and $\mathrm{Mg}_{2}$ in Fig. 11. All these findings show that the cooler giants with higher metallicity indicators also show high Ca4227 indices. These figures also show that the metallicity indices $\mathrm{Mg}_{2}$ and $\langle\mathrm{Fe}\rangle$ grow non-linearly at low temperatures.

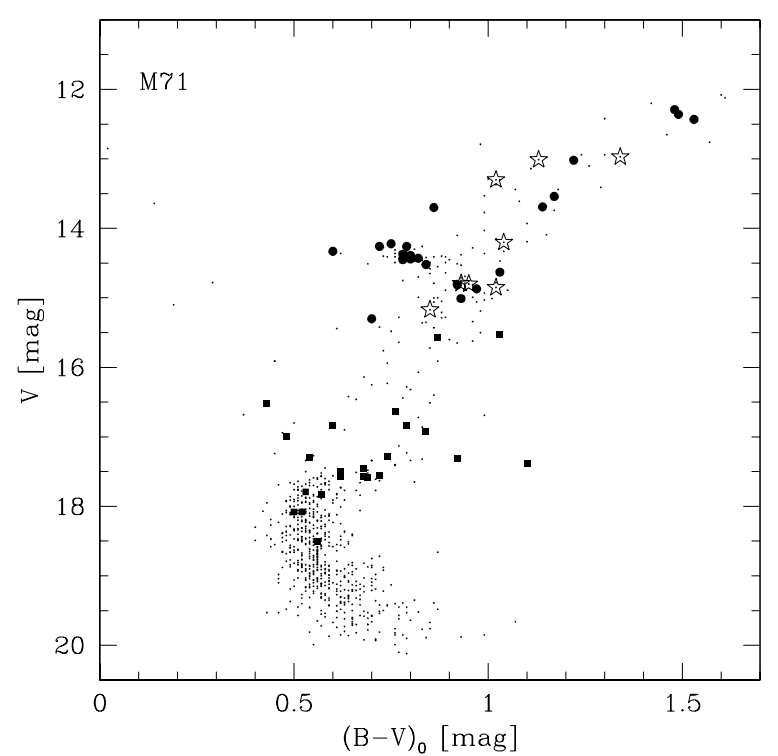

Fig. 4. V, B-V CMD with the CN-strong stars (open stars), $\mathrm{CN}$ weak (filled circles), and the subgiants (filled squares) for which the $\mathrm{CN}$ measurements are not qualified as strong or weak.

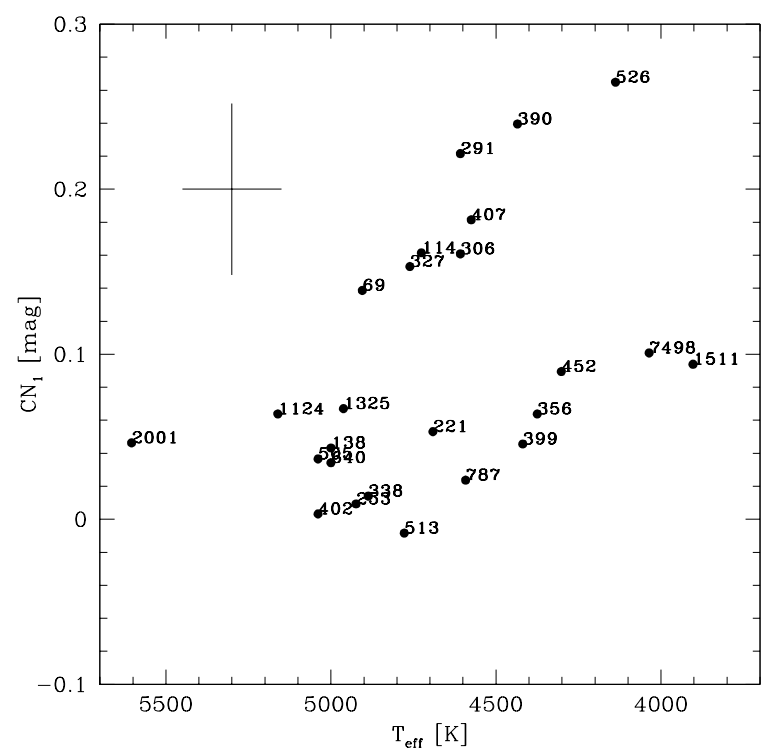

Fig. 5. $\mathrm{CN}_{1}$ vs. effective temperature. Error bar on $\mathrm{CN}_{1}$ is as explained in Fig. 3, while on $\mathrm{T}_{\text {eff }}$ it resembles the value determined with the photometric calibration employed.

\section{4. $H_{\beta}$}

$\mathrm{H}_{\beta}$ index is widely used as an age indicator in stellar population studies and is known to be extremely temperature- and gravitydependent. We found a mean $\mathrm{H}_{\beta}$ index of $\left\langle\mathrm{H}_{\beta}\right\rangle=1.57 \pm 0.68 \AA$ $(\mathrm{N}=31)$. We notice that there is a large variation of $\mathrm{H}_{\beta}$ measurements for stars with $\mathrm{V}<14$ and this effect appears to be real since Figs 12 a, b suggest a higher dispersion on the $\mathrm{H}_{\beta}$ measurements for stars cooler than $4500 \mathrm{~K}$. 


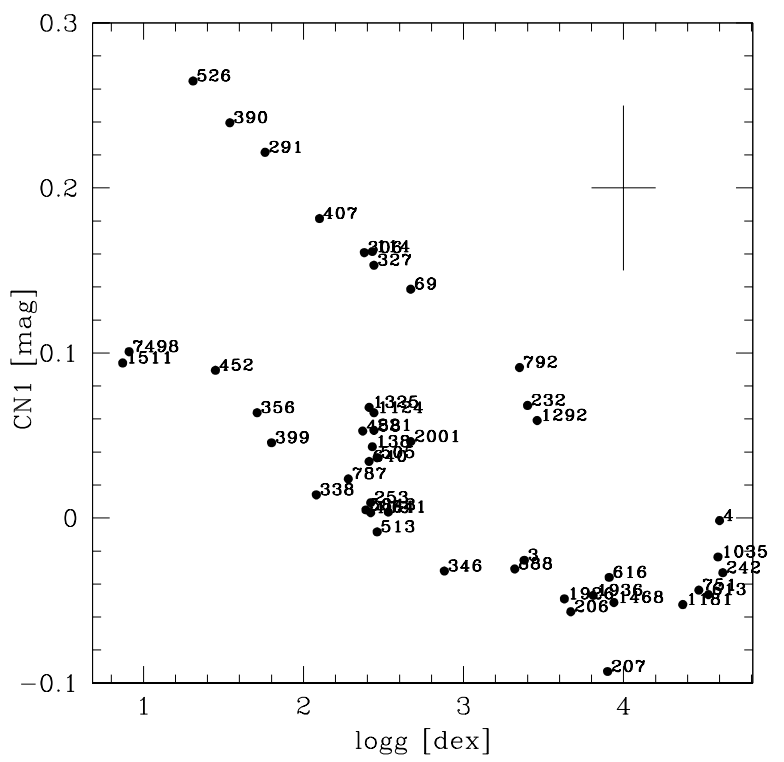

Fig. 6. $\mathrm{CN}_{1}$ vs. $\log$ g. Error bar is indicated.

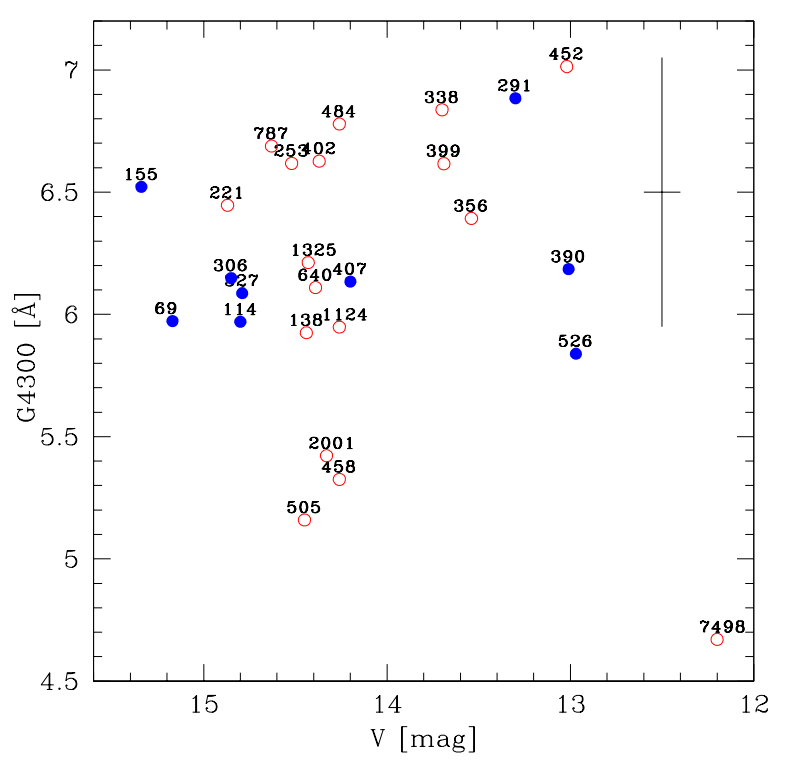

Fig. 7. G-band as function of $\mathrm{V}$ magnitude, where $\mathrm{CN}$-strong (filled circles) and CN-weak (open circles) stars are plotted separately.

\section{5. $\mathrm{NaD}$ and $\mathrm{A} / 3953$}

$\mathrm{NaD}$ and $\mathrm{A} 13953$ features included in the present analysis are as defined in Worthey et al. (1994) and Serven et al. (2005), respectively. As shown in Table 2 of Serven et al. (2005), the new index Al3953 has a high spectral response to aluminum abundance variations. However, although both are very useful indices able to rule out important clues for understanding the abundance variations in stellar populations, they are composed of resonance lines and subject to effects from interstellar absorption, that have to be taken into account when trying to interpret them. We found $\langle\mathrm{NaD}\rangle=4.60 \pm 2.38 \AA(\mathrm{N}=28)$ and $\langle\mathrm{A} 13953\rangle=2.76 \pm 1.35 \AA$ $(\mathrm{N}=25)$.

Figure 13 displays the behaviour of $\mathrm{NaD}$ and $\mathrm{Al} 3953$ as a function of the $\mathrm{CN}$ band, while Fig. 14 shows the behaviour of

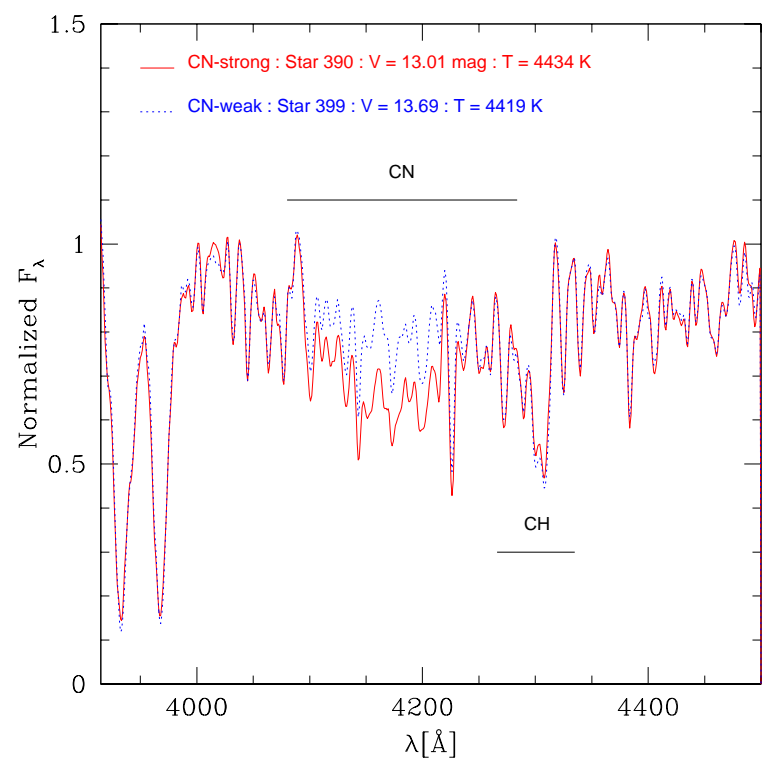

Fig. 8. Stars 390 and 399 in the molecular $\mathrm{CN}$ and $\mathrm{CH}$ band region. The full and dashed lines represent the $\mathrm{CN}$-strong and $\mathrm{CN}$ weak stars, respectively. These stars display approximately the same temperatures.

$\mathrm{NaD}$ and $\mathrm{Mg}_{2}$ indices against the new index Al3953. An Na-Al anticorrelation is clearly seen.

\subsection{Fitting functions}

The fitting functions approach is a useful tool at low resolution to derive abundances that are both reddening and distance modulus independent. In this section, we use the fitting functions derived by Barbuy et al. (2003) for the indices Fe5270, Fe5335 and $\mathrm{Mg}_{2}$, as a function of stellar parameters, in order to estimate metallicities for M 71 stars, based on the Lick index measurements presented in the previous sections.

The Fe5270, Fe5335 and $\mathrm{Mg}_{2}$ features are known to be suitable metallicity indicators due to their relatively weak dependence on gravity and temperature. A relation between these indices and $[\mathrm{Fe} / \mathrm{H}]$ was derived by Barbuy et al. (2003) based on synthetic spectra for resolutions of $8.3 \AA$ and $3.5 \AA$. We use their Value1 fitting function coefficients for Fe5270, Fe5335 and $\mathrm{Mg}_{2}$ computed with FWHM $=3.5 \AA$, valid for $-3 \leq[\mathrm{Fe} / \mathrm{H}] \leq+0.3,0$ $\leq \log \mathrm{g} \leq 3$ and $4000 \leq \mathrm{T}_{\text {eff }} \leq 7000$.

A mean $\mathrm{Fe}=(\mathrm{Fe} 5270+\mathrm{Fe} 5335) / 2$ and $\mathrm{Mg}_{2}$ indices were used as metallicity indicators. Mean values of $\langle\mathrm{Fe} 5270\rangle=$ $2.70 \pm 1.47(\mathrm{~N}=30),<\mathrm{Fe} 5335\rangle=2.53 \pm 1.48(\mathrm{~N}=29)$ and $\left\langle\mathrm{Mg}_{2}\right\rangle$ $=0.17227 \pm 0.11828(\mathrm{~N}=28)$ were obtained for giants. Based on stars in the range $4500<\mathrm{T}_{\text {eff }}<5000 \mathrm{~K}$ (validity of the fitting functions for $\mathrm{Mg}_{2}$, mean values of Fe5270 = 2.21 \pm 0.72 (18 giants), $\mathrm{Fe} 5335=2.04 \pm 0.63$ (17 giants) and $\mathrm{Mg}_{2}=0.12 \pm 0.03$ (11 giants) are found.

Adopting mean parameters $\mathrm{T}_{\mathrm{eff}}=4768 \mathrm{~K}$ and $\log \mathrm{g}=2.29$ dex, metallicities of $[\mathrm{Fe} / \mathrm{H}]=-0.81,-0.91$ and -0.68 , corresponding to $\mathrm{Fe} 5270, \mathrm{Fe} 5335$ and $\mathrm{Mg}_{2}$ respectively, are obtained. In Table 6 are reported $[\mathrm{Fe} / \mathrm{H}]$ values from high-resolution spectroscopy and those from fitting functions, where a good agreement is found. 
Table 6. Literature and present values of metallicity for M71

\begin{tabular}{ccccc}
\hline \hline$[\mathrm{Fe} / \mathrm{H}]$ & {$[\mathrm{FeI} / \mathrm{H}]$} & {$[\mathrm{FeII} / \mathrm{H}]$} & Method & Reference \\
\hline-0.79 & -0.79 & -0.79 & High-resolution : 10 giants & Sneden et al. (1994) \\
-0.73 & - & - & Compilation & Harris (1996) \\
-0.71 & -0.71 & -0.84 & High-resolution : 25 stars & Ramirez et al. (2001) \\
-0.82 & -0.81 & -0.82 & Revision of Sneden et al.'s 10 giants & Kraft \& Ivans (2003) \\
-0.80 & -0.81 & -0.85 & High-resolution : 5 dwarfs & Boesgaard et al. (2005) \\
-0.81 & - & - & Fitting Functions & Fe5270 index (Present work) \\
-0.91 & - & - & Idem & Fe5335 index (Present work) \\
-0.68 & - & - & Idem & $\mathrm{Mg}_{2}$ index (Present work) \\
\hline
\end{tabular}
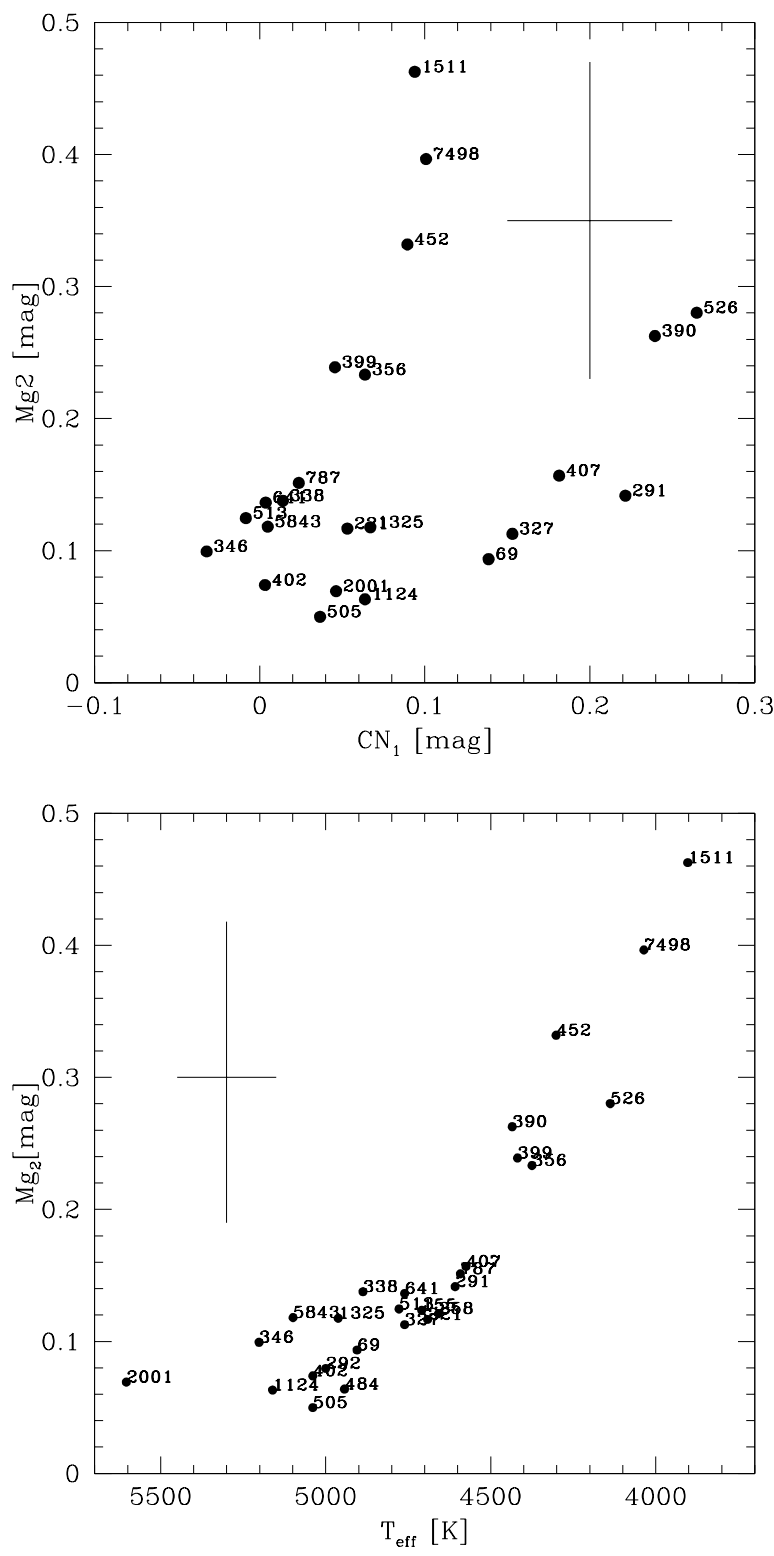

Fig. 9. Upper panel: $\mathrm{Mg}_{2}$ plotted against $\mathrm{CN}_{1}$; Lower panel: $\mathrm{Mg}_{2}$ as a function of the effective temperature. Error bars are as previously discussed.

\subsection{Spectrum synthesis}

By adopting $[\mathrm{Fe} / \mathrm{H}] \approx-0.8$ for $\mathrm{M} 71$, taking into account the values given in Table 6, we carried out a spectrum synthesis calculation of $\mathrm{CN}$ and $\mathrm{CH}$ bands in the wavelength region 4000-4400

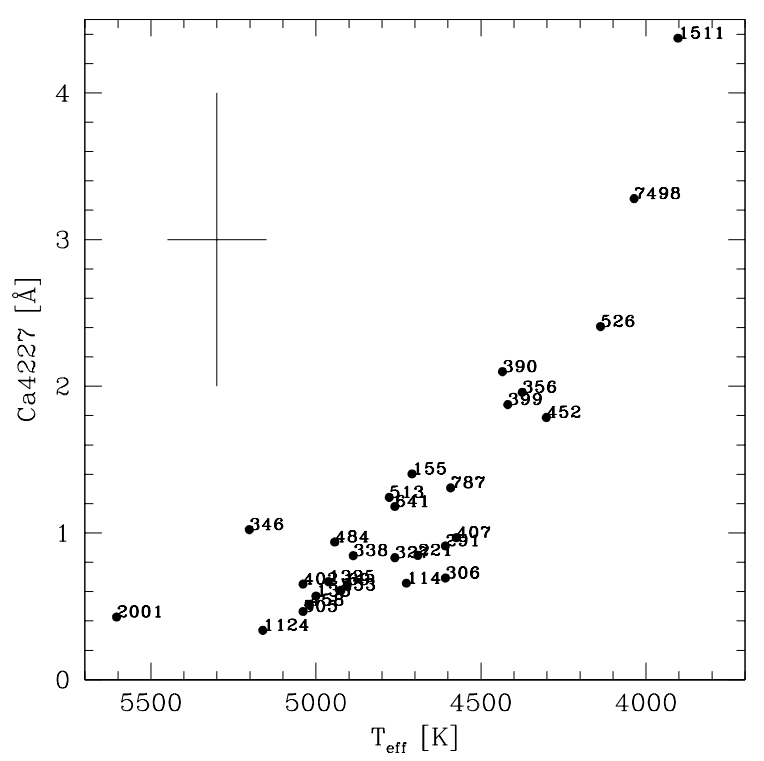

Fig. 10. Ca4227 feature against the effective temperature.

$\AA$. The code is described by Cayrel et al. (1991) and Barbuy et al. (2003), where CN and CH line lists are from Kurucz (1993), and implemented in our code as described in Castilho et al. (1999). MARCS model atmospheres from Gustafsson et al. (2006) were used.

Synthetic spectra were computed for a pair of CN-weak/CNstrong stars with similar stellar parameters: stars 390 and 399, with $\left(\mathrm{T}_{\mathrm{eff}}, \log \mathrm{g}, \mathrm{v}_{\mathrm{t}}\right)=(4434 \mathrm{~K}, 1.54,1.5 \mathrm{~km} / \mathrm{s})$ and $(4419 \mathrm{~K}$, $1.8,1.5 \mathrm{~km} / \mathrm{s})$. Carbon and nitrogen abundances were found to be of $[\mathrm{C} / \mathrm{Fe}]=0.0,[\mathrm{~N} / \mathrm{Fe}]=+1.0$ for the $\mathrm{CN}$-strong star 390 and $[\mathrm{C} / \mathrm{Fe}]=0.0,[\mathrm{~N} / \mathrm{Fe}]=+0.50$ for the $\mathrm{CN}$-weak star 399, assuming $[\mathrm{O} / \mathrm{Fe}]=+0.3$ in both cases. The difference in nitrogen abundances is clear, as shown in Fig. 15

\section{Discussion}

The light elements $\mathrm{C}, \mathrm{N}, \mathrm{O}, \mathrm{Na}, \mathrm{Mg}$ and $\mathrm{Al}$ show variations in globular cluster stars. In M71 a bimodal distribution of CNstrong and $\mathrm{CN}$-weak stars and an anticorrelation between $\mathrm{CN}$ and CH were first made evident by Smith \& Norris (1982). For stars brighter than the Horizontal Branch (HB) level they showed that $\mathrm{CN}$ and $\mathrm{CO}$ are anticorrelated, and $\mathrm{CN}$ correlated with $\mathrm{Na}$. Smith \& Penny (1989) measured $\mathrm{CN}$ and $\mathrm{CH}$ based on the bandheads CN $3883 \AA$, CN $4215 \AA$ and $\mathrm{CH} 4300 \AA$ for a sample of $\mathrm{HB}$ stars in $\mathrm{M} 71$, and revealed an anticorrelation between $\mathrm{CN}$ and $\mathrm{CH}$. $\mathrm{CN}$-strong and $\mathrm{CN}$-weak components were also revealed by Penny et al. (1992), who also showed an anticorrela- 

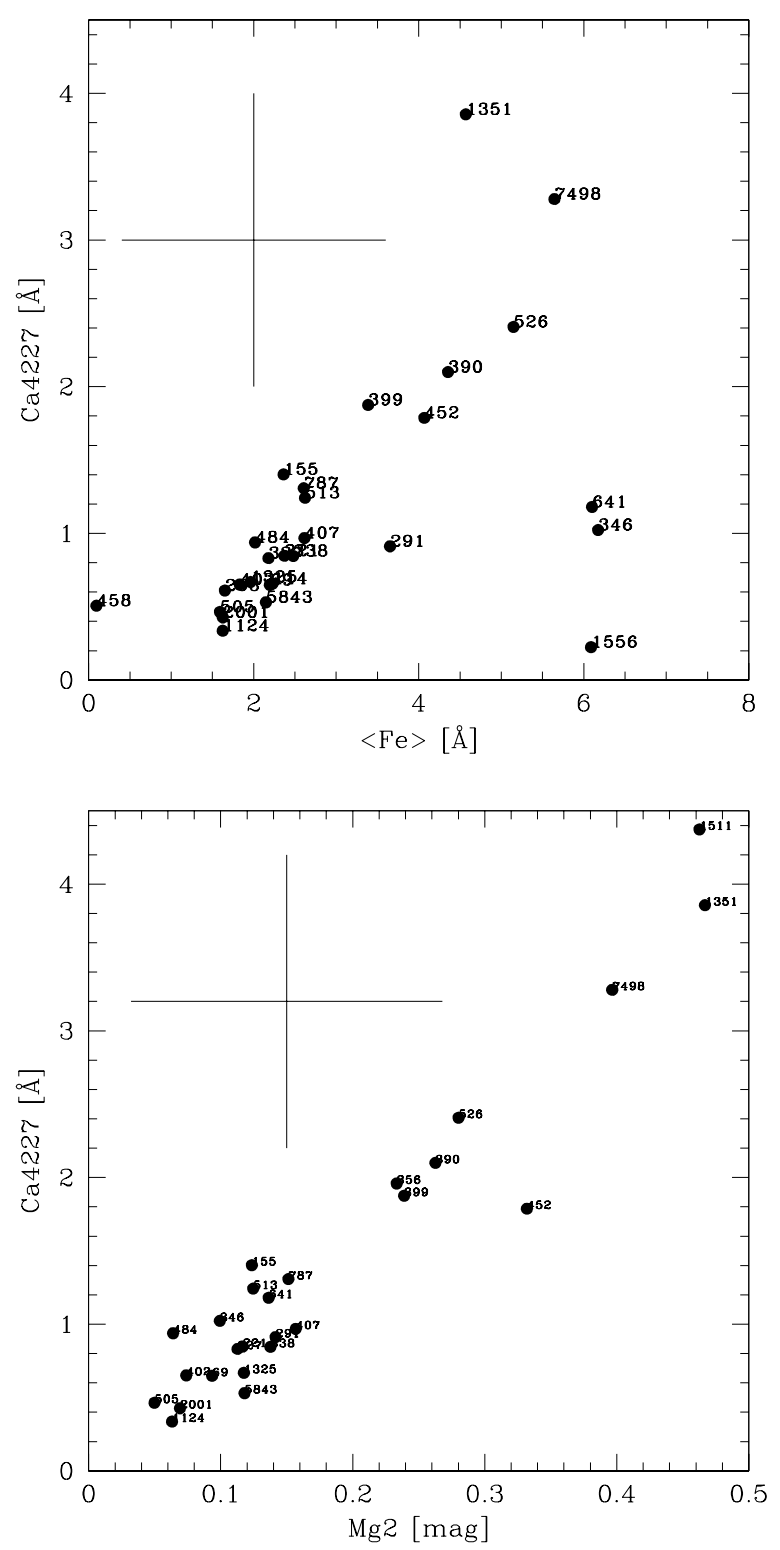

Fig. 11. Upper panel: $\mathrm{Ca} 4227$ vs. $\langle\mathrm{Fe}\rangle$, and Lower panel: $\mathrm{Ca} 4227$ vs. $\mathrm{Mg}_{2} .\langle\mathrm{Fe}\rangle=(\mathrm{Fe} 4383+\mathrm{Fe} 5270+\mathrm{Fe} 5335+$ $\mathrm{Fe} 5406) / 4$.

tion $\mathrm{CN}-\mathrm{CH}$ for subgiants in $\mathrm{M} 71$. A CN-bimodality and a $\mathrm{CN}$ $\mathrm{CH}$ anticorrelation were also found for a sample of $79 \mathrm{MS}$ stars in M71 by Cohen (1999). Briley et al. (2001) further derived $\mathrm{CN}$ and $\mathrm{CH}$ for 75 giants of M71 based on DDO photometric indices $\mathrm{C}(41-42)$ and $\mathrm{C}(42-45)$, and confirmed the $\mathrm{C}$ vs. $\mathrm{N}$ anticorrelation and the $\mathrm{CN}$-strong and $\mathrm{CN}$-weak components. Lee (2005) studied $\mathrm{CN}$ and $\mathrm{CH}$ band strength variations in 14 M71 giants showing clearly the $\mathrm{CN}$ bimodality, whereas the $\mathrm{CN}-\mathrm{CH}$ anticorrelation is not clear in his analysis.

The behaviour of the $\mathrm{CN}$ and $\mathrm{CH}$ bands above is also reported for stars on the RGB and MS of 47 Tuc (see e.g. Norris \& Freeman 1979; Norris, Freeman \& Da Costa 1984; Cannon et al. 1998), another well studied Galactic globular cluster with metallicity close to that of M71 $([\mathrm{Fe} / \mathrm{H}]=-0.67$, Alves-Brito et al. 2005). However, 47 Tuc is more massive than M 71, as well as more concentraded with a half-mass radius $r_{h}=2.79$ arcmin
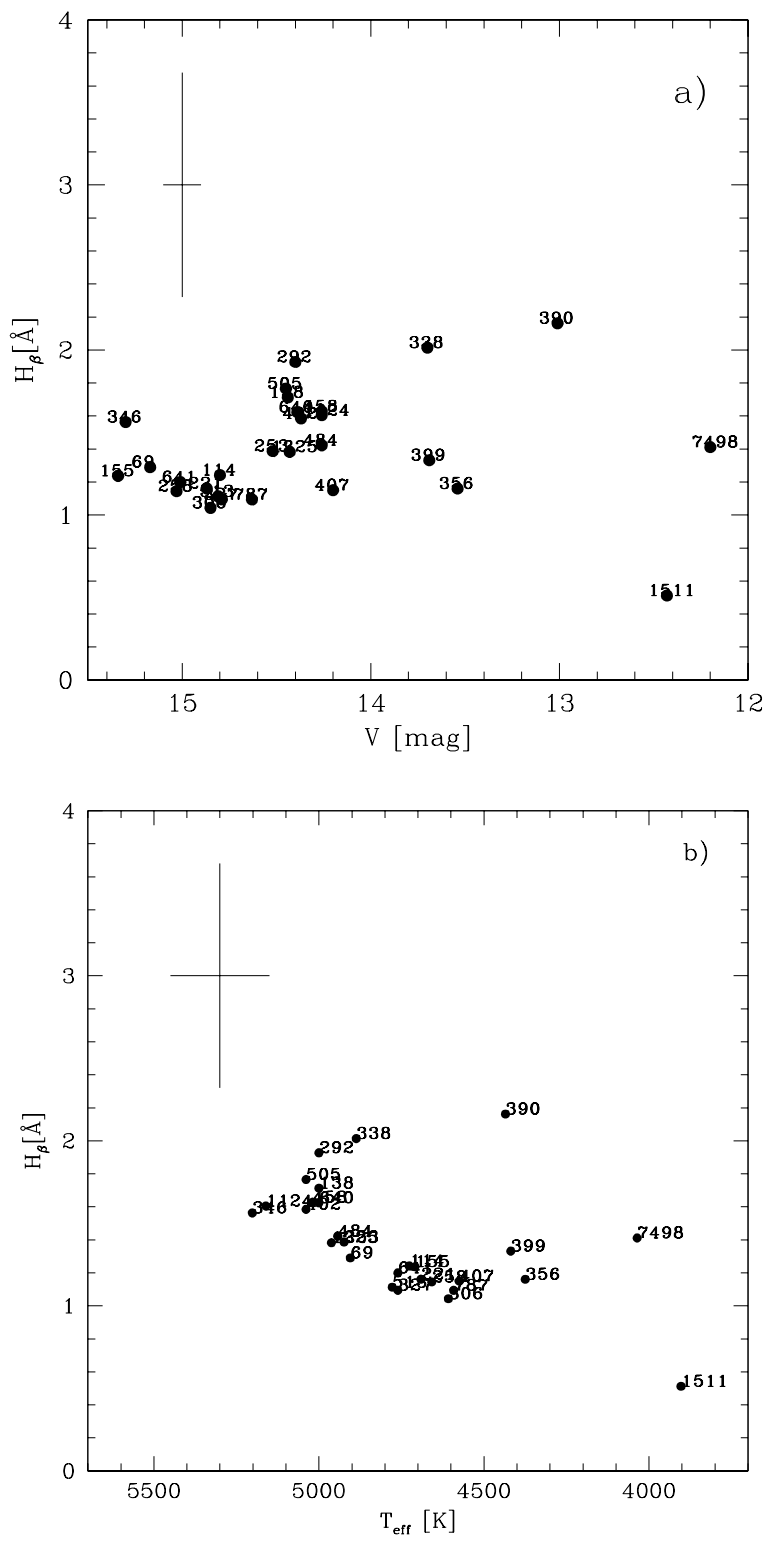

Fig. 12. $a): \mathrm{H}_{\beta}$ plotted against $\mathrm{V}$, and $\left.b\right): \mathrm{H}_{\beta}$ against $\mathrm{T}_{\mathrm{eff}}$

and concentration parameter $\mathrm{c}=2.03$, whereas $\mathrm{M} 71$ has $\mathrm{r}_{\mathrm{h}}==$ 1.65 arcmin and $c=1.15$ (Harris 1996).

Based on the Cudworth $(1985 ; 2006)$ star designations, it was possible to identify several stars in common with other spectroscopic studies (e.g. in Smith \& Penny 1989; Penny et al. 1992; Lee 2005), which allows us to do a direct $\mathrm{CN}-\mathrm{CH}$ band-strength comparison. The cross-check is possible for 15 out of 22 stars overlapping with our sample - 4 stars have no $\mathrm{CN}$ measurements in the literature, whereas we have no $\mathrm{CN}$ measurements for 3 other stars due to the position of the CCD gaps in their spectra. The comparison shows that 13 out of 15 stars present the same classification of $\mathrm{CN}$-weak or $\mathrm{CN}$-strong found in the present work, while 2 stars were found to present a different classification - stars 1-43 and 1-88 were previously classified as $\mathrm{CN}$-strong. On the other hand, within a $1 \sigma$-uncertainty, those authors present the same $\mathrm{CN}$ values.

Regarding our $\mathrm{CN}-\mathrm{CH}$ strength results, Fig. 7 illustrates the $\mathrm{CN}$ bimodality and $\mathrm{CN}-\mathrm{CH}$ anticorrelations. Note, however, as discussed above, that 3 stars (IDs 1556, 1351 and 640) have inac- 

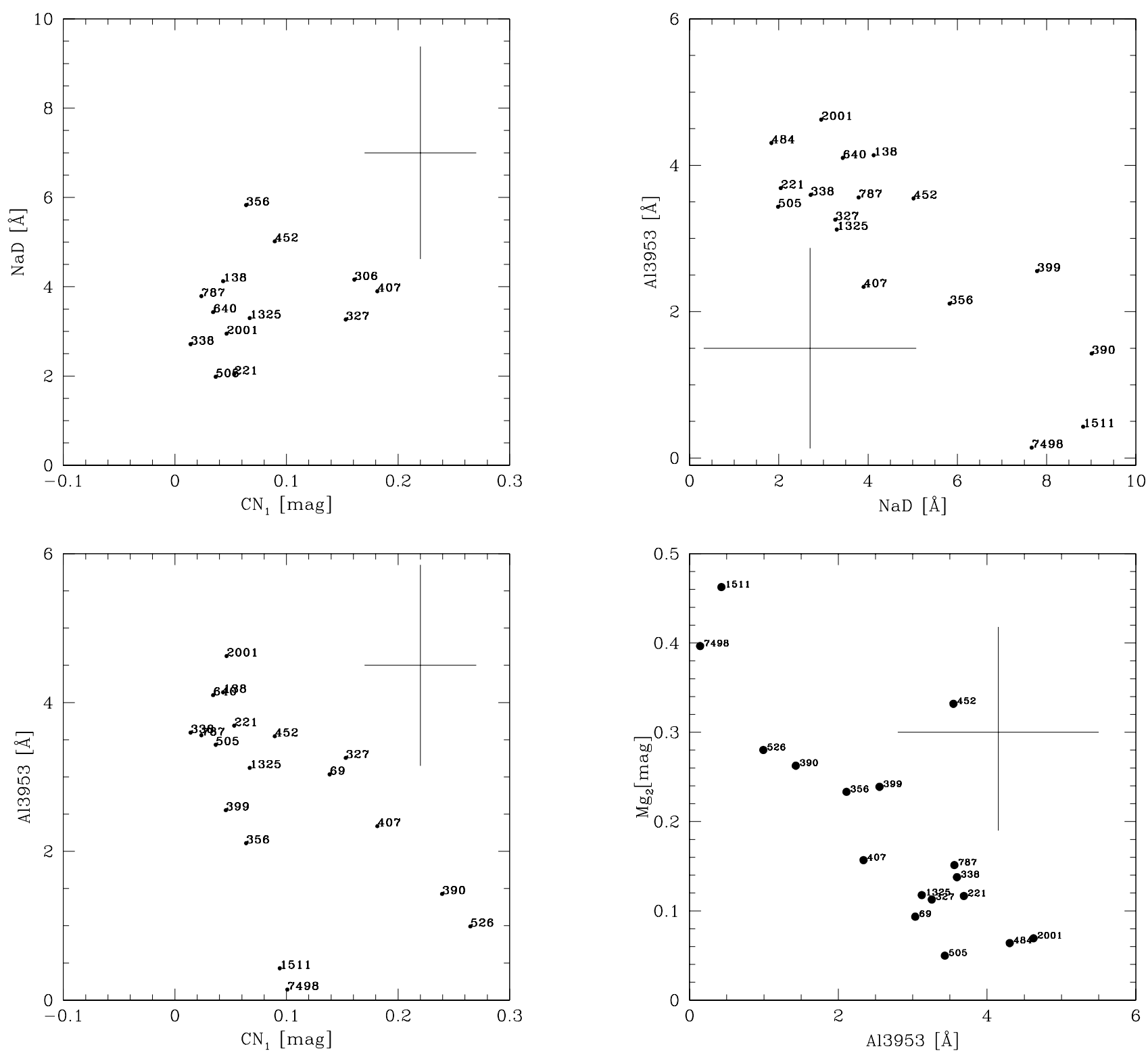

Fig. 13. $\mathrm{NaD}$ and $\mathrm{Al} 3953$ as a function of the $\mathrm{CN}$ index.

curate CN measurements due to the CCD gaps. Stars 2001, 458, and 505, which are classified as $\mathrm{CN}$-weak, show lower $\mathrm{CH}$ values than other $\mathrm{CN}$-weak stars. Even with some statistical outliers our $\mathrm{CN}-\mathrm{CH}$ distribution has similar proportions as those given in Smith \& Norris (1982).

Within the canonical framework of stellar structure and evolution of low-mass stars, the enhancement of nitrogen followed by the depletion of carbon in the $\mathrm{CN}$-strong stars is attributed to the dredge-up of $\mathrm{CN}$-processed material into the surface layers of such stars (Iben 1964; Charbonnel 1994). The present CN variations followed by an anticorrelation in the $\mathrm{CH}$ band confirm that an episode of deep mixing occurred in the M71 giants studied. On the other hand, the CN bimodality is better explained within a primordial pollution scenario. The mixing hypothesis does not explain the behaviour seen for the positive correlation between $\mathrm{CN}-\mathrm{Na}$ and $\mathrm{CN}-\mathrm{Al}$, given that $\mathrm{Na}$ and $\mathrm{Al}$ are not produced during these mixing events.

Elements such as $\mathrm{Al}$ and $\mathrm{Mg}$ are produced by p-capture at higher temperatures (e.g. Langer \& Hoffman 1995). As shown in Fig. 14, there is a clear anticorrelation between Al3953 vs. $\mathrm{NaD}$ and $\mathrm{Mg}_{2}$ indices. The Al-Mg anticorrelation seen in some globular cluster red giants is well explained by the enhanced extra mixing discussed in Denissenkov \& VandenBerg (2003). Ramirez \& Cohen (2002) reported a $[\mathrm{Na} / \mathrm{Fe}]:[\mathrm{Al} / \mathrm{Fe}]$ correlation for their sample of M71 stars, however their results show a $2 \sigma$ uncertainty (see their Fig. 13).

A scenario that appears plausible is that CNO-processed material in intermediate mass stars (IMS) on the AGB occurs early in the cluster's life, and their stellar winds are captured by lowmass stars (Gratton et al. 2004) or else by fast rotating massive stars (Decressin et al. 2007). Both the AGB or massive star early pollution possibilities are consistent with scenarios of selfenrichment proposed by Cayrel (1986), Parmentier et al. (1999), Parmentier \& Gilmore (2001), Thoul et al. (2002), and Bekki et al. (2007). The latter developed a model of globular cluster formation in the central regions of low mass proto-galaxies embedded in dark matter halos. These proto-galaxies would retain the AGB ejecta and cause an "external pollution" of the globular 

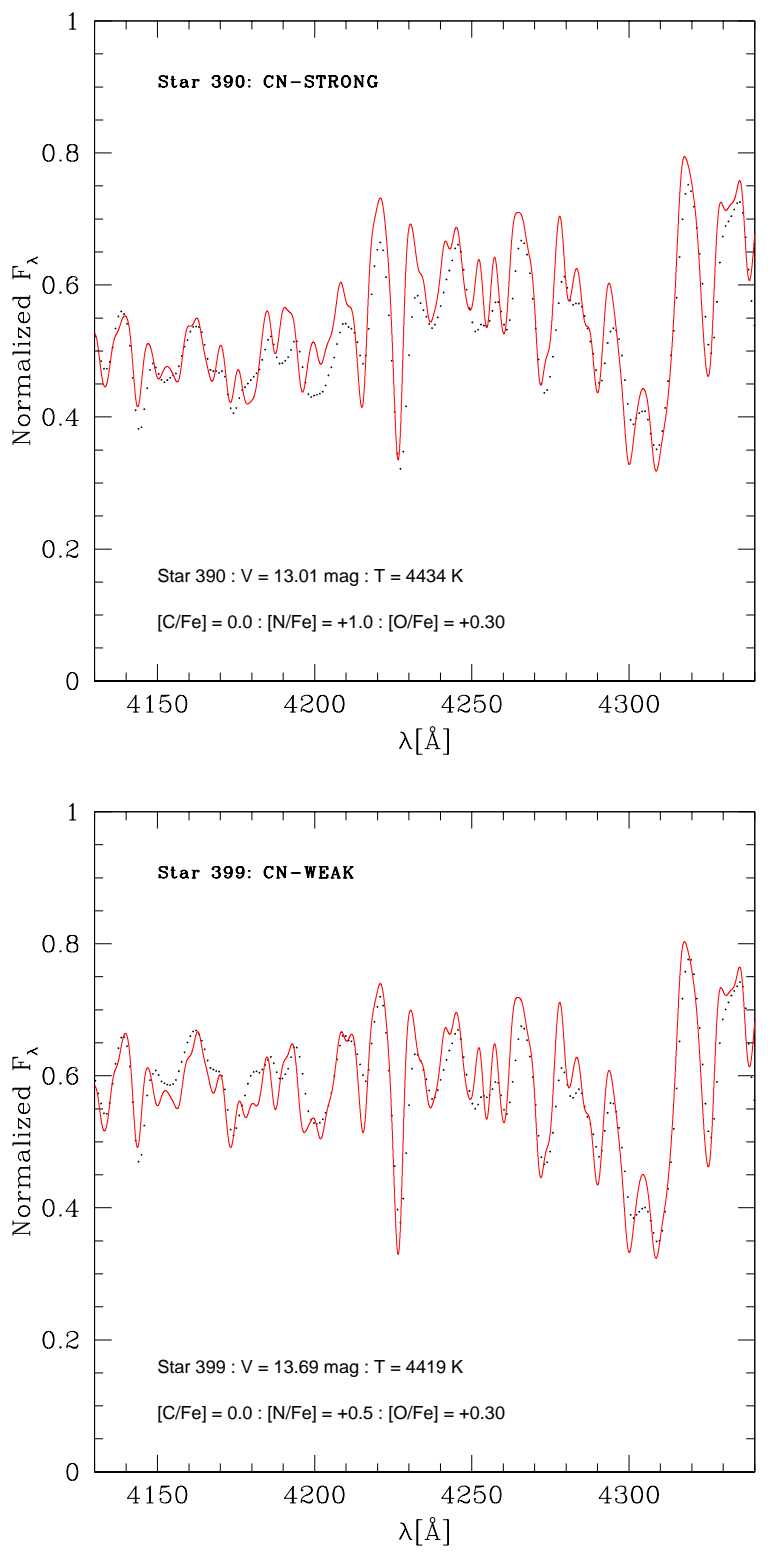

Fig. 15. Synthetic (solid line) and observed spectra (dotted line) in the region of $\mathrm{CN}$ and $\mathrm{CH}$ bands. Upper panel: Star $390(\mathrm{CN}-$ strong): $\left.\mathrm{T}_{\mathrm{eff}}, \log \mathrm{g}, \mathrm{v}_{\mathrm{t}}\right)=(4434 \mathrm{~K}, 1.54,1.5 \mathrm{~km} / \mathrm{s})$ computed for $[\mathrm{C} / \mathrm{Fe}]=0.0,[\mathrm{~N} / \mathrm{Fe}]=+1.0$; Lower panel: Star 399 (CN-weak): $(4419 \mathrm{~K}, 1.8,1.5 \mathrm{~km} / \mathrm{s})$ computed for $[\mathrm{C} / \mathrm{Fe}]=0.0,[\mathrm{~N} / \mathrm{Fe}]=+0.50$

cluster stars. This model can explain the $\mathrm{C}-\mathrm{N}$ and $\mathrm{Mg}-\mathrm{Al}$ anticorrelations, but shows a strong disagreement with the observed $\mathrm{O}-\mathrm{Na}$ anticorrelation.

For the present sample, we found that $\mathrm{CN}$ and $\mathrm{Na}$ are correlated, while a $\mathrm{CN}-\mathrm{Al}$ correlation does not appear. These $\mathrm{CN}-\mathrm{Na}$ results imply a primordial explanation for abundance variations in M71.

\section{Summary and conclusions}

In M71 previous studies such that of Smith \& Norris (1982) that first showed a bimodal distribution of $\mathrm{CN}$-strong and $\mathrm{CN}$-weak stars and an anticorrelation between $\mathrm{CN}$ and $\mathrm{CH}$. This was followed by Smith \& Penny (1989), Penny et al. (1992), Briley et al. (2001), Cohen (1999), Ramirez et al. 2001, Ramírez \& Cohen (2002), Boesgaard et al. (2005), and Lee (2005).

We measured $\mathrm{CN}, \mathrm{CH}, \mathrm{Ca} 4277$, iron and magnesium indicators, $\mathrm{H}_{\beta}, \mathrm{NaD}$ and $\mathrm{Al} 3953$ spectral indice, from low-resolution spectra of 89 stars of the metal-rich globular cluster M71, observed with the Gemini Multi-Object Spectrograph (GMOS) at the Gemini-North telescope. $\mathrm{CN}$ and $\mathrm{CH}$ strengths were obtained for 89 stars, among which 33 giants. As expected from evolutionary mixing theories and additional extra-mixing (Iben 1964; Charbonnel 1994; Denissenkov \& VandenBerg 2003), we find a $\mathrm{CN}-\mathrm{CH}$ anticorrelation. We find $\mathrm{CN}$-strong and $\mathrm{CN}$-weak stars, with around $30 \%$ of $\mathrm{CN}$-strong ones, similar to other clusters such as NGC 6752 with about $50 \%$.

We confirm a CN-bimodality besides the $\mathrm{CN}-\mathrm{CH}$ anticorrelation, a $\mathrm{CN}-\mathrm{Na}$ correlation, and $\mathrm{Al}-\mathrm{Na}$ and $\mathrm{Mg}_{2}-\mathrm{Al}$ anticorrelation. The interpretation of $\mathrm{CN}$ bimodality is instead better understood in terms of primordial variations, and possible scenarios include an early enrichment by winds from intermediate mass stars in the AGB phase, and captured by low-mass stars, early in the cluster's life (Gratton et al. 2004 and references therein; Bekki et al. 2007) or early pollution by fast rotating massive stars (Decressin et al. 2007).

$\mathrm{CN}$-strong and $\mathrm{CN}$-weak bimodality is only seen in relatively metal-rich globular clusters, but not in all of them. Such behaviour is well studied in particular in 47 Tucanae, NGC 6752 and M4. Such abundance variations in metal-rich globular clusters is undoubtedly one of the most intrincate challenges for the current theory of stellar evolution, and further observations with larger samples would be interesting.

Acknowledgements. AA acknowledges a FAPESP fellowship no. 04/00287-9. AA would like to thank the hospitality of the Department of Astronomy at the University of Virginia, during a visit in which part of this work was developed. Likewise, RPS would like to warmly than the hospitality of the Astronomy Department at the University of São Paulo, during which much of this work was conceived. We are grateful to Professor Kyle Cudworth for cordially making his preliminary reduction of proper motions and photometry for M71 stars available to us. All observations were part of GEMINI Program GN-2002B-Q-42. This work is based on observations obtained at the Gemini Observatory, which is operated by the AURA, Inc., under a cooperative agreement with the NSF on behalf of the Gemini partnership: the NSF (United States), the PPARC (United Kingdom), the NRC (Canada), CONICYT (Chile), the ARC (Australia), CNPq (Brazil) and CONICET (Argentina)

\section{References}

Alonso, A., Arribas, S., \& Martínez-Roger, C. 1996, A\&AS, 313, 873

Alonso, A., Arribas, S., \& Martínez-Roger, C. 1999, A\&ASS, 140, 261

Alonso, A., Arribas, S., \& Martínez-Roger, C. 2001, A\&A, 376, 1039

Alves-Brito, A., Barbuy,B., Ortolani, S. et al. 2005, A\&A, 435, 657

Barbuy, B., Perrin, M.-N., Katz, D. et al. 2003, A\&A, 404, 661

Bekki, K., Campbell, S.W., Lattanzio, J.C, Norris, J.E. 2007, MNRAS, 377, 335

Boesgaard, A. M., King, J. R., Cody, A. M., Stephens, A., Deliyannis, C. P. 2005, ApJ, 629, 832

Briley, M. M., Smith, G. H., Claver, C. F. 2001, AJ, 122, 2561

Cannon, R.D., Croke, B.F.W., Bell, R.A., Hesser, J.E., Stathakis, R.A. 1998, MNRAS, 298, 601

Cardiel, N., Gorgas, J., Cenarro, J., Gonzalez, J. J. 1998, A\&AS, 127, 597

Castilho, B., Spite, F., Barbuy, B. et al. 1999, A\&A, 345, 249

Cayrel, R. 1986, A\&A, 168, 81

Cayrel, R., Perrin, M.-N., Buser, R., Barbuy, B., Coupry, M.-F. 1991, A\&A, 247, 122

Charbonnel, C. 1994, A\&A, 282, 811

Coelho, P, Barbuy, B., Meléndez, J., Schiavon, R., Castilho, B. 2005, A\&A, 443, 735

Cohen, J.G. 1980, ApJ, 241, 981

Cohen, J.G., Gratton, R.G., Behr, B.B., \& Carretta, E. 1999, ApJ, 523, 739

Cohen, J. 1999, AJ, 117, 2434

Cudworth, K. M. 1985, AJ, 90, 65

Decressin, T., Meynet, G., Charbonnel, C., Prantzos, N., Ekström, S. 2007, A\&A, 464, 1029 
Denissenkov, P.A., VandenBerg, D.A. 2003, ApJ, 593, 509

Dickens, R. J., Bell, R. A., Gustafsson, B. 1979, ApJ, 232, 428

Dinescu, D. I., Girard, T. M., van Altena, W. F. 1999, AJ, 117, 1792

Geffert, M.; Maintz, G. 2000, A\&AS, 144, 227

Gratton, R., Sneden, C., Carretta, E. 2004, ARA\&A, 42, 385

Grundahl, F., Stetson, P. B., Andersen, M. I. 2002, A\&A, 395, 481

Gustafsson, B., Edvardsson, B., Eriksson, K., et al., 2008, A\&A, in press

Harris, W.E. 1996, ApJ, 112, 1487

Hesser, J. E., Hartwick, F. D. A., McClure, R. D. 1977, ApJS, 33, 471

Hook, I. M., Jorgensen, I., Allington-Smith, J. R. et al. 2004, PASP, 116, 425

Iben, I. Jr., 1964, ApJ, 140, 1631

Kim, Y-C., Demarque, P., Yi, S.K., Alexander, D. 2002, ApJSS, 143, 499

Kurúcz, R. L. 1993, CD-ROM 23

Lee, Jae-Woo, Carney, B. W., Balachandran, S. C. 2004, AJ, 128, 2388

Lee, S.-G. 2005, JKAS, 38, 23

Kraft, R.P. 1994, PASP, 106, 553

Kraft, R.P., Ivans, I.I. 2003, PASP, 115, 143

Langer, G.E., Hoffman, R.D. 1995, PASP, 107, 1177

Leep, E. M., Wallerstein, G., Oke, J. B. 1987, AJ, 93, 338

Meissner, F., Weiss, A. 2006, A\&A, 456, 1085

Norris, J., \& Freeman, K.C. 1979, ApJ, 230, L179

Norris, j., Freeman, K.C. \& Da Costa, G.S. 1984, ApJ, 277, 615

Parmentier, G., Jehin, E., Magain, P. et al. 1999, A\&A, 352, 138

Parmentier, G., \& Gilmore, G. 2001, A\&A, 378, 97

Penny, A. J., Smith, G. H., Churchill, C. W. 1992, MNRAS, 257, 89

Prochaska, L.C., Rose, J.A., Schiavon, R.P. 2005, AJ, 130, 2666

Ramírez, S., Cohen, J.G., Buss, J., Briley, M.M. 2001, 122, 1429

Ramírez, S., Cohen, J. G. 2002, AJ, 123, 3277

Serven, J., Worthey, G., Briley, M.M. 2005, ApJ, 627, 754

Smith, G. H., 1987, PASP, 99, 67

Smith, G. H., Norris, J. 1982, ApJ, 254, 149

Smith, G. H., Penny, A. J. 1989, AJ, 97, 1397

Sneden, C., Kraft, R. P., Langer, G. E., Prosser, C. F., Shetrone, M. D. 1994, AJ, 107,1773

Thoul, A., Jorissen, A., Goriely, S. et al. 2002, A\&A, 383, 491

Thomas, D., Maraston, C., Bender, R. 2003, MNRAS, 343, 279

Vazdekis, A., Cenarro, A.J., Gorgas, J., Cardiel, N., Peletier, R.F. 2003, MNRAS, 340,1317

Worthey, G., Faber, S. M., Gonzalez, J., Burstein, D. 1994, ApJS, 94, 687

Worthey, G., \& Ottaviani, D.L. 1997, ApJS, 111, 377

Yong, D., Aoki, W., Lambert, D. L. 2006, ApJ, 638, 1018 
A. Alves-Brito et al.: Abundance variations in the globular cluster M71 (NGC 6838), Online Material p 1

\section{Online Material}


A. Alves-Brito et al.: Abundance variations in the globular cluster M71 (NGC 6838), Online Material p 2

Table 1. Program stars : star identification (1, as given in the observation masks and Cudworth 1985;2006), coordinates J2000 (2)-(3), heliocentric radial velocities [km/s] (4), membership probabilities (5, provided by Cudworth 1985;2006), V magnitude (6), colours(7)-(8), bolometric magnitudes (9), gravities [dex](10), temperatures [K] (11).

\begin{tabular}{|c|c|c|c|c|c|c|c|c|c|c|}
\hline $\begin{array}{l}\text { ID } \\
(1)\end{array}$ & $\begin{array}{l}\alpha \\
(2)\end{array}$ & $\begin{array}{c}\delta \\
(3)\end{array}$ & $\begin{array}{l}\mathrm{v}_{r} \\
(4)\end{array}$ & $\begin{array}{l}P \\
(5)\end{array}$ & $\begin{array}{l}\mathrm{V} \\
(6)\end{array}$ & $\begin{array}{l}\text { B-V } \\
(7)\end{array}$ & $\begin{array}{c}(\mathrm{B}-\mathrm{V})_{o} \\
(8)\end{array}$ & $\begin{array}{c}\text { Mbol } \\
\text { (9) }\end{array}$ & $\begin{array}{l}\log g \\
(10)\end{array}$ & $\begin{array}{c}\mathrm{T}_{\mathrm{B}-\mathrm{V}} \\
\text { (11) }\end{array}$ \\
\hline $155:$ KC-141 & 298.4016 & +18.75612 & 16.13 & 91 & 15.34 & 1.23 & 0.960 & 1.370 & 2.63 & 4709 \\
\hline $138: \mathrm{KC}-127$ & 298.3995 & +18.79042 & -8.10 & 90 & 14.44 & 1.07 & 0.800 & 0.602 & 2.43 & 5000 \\
\hline $114:$ KC-136 & 298.3962 & +18.76293 & 16.62 & 93 & 14.80 & 1.22 & 0.950 & 0.839 & 2.43 & 4726 \\
\hline $253: \mathrm{KC}-119$ & 298.4147 & +18.81320 & 123.03 & 95 & 14.52 & 1.11 & 0.840 & 0.650 & 2.42 & 4924 \\
\hline $1468^{\dagger}: \ldots$ & 298.4188 & +18.77991 & -4.63 & 80 & 17.30 & 0.81 & 0.540 & 3.723 & 3.94 & 5799 \\
\hline $367:$ KC-343 & 298.4335 & +18.79543 & 10.66 & 8 & 16.33 & 0.63 & 0.360 & 2.914 & 3.81 & 6500 \\
\hline $327: 1-73$ & 298.4268 & +18.78301 & -31.76 & 96 & 14.79 & 1.20 & 0.930 & 0.846 & 2.44 & 4761 \\
\hline $346: \mathrm{KC}-215$ & 298.4298 & +18.79586 & 37.87 & 93 & 15.30 & 0.97 & 0.700 & 1.539 & 2.88 & 5202 \\
\hline $356: 1-71$ & 298.4318 & +18.79003 & -22.45 & 96 & 13.54 & 1.44 & 1.170 & -0.627 & 1.71 & 4375 \\
\hline $221: 1-109$ & 298.4103 & +18.77245 & 23.54 & 96 & 14.87 & 1.24 & 0.970 & 0.891 & 2.44 & 4691 \\
\hline $207: 1639$ & 298.4085 & +18.79252 & -4.87 & 95 & 17.00 & 0.75 & 0.480 & 477 & 3.90 & 6012 \\
\hline $291: 1-95$ & 298.4206 & +18.76555 & 16.01 & 96 & 13.30 & 1.29 & 1.020 & -0.723 & 1.76 & 4608 \\
\hline $306: 1-75$ & 298.4229 & +18.79264 & 58.09 & 96 & 14.85 & 1.29 & 1.020 & & 2.38 & 4608 \\
\hline $751: 1289$ & 298.4129 & +18.78219 & -1.69 & 90 & 17.83 & 0.84 & 0.570 & 4.227 & 4.47 & 5705 \\
\hline $3791^{\dagger}: \ldots$ & 8.4245 & +18.79 & 32.12 & 80 & 16.83 & 1.07 & 00 & 2 & 3.39 & 5000 \\
\hline $1936: 1280$ & 59 & +18.77 & 1.80 & 95 & 17.45 & 0.95 & & & 3.81 & 5366 \\
\hline $390: 1-66$ & 298.4382 & +18.779 & -14.50 & 81 & 13.01 & 1.40 & 1.1 & -1 . & 1.54 & 4435 \\
\hline $1511: 1-113$ & 298.4403 & +18.79596 & -11.98 & 95 & 12.43 & 1.80 & 1.530 & -2 & 0.87 & 3903 \\
\hline $1124: 1-8$ & 298.4363 & +18.7 & 5.84 & 90 & 14.26 & 0.99 & 0. & & 2.44 & 5161 \\
\hline $69: \mathrm{KC}-$ & 3.4608 & +18.8 & 43.91 & 94 & 15.17 & 1.12 & 0 & & 2.67 & 4905 \\
\hline $7677: 1346$ & 298.4740 & +18.79896 & 87.14 & 84 & 18.14 & 0.86 & 0.590 & 4.517 & 4.50 & 5634 \\
\hline $51^{\dagger}: \ldots$ & 298.4469 & +18.77311 & -6.75 & 80 & 17.30 & 0.71 & 0.440 & 3.813 & 4.08 & 6165 \\
\hline $488^{\dagger}: \ldots$ & 298.4532 & +18.78136 & -1.78 & 80 & 16.83 & 0.76 & 0.490 & 3.298 & 3.82 & 5976 \\
\hline $7277: \mathrm{KC}$ & 4 & +18 & 17 & & & & & & & \\
\hline $1351: 1-45$ & 97 & +18 & 39.18 & 94 & 0 & .76 & U & 1 & 0.89 & 3950 \\
\hline $573:$ KC-196 & 298.4697 & +18.79116 & 23.10 & 69 & 15.60 & 1.17 & 0.900 & & 2.80 & 4814 \\
\hline $505: 1-34$ & 298.4574 & +18.78078 & -107.0 & 95 & 14.45 & 1.05 & 0.780 & & 2.46 & 5039 \\
\hline $1556: 1-46$ & 2 & +1 & 75 & 93 & & 1 & & & 0.88 & 3962 \\
\hline $7498: \mathrm{A}^{2}$ & 3.4715 & +18.7 & 29. & 94 & 20 & 1.6 & 0 & & 0.91 & 4036 \\
\hline 917 : KC-200 & 298.4624 & +18.80419 & 62.6 & 86 & 15.53 & 1.30 & 1.030 & 1. & 2.64 & 4592 \\
\hline $1796: 1$ & & & & 91 & & 0.8 & & & & 5741 \\
\hline $458: 1-43$ & 2 & +1 & 27 & 94 & 14.26 & 1.06 & 0.790 & 430 & 2.37 & 5020 \\
\hline 676 & 3.4591 & +18 & 31 & & & & & & & \\
\hline $566:$ KC-363 & 298.4681 & +18.77355 & -74.33 & 0 & 16.36 & 1.43 & 1.160 & 2.203 & 2.85 & 4390 \\
\hline & & & & & & & & & $\cos ^{2}$ & \\
\hline 61 & 2 & +1 & 12 & 97 & 17.94 & 0.80 & 0.530 & & 4.37 & 5852 \\
\hline $1235: 1670$ & 298.4834 & +18.79839 & 93.59 & 0 & 16.77 & 0.86 & 0.590 & 8 & 3.66 & 5635 \\
\hline $640: 1-48$ & 298.4814 & +18.79968 & 62.93 & 94 & 14.39 & 1.07 & 0.800 & 0.552 & 2.41 & 5000 \\
\hline $122: \mathrm{KC}-3$ & & & & 0 & 16.01 & 081 & & & 3.42 & 5799 \\
\hline $1035: 1600$ & 9 & +18 & -17.9 & 97 & 17.57 & $0 c$ & 0 & 3.85 & 4.59 & 5336 \\
\hline $787: 1-59$ & 298.4237 & +18.80803 & 48.60 & 89 & 14.63 & 1.30 & 1.030 & .598 & 2.28 & 4592 \\
\hline $292: X$ & 298.4207 & +18.73372 & -46.00 & 90 & 14.40 & 1.07 & & & 2.42 & 5000 \\
\hline $258: \mathrm{KC}-1$ & 298.4158 & +18.73698 & -2.72 & 85 & 15.03 & 1.26 & 0.990 & 1.034 & 2.48 & 4658 \\
\hline $2984^{\dagger}: \ldots$ & 298.4104 & 1877215 & -7.12 & 80 & 17.02 & 0.84 & 0.570 & 3416 & 3.78 & 5699 \\
\hline $328^{\dagger}: \ldots$ & 0 & +18 & -53.12 & 80 & 16.52 & 0.70 & 0.430 & 3.042 & 3.78 & 6205 \\
\hline 1060: & 298.4140 & +18.77067 & -2.37 & 80 & $\cdots$ & $\ldots$ & $\cdots$ & $\cdots$ & $\ldots$ & $\ldots$ \\
\hline $1294: \ldots$ & 298.4180 & +18.78680 & -5.85 & $\ldots$ & $\ldots$ & $\ldots$ & $\ldots$ & $\ldots$ & $\ldots$ & $\ldots$ \\
\hline $792^{\dagger}:$ & 298.4254 & +18.79479 & -24.60 & 80 & 16.6 & 1.03 & 0.76 & 83 & 3.35 & 5079 \\
\hline-79 & 37 & +18.77783 & 34.37 & 51 & 13.99 & 1.43 & 1.160 & -0.167 & 1.90 & 4390 \\
\hline & & & & 80 & & 1.0 & & & 3.40 & 5020 \\
\hline $402: 1-87$ & 298.4396 & +18.761 & -12.73 & 95 & 14.37 & 1.05 & 0.780 & 0.548 & 2.42 & 5039 \\
\hline $4126: \ldots$ & 298.4290 & +18.77043 & -21.62 & $\ldots$ & $\ldots$ & $\ldots$ & $\ldots$ & $\ldots$ & $\ldots$ & $\ldots$ \\
\hline $1633: \mathrm{KC}$ & 298.4338 & +18.78996 & 2.4 & 0 & 16.2 & 1.23 & 0.960 & 2.300 & 3.01 & 4709 \\
\hline $2001: 1-103$ & & & -20.97 & 89 & 14.33 & 0.87 & 0.600 & 0.698 & 2.67 & 5604 \\
\hline $1873: \ldots$ & 298.4356 & +18.78181 & -31.61 & 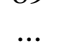 & $\ldots$ & & & & $\ldots$ & $\ldots$ \\
\hline $10387:$ KC-267 & 298.4380 & +18.77221 & -34.8 & 39 & 15.69 & 0.44 & 0.170 & 2.443 & 3.87 & 7499 \\
\hline
\end{tabular}


Table 1 - continued

\begin{tabular}{|c|c|c|c|c|c|c|c|c|c|c|}
\hline $\begin{array}{l}\text { ID } \\
(1)\end{array}$ & $\begin{array}{c}\alpha \\
(2)\end{array}$ & $\begin{array}{c}\delta \\
(3)\end{array}$ & $\begin{array}{l}\mathrm{v}_{r} \\
(4)\end{array}$ & $\begin{array}{l}\mathrm{P} \\
(5)\end{array}$ & $\begin{array}{l}\mathrm{V} \\
(6)\end{array}$ & $\begin{array}{c}\text { B-V } \\
(7)\end{array}$ & $\begin{array}{c}(\mathrm{B}-\mathrm{V})_{o} \\
(8)\end{array}$ & $\begin{array}{c}\text { Mbol } \\
\text { (9) }\end{array}$ & $\begin{array}{c}\log g \\
(10)\end{array}$ & $\begin{array}{c}\mathrm{T}_{\mathrm{B}-\mathrm{V}} \\
\text { (11) }\end{array}$ \\
\hline $1958: \ldots$ & 298.4417 & +18.77365 & -24.38 & $\ldots$ & ... & $\cdots$ & $\cdots$ & $\cdots$ & $\cdots$ & \\
\hline $921^{\dagger}: \ldots$ & 298.4650 & +18.77283 & -4.46 & 80 & 16.53 & 0.72 & 0.450 & 3.034 & 3.76 & 6126 \\
\hline $526: 1-53$ & 298.4607 & +18.81613 & 40.67 & 95 & 12.97 & 1.61 & 1.340 & -1.392 & 1.31 & 4138 \\
\hline $484: 1-55$ & 298.4526 & +18.80644 & 48.75 & 92 & 14.26 & 1.10 & 0.830 & 0.398 & 2.33 & 4943 \\
\hline $6548: 2071$ & 298.4558 & +18.80534 & -5.19 & 90 & 19.85 & 1.05 & 0.780 & 6.027 & 4.65 & 5039 \\
\hline $1181: 1058$ & 298.4628 & +18.79180 & -22.38 & 93 & 17.79 & 0.80 & 0.530 & 4.227 & 4.37 & 5852 \\
\hline $1785: 1-36$ & 298.4463 & +18.77901 & -28.97 & 64 & 12.79 & 1.25 & 0.980 & -1.197 & 1.60 & 4675 \\
\hline $11860: \ldots$ & 298.4575 & +18.80072 & 30.41 & $\ldots$ & $\ldots$ & $\ldots$ & $\ldots$ & $\ldots$ & $\ldots$ & $\ldots$ \\
\hline $5871: \ldots$ & 298.4479 & +18.79313 & -57.30 & $\ldots$ & $\ldots$ & $\ldots$ & $\ldots$ & $\ldots$ & $\ldots$ & $\ldots$ \\
\hline $6079: \ldots$ & 298.4502 & +18.77050 & -55.70 & $\ldots$ & $\ldots$ & $\ldots$ & $\ldots$ & $\ldots$ & $\ldots$ & $\ldots$ \\
\hline $7299: \ldots$ & 298.4678 & +18.80609 & -63.31 & $\ldots$ & $\ldots$ & $\ldots$ & $\ldots$ & $\ldots$ & $\ldots$ & $\ldots$ \\
\hline $7453: \ldots$ & 298.4694 & +18.80521 & 36.21 & $\ldots$ & & $\ldots$ & $\ldots$ & $\ldots$ & $\ldots$ & $\ldots$ \\
\hline $1214: 2084$ & 298.4746 & +18.80516 & 32.43 & 60 & 19.00 & 0.91 & 0.640 & 5.327 & 4.56 & 5465 \\
\hline $951: 2080$ & 298.4727 & +18.80355 & 48.11 & 82 & 18.08 & 0.77 & 0.500 & 4.546 & 4.31 & 5967 \\
\hline $2154: \ldots$ & 298.4710 & +18.78277 & -6.90 & & & & & & & \\
\hline $1219: 1356$ & 298.4765 & +18.79601 & 61.95 & 0 & 17.92 & 0.98 & 0.710 & 4.173 & 4.62 & 5243 \\
\hline $1716: \ldots$ & 298.4827 & +18.79184 & -29.50 & $\ldots$ & $\ldots$ & $\cdots$ & $\cdots$ & $\cdots$ & $\ldots$ & ... \\
\hline $8009: \ldots$ & 298.4805 & +18.79990 & -139.8 & $\ldots$ & . & . & & & . & \\
\hline $654: 1669$ & 298.4843 & +18.80037 & 52.82 & 0 & 17.26 & 1.28 & 1.010 & 3.246 & 3.35 & 4624 \\
\hline $1926: 1633$ & 298.4001 & +18.78803 & -22.54 & 97 & 17.28 & 1.01 & 0.740 & 3.489 & 3.63 & 5120 \\
\hline $3: 1995$ & 298.3983 & +18.77371 & 3.43 & 98 & 16.92 & 1.11 & 0.840 & 3.050 & 3.38 & 4924 \\
\hline $338: 1-107$ & 8.4283 & +18.77441 & 0.02 & 90 & 13.70 & 1.13 & 0.860 & -0.186 & 2.08 & 4887 \\
\hline $391:$ KC-234 & 298.4385 & +18.76578 & 18.32 & 81 & 15.59 & 0.12 & 0.150 & & $\ldots$ & . \\
\hline $223: \mathrm{KC}-300$ & 298.4105 & +18.77746 & 5.90 & 26 & 16.11 & 1.12 & 0.850 & 2.232 & 3.05 & 4905 \\
\hline $314: \ldots$ & .4240 & .79783 & 113.38 & $\ldots$ & & & $\ldots$ & & 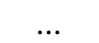 & \\
\hline $1325: 1-70$ & 298.4343 & +18.78580 & 18.25 & 92 & 14.43 & 1.09 & 0.820 & 0.576 & 2.41 & 4962 \\
\hline $294: 1308$ & 298.4210 & +18.79190 & 37.53 & 0 & 16.31 & 0.83 & 0.560 & 2.715 & 3.51 & 5732 \\
\hline $4448: \ldots$ & 298.4327 & +18.78299 & 0.11 & $\ldots$ & $\ldots$ & $\ldots$ & $\ldots$ & $\ldots$ & $\ldots$ & $\ldots$ \\
\hline $10218: \ldots$ & 298.4360 & +18.78151 & -10.03 & $\ldots$ & $\ldots$ & $\ldots$ & $\ldots$ & $\ldots$ & $\ldots$ & $\ldots$ \\
\hline $3915: \ldots$ & 298.4260 & +18.78303 & 29.04 & $\ldots$ & $\ldots$ & $\ldots$ & $\ldots$ & $\ldots$ & $\ldots$ & $\ldots$ \\
\hline $813: \ldots$ & 298.4306 & +18.77201 & 5.21 & & & & & & $\ldots$ & \\
\hline $266: \mathrm{KC}-2$ & .4171 & +18.77581 & 63.33 & 0 & 15.54 & 0.96 & 0.690 & 1.826 & 3.04 & 5338 \\
\hline $256: \mathrm{KC}-224$ & 298.4154 & +18.76982 & 61.72 & 0 & 15.13 & 0.63 & 0.360 & 1.714 & 3.33 & 6500 \\
\hline $1934: \ldots$ & 298.4136 & +18.78399 & 7.47 & & & & & & & \\
\hline $206: 1604$ & 298.4084 & +18.77378 & 48.45 & 83 & 16.83 & 0.87 & 0.600 & 3.198 & 3.67 & 5604 \\
\hline $407: 1-65$ & 4402 & + & 468 & 80 & 14.20 & 1.31 & 1.040 & 0.159 & 2.10 & 4575 \\
\hline $1693: \ldots$ & 298.4683 & +18.805 & 51.17 & $\ldots$ & $\ldots$ & $\ldots$ & $\ldots$ & $\ldots$ & $\ldots$ & $\ldots$ \\
\hline $1818: \ldots$ & 298.4662 & +18.80561 & 81.33 & $\ldots$ & $\ldots$ & $\ldots$ & $\ldots$ & $\ldots$ & $\ldots$ & $\ldots$ \\
\hline $6868: \ldots$ & 298.4617 & +18.80363 & 84.90 & $\ldots$ & 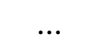 & $\ldots$ & & & $\ldots$ & \\
\hline $1210: 1342$ & .4741 & + & 72.68 & 92 & 18.50 & 0.83 & 0.560 & 4.907 & 4.45 & 5741 \\
\hline $2013: \ldots$ & .4565 & +18.80247 & 120.85 & $\ldots$ & $\ldots$ & $\ldots$ & $\ldots$ & $\ldots$ & $\ldots$ & $\ldots$ \\
\hline $1161: \ldots$ & 298.4523 & +18.80226 & 72.23 & $\ldots$ & $\ldots$ & $\ldots$ & $\ldots$ & $\ldots$ & $\ldots$ & $\ldots$ \\
\hline $6786: \ldots$ & 298.4601 & +18.73407 & -11.68 & $\ldots$ & $\ldots$ & $\ldots$ & $\ldots$ & $\ldots$ & $\ldots$ & $\ldots$ \\
\hline $12299: \ldots$ & 298.4637 & +18.78218 & 12.36 & $\ldots$ & $\ldots$ & $\ldots$ & $\ldots$ & $\ldots$ & $\ldots$ & $\cdots$ \\
\hline $888^{\dagger}: \ldots$ & 298.4543 & +18.78301 & 3.27 & 80 & 17.39 & 1.37 & 1.100 & 3.293 & 3.32 & 4481 \\
\hline $7505: \ldots$ & 298.4702 & +18.79745 & 60.95 & $\ldots$ & $\ldots$ & $\ldots$ & $\ldots$ & $\ldots$ & $\ldots$ & $\ldots$ \\
\hline $7573: \ldots$ & 298.4724 & +18.79126 & 93.07 & $\ldots$ & 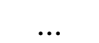 & $\ldots$ & 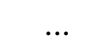 & & $\ldots$ & \\
\hline $452: 1-21$ & 298.4475 & +18.76873 & 4.58 & 95 & 13.02 & 1.49 & 1.220 & -1.200 & 1.45 & 4302 \\
\hline $10927: \ldots$ & 298.4456 & +18.77864 & 219.80 & $\ldots$ & $\ldots$ & $\ldots$ & $\ldots$ & $\ldots$ & $\ldots$ & $\ldots$ \\
\hline $5964: \ldots$ & 298.4495 & +18.77822 & 11.88 & $\ldots$ & $\ldots$ & $\ldots$ & $\ldots$ & $\ldots$ & $\ldots$ & $\ldots$ \\
\hline $1897: \ldots$ & 298.4584 & +18.77371 & -2.35 & $\ldots$ & 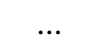 & $\ldots$ & & & 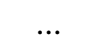 & \\
\hline $613: 1378$ & 298.4761 & +18.78647 & 27.41 & 97 & 17.57 & 0.89 & 0.620 & 3.917 & 4.53 & 5531 \\
\hline $641: \mathrm{KC}-19$ & 298.4816 & .794 & 25.35 & 85 & 15.01 & 1.20 & 0.930 & 1.066 & 2.53 & 4761 \\
\hline $651: \mathrm{KC}-170$ & 298.4838 & +18.75471 & -15.25 & 92 & 15.57 & 1.14 & 0.870 & 1.676 & 2.82 & 4868 \\
\hline $720: \mathrm{KC}-125$ & 298.4006 & +18.79778 & 57.44 & 38 & 15.32 & 1.12 & 0.850 & 1.442 & 2.73 & 4905 \\
\hline $4: 2$ & 29 & +18.78664 & -31.06 & 99 & 17.59 & 0.96 & 0.690 & 3.865 & 4.60 & 5305 \\
\hline $399: 1-81$ & 298.4392 & +18.77778 & -0.78 & 95 & 13.69 & 1.41 & 1.140 & -0.447 & 1.80 & 4419 \\
\hline $1282:$ KC-298 & 298.4108 & +18.79258 & -20.66 & 8 & 16.15 & 1.22 & 0.950 & 2.189 & 2.97 & 4726 \\
\hline $1081: \ldots$ & 298.4221 & +18.77992 & -2.77 & $\cdots$ & $\ldots$ & $\ldots$ & ... & $\ldots$ & $\ldots$ & $\ldots$ \\
\hline
\end{tabular}


A. Alves-Brito et al.: Abundance variations in the globular cluster M71 (NGC 6838), Online Material p 4

Table 1 - continued

\begin{tabular}{|c|c|c|c|c|c|c|c|c|c|c|}
\hline $\begin{array}{l}\text { ID } \\
(1)\end{array}$ & $\begin{array}{c}\alpha \\
(2)\end{array}$ & $\begin{array}{c}\delta \\
(3)\end{array}$ & $\begin{array}{l}\mathrm{v}_{r} \\
\text { (4) }\end{array}$ & $\begin{array}{l}P \\
(5)\end{array}$ & $\begin{array}{l}\text { V } \\
\text { (6) }\end{array}$ & $\begin{array}{l}\overline{\text { B-V }} \\
\text { (7) }\end{array}$ & $\begin{array}{c}(\mathrm{B}-\mathrm{V})_{o} \\
(8)\end{array}$ & $\begin{array}{l}\text { Mbol } \\
\text { (9) }\end{array}$ & $\begin{array}{r}\log g \\
(10)\end{array}$ & $\begin{array}{c}\mathrm{T}_{\mathrm{B}-\mathrm{V}} \\
\text { (11) }\end{array}$ \\
\hline $829: \mathrm{KC}-265$ & 298.4352 & +18.77724 & -7.32 & 70 & 15.50 & 1.25 & 0.980 & 1.513 & 2.68 & 4675 \\
\hline $4482: \ldots$ & 298.4329 & +18.79019 & -21.82 & $\ldots$ & $\ldots$ & $\ldots$ & $\ldots$ & $\ldots$ & $\ldots$ & $\ldots$ \\
\hline $1486: \ldots$ & 298.4293 & +18.77786 & -16.28 & $\ldots$ & $\ldots$ & $\ldots$ & $\ldots$ & $\ldots$ & $\ldots$ & $\ldots$ \\
\hline $3909: \ldots$ & 298.4273 & +18.78753 & -17.13 & $\ldots$ & $\ldots$ & $\ldots$ & $\ldots$ & $\ldots$ & $\ldots$ & $\ldots$ \\
\hline $1087: \ldots$ & 298.4247 & +18.77539 & -7.65 & $\ldots$ & ... & ... & $\ldots$ & ... & $\ldots$ & ... \\
\hline $387: \ldots$ & 298.4374 & +18.79451 & -9.97 & $\ldots$ & $\ldots$ & $\ldots$ & $\ldots$ & $\ldots$ & $\ldots$ & $\ldots$ \\
\hline $778: \ldots$ & 298.4201 & +18.78474 & -22.07 & $\ldots$ & $\ldots$ & $\ldots$ & $\ldots$ & $\ldots$ & $\ldots$ & $\ldots$ \\
\hline $2045: \ldots$ & 298.4178 & +18.78361 & -26.96 & $\ldots$ & $\ldots$ & $\ldots$ & $\ldots$ & $\ldots$ & $\ldots$ & $\ldots$ \\
\hline $1292^{\dagger}: \ldots$ & 298.4159 & +18.77535 & -10.03 & 80 & 17.31 & 1.19 & 0.920 & 3.374 & 3.46 & 4778 \\
\hline $242: 1281$ & 298.4135 & +18.77435 & 21.63 & 94 & 17.56 & 0.99 & 0.720 & 3.803 & 4.62 & 5213 \\
\hline $212: \mathrm{KC}-128$ & 298.4089 & +18.78764 & -21.42 & 0 & 15.19 & 1.37 & 1.100 & 1.093 & 2.44 & 4481 \\
\hline $5412: \ldots$ & 298.4417 & +18.78268 & -11.30 & $\ldots$ & $\ldots$ & $\ldots$ & $\ldots$ & $\ldots$ & $\ldots$ & $\ldots$ \\
\hline $574: \ldots$ & 298.4698 & +18.80458 & 66.35 & & $\ldots$ & . & & . & $\ldots$ & \\
\hline $78: 1341$ & 298.4731 & +18.80265 & 51.13 & 96 & 18.08 & 0.79 & 0.520 & 4.526 & 4.34 & 5890 \\
\hline $1561: \ldots$ & 298.4658 & +18.80221 & 55.75 & $\ldots$ & $\ldots$ & $\ldots$ & $\ldots$ & $\ldots$ & $\ldots$ & $\ldots$ \\
\hline $1894: \ldots$ & 298.4537 & +18.80117 & 81.02 & $\ldots$ & $\cdots$ & $\ldots$ & $\ldots$ & $\ldots$ & $\cdots$ & \\
\hline $881:$ KC-252 & 298.4516 & +18.78288 & -19.77 & 0 & 15.38 & 0.69 & 0.420 & 1.911 & 3.34 & 6245 \\
\hline $7014: \ldots$ & 298.4625 & +18.78173 & -22.03 & $\ldots$ & $\ldots$ & $\ldots$ & $\ldots$ & $\ldots$ & $\ldots$ & $\ldots$ \\
\hline $11907: \ldots$ & 298.4568 & +18.79274 & -34.30 & $\ldots$ & $\ldots$ & $\ldots$ & $\ldots$ & $\ldots$ & $\ldots$ & $\ldots$ \\
\hline $523: \ldots$ & 298.4605 & +18.78475 & -11.23 & $\ldots$ & $\ldots$ & $\ldots$ & $\ldots$ & $\ldots$ & $\ldots$ & $\ldots$ \\
\hline $2229: \ldots$ & 298.4750 & +18.78421 & 14.80 & $\ldots$ & ... & ... & $\ldots$ & $\ldots$ & $\ldots$ & $\ldots$ \\
\hline $2153: \ldots$ & 298.4674 & +18.79044 & 1.29 & & . & $\ldots$ & $\ldots$ & 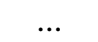 & $\ldots$ & \\
\hline $513: 1-11$ & 298.4587 & +18.76193 & 1.72 & 87 & 14.81 & 1.19 & 0.920 & 0.874 & 2.46 & 4778 \\
\hline $5843: 1-42$ & 298.4474 & +18.78542 & -236.7 & 94 & 14.22 & 1.02 & 0.750 & 0.421 & 2.39 & 5099 \\
\hline $11331: \ldots$ & 298.4495 & +18.77523 & -18.35 & $\ldots$ & $\ldots$ & $\ldots$ & $\ldots$ & $\ldots$ & $\ldots$ & $\ldots$ \\
\hline $1144: \ldots$ & 298.4455 & +18.78746 & -6.37 & $\ldots$ & $\ldots$ & $\ldots$ & $\ldots$ & $\ldots$ & $\ldots$ & $\ldots$ \\
\hline $1815: \ldots$ & 298.4642 & +18.77378 & -12.25 & 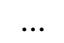 & 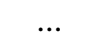 & $\ldots$ & $\ldots$ & $\ldots$ & $\ldots$ & $\ldots$ \\
\hline $616: 1158$ & 298.4767 & +18.77737 & -4.03 & 99 & 17.50 & 0.89 & 0.620 & 3.850 & 3.91 & 5542 \\
\hline $8076: \ldots$ & 298.4831 & +18.79152 & -8.45 & $\cdots$ & $\ldots$ & $\ldots$ & $\cdots$ & $\ldots$ & $\ldots$ & $\ldots$ \\
\hline $1409: \ldots$ & 298.4810 & +18.79049 & -5.78 & $\ldots$ & $\ldots$ & $\ldots$ & $\ldots$ & $\ldots$ & $\ldots$ & $\ldots$ \\
\hline
\end{tabular}


Table 3. Selected spectral indices and uncertainties

\begin{tabular}{|c|c|c|c|c|c|c|c|c|c|c|}
\hline $\begin{array}{l}\text { ID } \\
\text { (1) }\end{array}$ & $\begin{array}{c}\mathrm{CN}_{1} \\
(2)\end{array}$ & $\begin{array}{c}\sigma \mathrm{CN}_{1} \\
(3)\end{array}$ & $\begin{array}{c}\mathrm{CN}_{2} \\
(4)\end{array}$ & $\begin{array}{c}\sigma \mathrm{CN}_{2} \\
(5)\end{array}$ & $\begin{array}{c}\mathrm{Ca} 4227 \\
(6)\end{array}$ & $\begin{array}{c}\sigma \mathrm{Ca} 4227 \\
(7)\end{array}$ & $\begin{array}{c}\text { G4300 } \\
(8)\end{array}$ & $\begin{array}{c}\sigma \mathrm{G} 4300 \\
(9)\end{array}$ & $\begin{array}{c}\mathrm{Fe} 4383 \\
(10)\end{array}$ & $\begin{array}{c}\sigma \mathrm{Fe} 4383 \\
(11)\end{array}$ \\
\hline 155 & & & & & 1.40243 & 0.06233 & 6.52152 & 0.10159 & 4.20713 & 0.14444 \\
\hline 138 & 0.04322 & 0.00209 & 0.07336 & 0.00244 & 0.57001 & 0.03885 & 5.92503 & 0.05891 & $\ldots$ & $\ldots$ \\
\hline 114 & 0.16148 & 0.00286 & 0.20422 & 0.00334 & 0.65743 & 0.05216 & 5.96941 & 0.07767 & 3.61326 & 0.11121 \\
\hline 253 & 0.00931 & 0.00229 & 0.03234 & 0.00269 & 0.61062 & 0.04255 & 6.61777 & 0.06490 & 2.60329 & 0.09691 \\
\hline 1468 & -0.05119 & 0.00791 & -0.02598 & 0.00911 & 1.20442 & 0.13622 & 3.78093 & 0.23611 & 1.77363 & 0.32466 \\
\hline 367 & -0.11786 & 0.00402 & -0.07367 & 0.00460 & 0.22357 & 0.07454 & 9.08490 & 0.15210 & 0.83578 & 0.18196 \\
\hline 327 & 0.15312 & 0.00276 & 0.19179 & 0.00323 & 0.83128 & 0.05027 & 6.08654 & 0.07403 & 3.37153 & 0.10663 \\
\hline 346 & -0.03214 & 0.00320 & -0.00845 & 0.00374 & 1.02249 & 0.05736 & $\ldots$ & $\ldots$ & 2.97693 & 0.13212 \\
\hline 356 & 0.06381 & 0.00178 & 0.11698 & 0.00207 & 1.95910 & 0.02910 & 6.39225 & 0.04704 & & \\
\hline 221 & 0.05313 & 0.00288 & 0.08605 & 0.00337 & 0.84705 & 0.05208 & 6.44599 & 0.07955 & 4.06963 & 0.11329 \\
\hline 207 & -0.09300 & 0.00632 & -0.04139 & 0.00723 & 0.33972 & 0.11780 & 0.85977 & 0.20239 & & $\ldots$ \\
\hline 291 & 0.22158 & 0.00150 & 0.27198 & 0.00175 & 0.91187 & 0.02664 & 6.88402 & 0.03843 & 4.58861 & 0.05606 \\
\hline 306 & 0.16083 & 0.00292 & 0.18856 & 0.00342 & 0.69245 & 0.05200 & 6.14833 & 0.07913 & & \\
\hline 751 & -0.04367 & 0.01090 & -0.00666 & 0.01261 & $\ldots$ & $\ldots$ & 3.92085 & 0.32847 & 1.47634 & 0.44154 \\
\hline 3791 & -0.12458 & 0.00753 & -0.10661 & 0.00893 & 0.76429 & 0.12619 & $\ldots$ & $\ldots$ & 3.96273 & 0.26997 \\
\hline 1936 & -0.04689 & 0.00953 & -0.01048 & 0.01100 & 0.54118 & 0.17870 & 4.96705 & 0.27965 & 1.76341 & 0.39538 \\
\hline 390 & 0.23949 & 0.00155 & 0.30867 & 0.00180 & 2.09909 & 0.02481 & 6.18513 & 0.03913 & 5.44020 & 0.05304 \\
\hline 1511 & 0.09395 & 0.00150 & 0.18146 & 0.00173 & 4.37277 & 0.01886 & $\ldots$ & $\ldots$ & 7.48770 & 0.04667 \\
\hline 1124 & 0.06381 & 0.00191 & 0.09721 & 0.00223 & 0.33596 & 0.03605 & 5.94786 & 0.05428 & 2.55372 & 0.08127 \\
\hline 69 & 0.13869 & 0.00331 & 0.17676 & 0.00388 & 0.64753 & 0.06135 & 5.97267 & 0.09010 & 3.79636 & 0.12857 \\
\hline 7677 & -0.16205 & 0.01560 & -0.10893 & 0.01828 & & 然 & 3.00907 & 0.41338 & 0.16882 & 0.56815 \\
\hline 51 & -0.11096 & 0.00500 & -0.07487 & 0.00573 & 0.43956 & 0.09148 & 0.12812 & 0.16555 & 0.69300 & 0.22525 \\
\hline 488 & -0.11935 & 0.00471 & -0.08912 & 0.00539 & 0.45728 & 0.08761 & 0.04795 & 0.15723 & -0.34789 & 0.21842 \\
\hline 7277 & 0.08145 & 0.00807 & 0.12601 & 0.00939 & 0.55541 & 0.14618 & $\ldots$ & $\ldots$ & 3.42389 & 0.31066 \\
\hline 1351 & -0.05832 & 0.00184 & 0.02940 & 0.00225 & 3.85582 & 0.01897 & $\ldots$ & $\ldots$ & 6.14184 & 0.04448 \\
\hline 573 & 0.10763 & 0.00404 & 0.14294 & 0.00472 & 0.59885 & 0.07394 & 6.17838 & 0.10958 & & $\ldots$ \\
\hline 505 & 0.03659 & 0.00196 & 0.06304 & 0.00229 & 0.46435 & 0.03698 & 5.15907 & 0.05645 & 2.40308 & 0.08498 \\
\hline 1556 & -0.01914 & 0.00154 & 0.05687 & 0.00182 & 0.22444 & 0.05328 & 5.65096 & 0.03468 & 6.67513 & 0.04359 \\
\hline 7498 & 0.10080 & 0.00125 & 0.17497 & 0.00144 & 3.27895 & 0.01755 & 4.67087 & 0.03349 & 6.25388 & 0.04099 \\
\hline 917 & 0.27506 & 0.00421 & 0.30047 & 0.00504 & 1.26933 & 0.06688 & 6.48284 & 0.10694 & 4.26310 & 0.15185 \\
\hline 1796 & -0.11522 & 0.01992 & -0.04566 & 0.02258 & -0.59468 & 0.39629 & 2.63782 & 0.59020 & 4.59379 & 0.74652 \\
\hline 458 & 0.05273 & 0.00192 & 0.07980 & 0.00225 & 0.50643 & 0.03598 & 5.32540 & 0.05504 & & \\
\hline 6761 & -0.01236 & 0.00495 & 0.00076 & 0.00581 & 1.04621 & 0.08799 & 5.31722 & 0.14631 & 2.94120 & 0.20350 \\
\hline 566 & 0.30405 & 0.00956 & 0.35146 & 0.01113 & 1.94359 & 0.15123 & 6.34852 & 0.22361 & 8.89226 & 0.27095 \\
\hline 439 & 0.00500 & 0.00544 & 0.04180 & 0.00638 & 2.29010 & 0.08608 & 5.69465 & 0.15290 & 6.57911 & 0.19907 \\
\hline 619 & -0.28551 & 0.01437 & -0.26438 & 0.01701 & 0.86945 & 0.22357 & $\ldots$ & $\ldots$ & $\ldots$ & $\ldots$ \\
\hline 1235 & -0.22732 & 0.00721 & -0.20723 & 0.00878 & $\ldots$ & $\ldots$ & 3.81334 & 0.17853 & 3.68435 & 0.24416 \\
\hline 640 & 0.03427 & 0.00206 & 0.06479 & 0.00240 & $\ldots$ & $\ldots$ & 6.10977 & 0.05766 & 2.43395 & 0.08702 \\
\hline 122 & -0.05273 & 0.00420 & -0.01804 & 0.00488 & 0.98398 & 0.07342 & 5.08607 & 0.12400 & 3.63184 & 0.17351 \\
\hline 1035 & -0.02359 & 0.01100 & 0.00633 & 0.01277 & 1.24578 & 0.18844 & 6.25670 & 0.30724 & 2.31461 & 0.43753 \\
\hline 787 & 0.02371 & 0.00272 & 0.05826 & 0.00319 & 1.30720 & 0.04702 & 6.68840 & 0.07455 & 4.48230 & 0.10477 \\
\hline 292 & $\ldots$ & $\ldots$ & $\ldots$ & $\ldots$ & $\ldots$ & $\ldots$ & $\ldots$ & $\ldots$ & $\ldots$ & $\ldots$ \\
\hline 258 & $\ldots$ & $\ldots$ & $\ldots$ & $\ldots$ & $\ldots$ & $\ldots$ & $\ldots$ & $\ldots$ & $\ldots$ & $\ldots$ \\
\hline 2984 & -0.14430 & 0.00606 & -0.08624 & 0.00685 & 0.43245 & 0.10648 & $\ldots$ & $\ldots$ & 0.31503 & 0.26645 \\
\hline 328 & $\ldots$ & $\ldots$ & $\ldots$ & $\ldots$ & $\ldots$ & $\ldots$ & $\ldots$ & $\ldots$ & $\ldots$ & $\ldots$ \\
\hline 1060 & -0.04419 & 0.00658 & -0.02330 & 0.00766 & 1.01418 & 0.11492 & 5.22738 & 0.19162 & 4.25402 & 0.25825 \\
\hline 1294 & -0.08150 & 0.00653 & -0.05349 & 0.00753 & 0.76681 & 0.11435 & 3.83046 & 0.19669 & 3.35720 & 0.26601 \\
\hline 792 & 0.09121 & 0.00629 & 0.12761 & 0.00733 & 0.54454 & 0.11504 & $\ldots$ & $\ldots$ & 3.26673 & 0.24300 \\
\hline 13 & 0.33752 & 0.00245 & 0.38891 & 0.00287 & 2.20860 & 0.03768 & 6.56970 & 0.06089 & 8.60797 & 0.07663 \\
\hline 232 & 0.06822 & 0.00707 & 0.09758 & 0.00826 & 0.68816 & 0.12664 & 6.07985 & 0.19627 & 3.19207 & 0.27471 \\
\hline 402 & 0.00322 & 0.00201 & 0.03490 & 0.00236 & 0.65140 & 0.03694 & 6.62719 & 0.05728 & 3.13987 & 0.08479 \\
\hline 4126 & -0.06555 & 0.00987 & -0.03858 & 0.01148 & 0.52887 & 0.17753 & 5.21713 & 0.28995 & 2.85185 & 0.38755 \\
\hline 1633 & 0.03326 & 0.00600 & 0.07421 & 0.00697 & 0.94044 & 0.10219 & 4.80354 & 0.17021 & $\ldots$ & $\ldots$ \\
\hline 2001 & 0.04630 & 0.00192 & 0.08012 & 0.00224 & 0.42717 & 0.03574 & 5.42182 & 0.05505 & 2.65181 & 0.08199 \\
\hline 1873 & 0.07294 & 0.00462 & 0.11101 & 0.00540 & 0.74710 & 0.08374 & 5.98203 & 0.12879 & 3.46350 & 0.18147 \\
\hline 10387 & -0.04575 & 0.00919 & -0.00573 & 0.01066 & 0.98490 & 0.16133 & 4.32741 & 0.27375 & 1.49539 & 0.37778 \\
\hline 1958 & -0.00999 & 0.00909 & 0.00437 & 0.01062 & 1.27912 & 0.15579 & 5.13404 & 0.26472 & 3.77817 & 0.35257 \\
\hline 921 & -0.13095 & 0.00475 & -0.08016 & 0.00541 & 0.42099 & 0.08537 & 0.35964 & 0.15617 & 0.96461 & 0.21184 \\
\hline
\end{tabular}


Table 3 - continued

\begin{tabular}{|c|c|c|c|c|c|c|c|c|c|c|}
\hline $\begin{array}{l}\text { ID } \\
(1)\end{array}$ & $\begin{array}{c}\mathrm{CN}_{1} \\
(2)\end{array}$ & $\begin{array}{c}\sigma \mathrm{CN}_{1} \\
(3)\end{array}$ & $\begin{array}{c}\mathrm{CN}_{2} \\
(4)\end{array}$ & $\begin{array}{c}\sigma \mathrm{CN}_{2} \\
(5)\end{array}$ & $\begin{array}{c}\mathrm{Ca} 4227 \\
\text { (6) }\end{array}$ & $\begin{array}{c}\sigma \mathrm{Ca} 4227 \\
(7)\end{array}$ & $\begin{array}{c}\text { G4300 } \\
(8)\end{array}$ & $\begin{array}{c}\sigma \mathrm{G} 4300 \\
(9)\end{array}$ & $\begin{array}{c}\text { Fe4383 } \\
(10)\end{array}$ & $\begin{array}{c}\sigma \mathrm{Fe} 4383 \\
(11)\end{array}$ \\
\hline 526 & 0.26481 & 0.00159 & 0.34027 & 0.00184 & 2.40689 & 0.02432 & 5.83910 & 0.04022 & 6.13915 & 0.05277 \\
\hline 484 & -0.47637 & 0.00243 & -0.56421 & 0.00258 & 0.93837 & 0.03691 & 6.77858 & 0.05744 & 3.32696 & 0.08513 \\
\hline 6548 & -0.20698 & 0.08652 & -0.06987 & 0.09158 & 0.02042 & 1.63150 & 11.91655 & 1.72551 & 6.94459 & 2.48834 \\
\hline 1181 & -0.05243 & 0.01017 & -0.03674 & 0.01178 & 0.29992 & 0.18605 & 3.08939 & 0.31174 & & \\
\hline 1785 & 0.07411 & 0.00135 & 0.12348 & 0.00157 & 2.04942 & 0.02106 & 6.33864 & 0.03625 & 4.90075 & 0.05023 \\
\hline 11860 & -0.03443 & 0.01391 & -0.01236 & 0.01593 & & & 4.03324 & 0.40083 & 0.47772 & 0.57048 \\
\hline 5871 & -0.02782 & 0.01694 & 0.00359 & 0.01955 & 1.20888 & 0.30302 & 5.24213 & 0.47669 & & \\
\hline 6079 & -0.03227 & 0.00823 & 0.00465 & 0.00951 & 0.36602 & 0.14961 & 4.34266 & 0.24242 & 2.00205 & 0.33880 \\
\hline 7299 & -0.47582 & 0.02691 & -0.21301 & 0.02678 & -0.64381 & 0.44082 & 2.80661 & 0.69593 & 2.92516 & 0.86582 \\
\hline 7453 & -0.15532 & 0.02188 & 0.01301 & 0.02415 & -0.18546 & 0.38075 & 4.69649 & 0.58547 & 1.52503 & 0.78843 \\
\hline 1214 & -0.07199 & 0.03844 & 0.14304 & 0.04279 & 2.38127 & 0.57191 & 4.32146 & 1.08741 & 3.67873 & 1.27111 \\
\hline 951 & 0.87056 & 0.01535 & 0.91164 & 0.01855 & 0.55276 & 0.22763 & 4.29836 & 0.36736 & 3.39299 & 0.49865 \\
\hline 2154 & -0.05583 & 0.01052 & -0.02170 & 0.01215 & 0.68669 & 0.18524 & 3.49960 & 0.31683 & 1.77232 & 0.43230 \\
\hline 1219 & -0.10577 & 0.01253 & -0.06338 & 0.01435 & 0.49662 & 0.22758 & . & 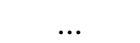 & 3.43794 & 0.48384 \\
\hline 1716 & -0.13661 & 0.00631 & -0.09596 & 0.00719 & 0.23661 & 0.11408 & -0.15670 & 0.20915 & & \\
\hline 8009 & 0.03526 & 0.00224 & 0.07428 & 0.00263 & $\ldots$ & $\ldots$ & 5.97122 & 0.06453 & 1.87757 & 0.09987 \\
\hline 654 & 0.18035 & 0.01310 & 0.22882 & 0.01521 & . & & 6.93690 & 0.32121 & 7.83077 & 0.39086 \\
\hline 1926 & -0.04897 & 0.00966 & -0.00731 & 0.01119 & 1.21283 & 0.16833 & 5.84349 & 0.27408 & & \\
\hline 3 & -0.02560 & 0.00823 & 0.00403 & 0.00958 & 1.49943 & 0.13918 & 6.89493 & 0.22869 & 4.09773 & 0.31600 \\
\hline 338 & 0.01406 & 0.00154 & 0.04509 & 0.00180 & 0.84549 & 0.02772 & 6.83656 & 0.04287 & 3.83291 & 0.06323 \\
\hline 391 & -0.17651 & 0.00202 & -0.12477 & 0.00232 & 0.07480 & 0.03770 & -1.95439 & 0.07245 & -0.24489 & 0.09981 \\
\hline 223 & -0.03701 & 0.00518 & -0.01518 & 0.00606 & 1.33425 & 0.08930 & 6.16913 & 0.14783 & 4.14466 & 0.20541 \\
\hline 314 & -0.06419 & 0.00442 & -0.03510 & 0.00551 & 0.63777 & 0.06511 & -5.31927 & 0.17046 & 5.54108 & 0.13067 \\
\hline 1325 & 0.06705 & 0.00221 & 0.10230 & 0.00258 & 0.66800 & 0.04039 & 6.21177 & 0.06147 & 3.24518 & 0.08977 \\
\hline 294 & -0.09128 & 0.00431 & -0.05734 & 0.00497 & 0.79088 & 0.07661 & 2.72706 & 0.13396 & & \\
\hline 4448 & -0.04674 & 0.00962 & -0.02689 & 0.01111 & 0.69301 & 0.16902 & 5.76952 & 0.26768 & 4.32254 & 0.36258 \\
\hline 10218 & -0.07782 & 0.00933 & -0.06129 & 0.01091 & 1.52458 & 0.15989 & 6.33231 & 0.27135 & 3.50866 & 0.37583 \\
\hline 3915 & -0.03427 & 0.00753 & -0.00254 & 0.00873 & 0.81765 & 0.13165 & 4.61150 & 0.22174 & 3.62914 & 0.29753 \\
\hline 813 & -0.05018 & 0.00941 & -0.02849 & 0.01090 & 0.85558 & 0.16762 & 5.60970 & 0.27368 & 1.34962 & 0.39138 \\
\hline 266 & 0.01584 & 0.00355 & 0.04366 & 0.00417 & 1.12150 & 0.06188 & 6.17802 & 0.10090 & 5.27360 & 0.13822 \\
\hline 256 & -0.10115 & 0.00225 & -0.05742 & 0.00259 & 0.46543 & 0.04089 & 1.27847 & 0.07316 & 0.84223 & 0.10319 \\
\hline 1934 & -0.03054 & 0.01361 & 0.00659 & 0.01574 & 0.87601 & 0.23547 & 5.99504 & 0.37867 & 3.59718 & 0.50286 \\
\hline 206 & -0.05680 & 0.00588 & -0.01722 & 0.00679 & 0.70195 & 0.10422 & 3.36285 & 0.17957 & 2.05268 & 0.25121 \\
\hline 407 & 0.18144 & 0.00221 & 0.23267 & 0.00258 & 0.96804 & 0.03931 & 6.13439 & 0.05880 & 4.30138 & 0.08311 \\
\hline 1693 & -0.47713 & 0.02065 & -0.05334 & 0.02048 & 0.89438 & 0.30345 & 4.56961 & 0.51913 & 0.27190 & 0.70931 \\
\hline 1818 & -0.36121 & 0.01282 & -0.03056 & 0.01330 & 0.50417 & 0.20503 & 3.65259 & 0.34537 & 1.34578 & 0.47705 \\
\hline 6868 & 0.91228 & 0.00644 & 0.92786 & 0.00797 & 0.97512 & 0.09404 & 6.20008 & 0.15204 & 3.91007 & 0.21252 \\
\hline 1210 & 0.65785 & 0.02053 & 0.68796 & 0.02464 & 0.91656 & 0.30387 & 4.07550 & 0.53275 & 1.32334 & 0.72966 \\
\hline 2013 & 0.34051 & 0.02131 & 0.37325 & 0.02540 & 1.09970 & 0.33150 & 3.14698 & 0.58426 & 4.16090 & 0.71026 \\
\hline 1161 & 0.08280 & 0.01091 & 0.11446 & 0.01263 & 0.25457 & 0.19455 & 3.52170 & 0.31192 & 1.42484 & 0.43431 \\
\hline 6786 & & & & & & & & & & \\
\hline 12299 & -0.07973 & 0.01201 & -0.04176 & 0.01378 & 0.84948 & 0.21222 & 2.92355 & 0.36646 & 0.57294 & 0.51187 \\
\hline 888 & -0.03084 & 0.00837 & -0.00614 & 0.00976 & 1.30186 & 0.14423 & 6.23319 & 0.23699 & 3.20632 & 0.32733 \\
\hline 7505 & -0.25368 & 0.02663 & -0.22219 & 0.03254 & 0.96518 & 0.37183 & & 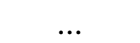 & 3.56761 & 0.81444 \\
\hline 7573 & -0.11943 & 0.00765 & -0.08628 & 0.00876 & 0.79454 & 0.13432 & 2.51309 & 0.23491 & & \\
\hline 452 & 0.08950 & 0.00139 & 0.14386 & 0.00162 & 1.78711 & 0.02295 & 7.01376 & 0.03626 & 5.66200 & 0.05088 \\
\hline 10927 & 0.01186 & 0.00224 & 0.04661 & 0.00262 & 0.88830 & 0.04067 & 6.49662 & 0.06284 & 3.43493 & 0.09240 \\
\hline 5964 & -0.07156 & 0.00758 & -0.04183 & 0.00874 & 0.52348 & 0.13665 & 3.78778 & 0.22987 & 1.98014 & 0.32230 \\
\hline 1897 & 0.10768 & 0.00286 & 0.14716 & 0.00336 & 0.66077 & 0.05207 & 6.78805 & 0.07778 & 4.07202 & 0.11229 \\
\hline 613 & -0.04641 & 0.01029 & -0.02407 & 0.01196 & 0.96931 & 0.18284 & 4.88181 & 0.30334 & 2.18303 & 0.41935 \\
\hline 641 & 0.00364 & 0.00305 & 0.03812 & 0.00357 & 1.18037 & 0.05298 & -1.41249 & 0.18450 & 4.14242 & 0.12083 \\
\hline 651 & & & & & 1.03547 & 0.07039 & 6.31482 & 0.11376 & 4.30139 & 0.15996 \\
\hline 720 & -0.13785 & 0.00441 & -0.11155 & 0.00548 & 0.74089 & 0.06422 & 1.89742 & 0.12369 & 4.84172 & 0.13704 \\
\hline 4 & -0.00156 & 0.01041 & 0.02518 & 0.01209 & 0.39857 & 0.19199 & 5.60566 & 0.29540 & 3.12601 & 0.40588 \\
\hline 399 & 0.04562 & 0.00178 & 0.09435 & 0.00208 & 1.87527 & 0.02910 & 6.61648 & 0.04830 & 5.00537 & 0.06630 \\
\hline 1282 & 0.06081 & 0.00595 & 0.09594 & 0.00694 & 0.64202 & 0.10821 & 5.74375 & 0.16551 & & \\
\hline 1081 & 0.08356 & 0.00902 & 0.12738 & 0.01054 & 0.40182 & 0.16364 & 5.85833 & 0.25165 & 3.55485 & 0.34161 \\
\hline 829 & 0.01706 & 0.00370 & 0.04976 & 0.00434 & 0.88499 & 0.06639 & 6.55853 & 0.10393 & 3.93711 & 0.14846 \\
\hline 4482 & -0.05420 & 0.00868 & -0.01129 & 0.01003 & 0.40235 & 0.15846 & 4.03163 & 0.26355 & 12.87503 & 0.33871 \\
\hline
\end{tabular}


A. Alves-Brito et al.: Abundance variations in the globular cluster M71 (NGC 6838), Online Material p 7

Table 3 - continued

\begin{tabular}{|c|c|c|c|c|c|c|c|c|c|c|}
\hline $\begin{array}{l}\text { ID } \\
(1)\end{array}$ & $\begin{array}{l}\mathrm{CN}_{1} \\
(2)\end{array}$ & $\begin{array}{c}\sigma \mathrm{CN}_{1} \\
(3)\end{array}$ & $\begin{array}{l}\mathrm{CN}_{2} \\
(4)\end{array}$ & $\begin{array}{c}\sigma \mathrm{CN}_{2} \\
(5)\end{array}$ & $\begin{array}{c}\mathrm{Ca} 4227 \\
\text { (6) }\end{array}$ & $\begin{array}{c}\sigma \mathrm{Ca} 4227 \\
(7)\end{array}$ & $\begin{array}{c}\text { G4300 } \\
(8)\end{array}$ & $\begin{array}{c}\sigma \mathrm{G} 4300 \\
(9)\end{array}$ & $\begin{array}{c}\text { Fe4383 } \\
(10)\end{array}$ & $\begin{array}{c}\sigma \mathrm{Fe} 4383 \\
(11)\end{array}$ \\
\hline 1486 & -0.02960 & 0.00616 & -0.00929 & 0.00721 & 0.98922 & 0.10984 & 6.09164 & 0.17795 & 3.34564 & 0.25024 \\
\hline 3909 & -0.03718 & 0.01094 & -0.01604 & 0.01276 & 1.34264 & 0.18482 & 6.19278 & 0.31139 & 4.52232 & 0.41026 \\
\hline 1087 & -0.03726 & 0.00854 & -0.02204 & 0.00998 & 1.06079 & 0.14747 & 5.41860 & 0.25044 & 3.34544 & 0.33815 \\
\hline 387 & -0.02069 & 0.00983 & 0.00733 & 0.01135 & 0.30317 & 0.17918 & & & 2.00333 & 0.40705 \\
\hline 778 & -0.05408 & 0.00809 & -0.02809 & 0.00942 & 0.87503 & 0.14206 & 6.25716 & 0.22945 & 3.22521 & 0.31751 \\
\hline 2045 & -0.02555 & 0.00873 & 0.00923 & 0.01013 & 0.71226 & 0.15574 & 4.90365 & 0.25730 & 2.94711 & 0.35295 \\
\hline 1292 & 0.05908 & 0.00881 & 0.08318 & 0.01027 & 0.66925 & 0.15659 & 5.30523 & 0.24976 & 3.09910 & 0.33919 \\
\hline 242 & -0.03314 & 0.01028 & -0.04201 & 0.01210 & -0.08970 & 0.19387 & -1.32111 & 0.34966 & -2.46920 & 0.43904 \\
\hline 212 & 0.32203 & 0.00430 & 0.36940 & 0.00504 & 1.75513 & 0.06757 & 6.36811 & 0.10780 & 2.63306 & 0.15386 \\
\hline 5412 & -0.02477 & 0.00416 & 0.00186 & 0.00488 & 1.22956 & 0.07329 & 6.54181 & 0.11903 & 3.79534 & 0.16883 \\
\hline 574 & -0.03900 & 0.01043 & -0.01161 & 0.01205 & 0.79684 & 0.17904 & 3.68958 & 0.30908 & 1.10257 & 0.43295 \\
\hline 78 & 0.59898 & 0.01486 & 0.64246 & 0.01777 & 0.69810 & 0.22874 & 2.62810 & 0.39217 & 2.19301 & 0.52092 \\
\hline 1561 & 0.14645 & 0.01022 & 0.16950 & 0.01205 & 0.97467 & 0.17233 & 5.39462 & 0.28533 & 2.85040 & 0.39194 \\
\hline 1894 & -0.06735 & 0.01336 & -0.01400 & 0.01535 & -0.50545 & 0.29880 & 4.20661 & 0.39315 & 1.57301 & 0.55144 \\
\hline 881 & -0.09442 & 0.00272 & -0.06150 & 0.00316 & 0.74754 & 0.04900 & 3.05938 & 0.08590 & 2.17886 & 0.12137 \\
\hline 7014 & -0.08444 & 0.00977 & -0.06065 & 0.01129 & 0.66799 & 0.17541 & 4.31525 & 0.29040 & 1.99912 & 0.40444 \\
\hline 11907 & -0.05077 & 0.01776 & -0.03992 & 0.02030 & 0.65460 & 0.32048 & 2.60527 & 0.52215 & & \\
\hline 523 & -0.05529 & 0.00580 & -0.03232 & 0.00677 & 0.78350 & 0.10449 & 5.52678 & 0.17170 & 2.27632 & 0.24667 \\
\hline 2229 & -0.03723 & 0.02017 & -0.07712 & 0.02343 & 0.80141 & 0.34639 & 2.40803 & 0.61903 & 1.39969 & 0.79086 \\
\hline 2153 & -0.06382 & 0.01067 & -0.04757 & 0.01232 & 0.36437 & 0.19238 & 1.93115 & 0.33241 & & \\
\hline 513 & -0.00838 & 0.00270 & 0.02281 & 0.00317 & 1.24215 & 0.04679 & 6.60797 & 0.07623 & 4.45550 & 0.10726 \\
\hline 5843 & 0.00490 & 0.00216 & 0.04651 & 0.00253 & 0.53005 & 0.03981 & 6.34083 & 0.06206 & 3.13525 & 0.09067 \\
\hline 11331 & -0.07463 & 0.01154 & -0.03743 & 0.01316 & 0.46931 & 0.20410 & 1.90226 & 0.36061 & 1.69964 & 0.48202 \\
\hline 1144 & -0.06654 & 0.00631 & -0.04187 & 0.00734 & 0.55505 & 0.11493 & 3.58999 & 0.19515 & 1.04941 & 0.27398 \\
\hline 1815 & -0.03459 & 0.00859 & 0.00321 & 0.00995 & 0.68996 & 0.15462 & 3.67910 & 0.26479 & 2.20097 & 0.36367 \\
\hline 616 & -0.03597 & 0.00954 & -0.00280 & 0.01104 & 0.37572 & 0.17640 & 4.65663 & 0.27798 & 2.23361 & 0.39137 \\
\hline 8076 & -0.02301 & 0.01376 & -0.00136 & 0.01594 & 1.00646 & 0.23899 & 5.91934 & 0.39427 & $\ldots$ & $\ldots$ \\
\hline 1409 & -0.06957 & 0.01594 & -0.04636 & 0.01848 & 1.24008 & 0.27302 & 4.27523 & 0.47819 & $\cdots$ & $\ldots$ \\
\hline
\end{tabular}


Table 4. Selected specral indices and uncertainties.

\begin{tabular}{|c|c|c|c|c|c|c|c|c|c|c|}
\hline $\begin{array}{l}\text { ID } \\
(1)\end{array}$ & $\begin{array}{l}\mathrm{H}_{\beta} \\
\text { (2) }\end{array}$ & $\begin{array}{c}\sigma \mathrm{H}_{\beta} \\
(3)\end{array}$ & $\begin{array}{c}\mathrm{Mg}_{1} \\
(4)\end{array}$ & $\begin{array}{c}\sigma \mathrm{Mg}_{1} \\
\quad(5)\end{array}$ & $\begin{array}{c}\mathrm{Mg}_{2} \\
(6)\end{array}$ & $\begin{array}{c}\sigma \mathrm{Mg}_{2} \\
(7)\end{array}$ & $\begin{array}{c}\text { Mgb } \\
(8)\end{array}$ & $\begin{array}{c}\sigma \mathrm{Mgb} \\
(9)\end{array}$ & $\begin{array}{c}\mathrm{Fe} 5270 \\
(10)\end{array}$ & $\begin{array}{c}\sigma \mathrm{Fe} 5270 \\
(11)\end{array}$ \\
\hline 155 & 1.23728 & 05199 & 0.08470 & 0.00105 & 0.12360 & 0.00118 & 2.00090 & & 2.22092 & 0.04909 \\
\hline 138 & 1.71328 & 0.03203 & -0.12243 & 0.00070 & -0.11571 & 0.00082 & 1.48913 & 0.02953 & 1.77792 & 0.03179 \\
\hline 114 & 1.24208 & 0.04006 & -0.15352 & 0.00085 & -0.00161 & 0.00100 & 2.54644 & 0.03525 & 2.30571 & 0.03787 \\
\hline 253 & 1.38706 & 0.03437 & -0.20548 & 0.00073 & -0.07328 & 0.00086 & 1.51620 & 0.03057 & 1.78977 & 3300 \\
\hline 1468 & 2.65934 & 0.11462 & -0.00489 & 0.00239 & 0.05761 & 0.00277 & 1.93860 & 0.10763 & 1.13950 & 0.12007 \\
\hline 367 & 4.51381 & 0.06618 & -0.01103 & 0.00146 & 0.03080 & 0.00170 & 0.83520 & 0.06797 & & \\
\hline 327 & 1.09457 & 0.03862 & 0.02683 & 0.00076 & 0.11273 & 0.00088 & 2.63517 & 0.03389 & 26211 & .03668 \\
\hline 346 & 1.56316 & 0.04784 & 0.01315 & 0.00095 & 0.09936 & 0.00110 & 2.33412 & 0.04280 & & \\
\hline 356 & 1.16060 & 0.02257 & 0.05118 & 0.00044 & 0.23330 & 0.00051 & 5.80145 & 0.01837 & 5.23928 & 0.01947 \\
\hline 221 & 1.16138 & 0.04050 & 0.03127 & 0.00079 & 0.11667 & 0.00092 & 2.51160 & 0.03568 & 2.33846 & 0.03833 \\
\hline 207 & 3.56054 & 0.09910 & -0.15108 & 0.00235 & -0.16891 & 0.00276 & 1.31818 & 0.09635 & -1.42167 & 0.11879 \\
\hline 291 & & & -0.03089 & 0.00040 & 0.14155 & 0.00047 & 5.58068 & 0.01603 & 4.32468 & 0.01797 \\
\hline 306 & 1.04347 & 0.04056 & -0.14163 & 0.00088 & -0.11593 & 0.00104 & 2.51789 & 0.03535 & 0.49334 & 0.04177 \\
\hline 751 & 2.30296 & 0.14787 & -0.01354 & 0.00298 & 0.06002 & 0.00347 & 2.08246 & 0.13429 & 1.06271 & 0.14987 \\
\hline 3791 & 1.44281 & 0.09524 & 0.01762 & 0.00186 & 0.12448 & 0.00216 & 2.91656 & 0.08285 & & \\
\hline 1936 & 2.17713 & 0.13621 & 0.00159 & 0.00277 & 0.06561 & 0.00321 & 2.30901 & 0.12321 & 1.38998 & .13753 \\
\hline 390 & 2.16206 & 0.01801 & 0.07967 & 0.00036 & 0.26260 & 0.00042 & 5.87791 & 0.01494 & 4.67364 & 0.01597 \\
\hline 1511 & 0.51285 & 0.01603 & 0.16339 & 0.00029 & 0.46267 & 0.00034 & 9.33388 & 0.01097 & & \\
\hline 1124 & 1.60465 & 0.03012 & -0.00090 & 0.00061 & 18 & 0.00070 & 1.38917 & 0.02795 & 1.67990 & 0.03005 \\
\hline 69 & 1.29073 & 0.04644 & -0.01062 & 0.00091 & 53 & 0.00 & 2.53874 & 0.04057 & 2.11044 & 0.04414 \\
\hline 7677 & 2.53599 & 0.18895 & 0.01715 & 0.00383 & 0.29555 & 0.00464 & & & 0.46097 & 0.19353 \\
\hline 51 & 4.17705 & 0.08207 & -0.01638 & 0.00181 & 0.02145 & 0.00210 & 0.70527 & 0.08436 & 0.87296 & 0.09253 \\
\hline 488 & 4.67647 & 0.07682 & -0.01882 & 0.00 & 28 & 0.00 & 43 & 0.08 & 508 & 0.08909 \\
\hline 7277 & 1.26708 & 0.11188 & 0.0 & 0.00 & & 0.0 & & 0.0 & 239 & 577 \\
\hline 1351 & 3.44805 & 0.01349 & 0.13626 & 0.00027 & 0.46681 & 0.00032 & 7.98301 & 0.01116 & 4.47050 & 0.01307 \\
\hline 573 & 1.33233 & 0.05689 & -0.14624 & 0.00 & & & & & & 0.05484 \\
\hline 505 & 1.76574 & 0.03115 & -0.0 & 0.00 & & 0.0 & 8 & 0.0 & 92 & 3116 \\
\hline 1556 & 2.09879 & 0.01436 & 0.10862 & 0.00027 & 0.83 & 0.00000 & 1.00676 & 0.00 & 6.77846 & 171 \\
\hline 7498 & 1.41136 & 0.01379 & 0.09837 & 0.00026 & 0.39654 & 0.00031 & 9.42370 & 0.00970 & 6.78767 & 0.01087 \\
\hline 917 & 1.27861 & 0.05491 & & & & & 2.89567 & 0.04731 & & \\
\hline 1796 & 2.85003 & 0.24088 & 0 & 0.00 & 08 & 0.00 & & & 956 & 3596 \\
\hline 458 & 1.62785 & 0.02992 & -0.16368 & 0.00067 & -0.17168 & 0.00079 & 1.52897 & 0.02749 & 1.75849 & 0.02974 \\
\hline 6761 & 1.29554 & 0.07244 & 0.01929 & 0.00143 & 0.12197 & 0.00166 & 3.07572 & 0.06320 & 1.98001 & 0.06970 \\
\hline 566 & 53 & 69 & & & & & & & 64 & 8006 \\
\hline 439 & 64 & 0.07617 & 57 & 0.0 & & 0.0 & 5.40309 & 0.06666 & 4.03782 & 0.07239 \\
\hline 619 & 2.84987 & 0.16601 & 0.00785 & 0.00336 & 0.07498 & 0.00390 & 1.69603 & 0.15437 & & \\
\hline 1235 & 3.39252 & 0.09002 & 0.00456 & 0.00190 & 0.10344 & 0.00221 & $\ldots$ & $\ldots$ & 367 & 0.09305 \\
\hline 640 & & 003179 & & & & & & & & 0.03095 \\
\hline 122 & 23 & 20 & 02 & & 73 & 0.00 & 2.58008 & 0.06 & 205 & 0.06691 \\
\hline 1035 & 2.23247 & 0.14782 & -0.00871 & 0.00297 & 0.06649 & 0.00345 & 2.43341 & 0.13191 & 1.24939 & 0.14682 \\
\hline 787 & 1.09383 & 0.03680 & 0.00699 & 0.00070 & & & 3.97123 & & & 0.03365 \\
\hline 292 & & 003211 & & 000 & & 000 & 130 & 0.03 & 10 & 0.03202 \\
\hline 258 & 1.14495 & 0.04660 & & 0.00090 & & 0.00 & 2.73249 & 0.04020 & 2.19098 & 0.04347 \\
\hline 2984 & 4.76758 & 0.09328 & -0.01603 & 0.00207 & 0.02870 & 0.00240 & 1.06460 & 0.09508 & 0.97310 & 0.10535 \\
\hline 328 & 6.10282 & 0.06981 & & & & & & & 0.47747 & 0.08361 \\
\hline 1060 & & 09482 & & 0.00198 & 12179 & 0.00231 & 3.1800 & 0.08793 & 2.66695 & 0.09571 \\
\hline 1294 & 3.51839 & 0.09689 & -0.01609 & 0.00206 & 0.06787 & 0.00240 & 1.99589 & 0.09330 & 1.96330 & 0.10188 \\
\hline 792 & 1.23244 & 0.08777 & 0.02261 & 0.00171 & 0.12557 & 0.00199 & 2.88605 & 0.07623 & & \\
\hline 13 & & 0.02839 & & & & & & & & \\
\hline 232 & & 0.09753 & & & 10 & 0.00 & 2.79735 & 0.08584 & 1.91094 & 0.09458 \\
\hline 402 & 1.58513 & 0.03117 & 0.01555 & 0.00 & 0.07392 & 0.00073 & 1.52584 & 0.02889 & 1.84671 & 0.03105 \\
\hline 4126 & 1.75579 & 0.13275 & 0.00465 & 0.00266 & 0.10422 & 0.00310 & 2.91400 & 0.11802 & 1.91177 & 0.13038 \\
\hline 1633 & 1.61262 & 0.07893 & & & & & & & 2.60730 & 0.07467 \\
\hline 2001 & & & 0.00 & & & & & & 1.68 & 0.03051 \\
\hline 1873 & 1.25060 & 0.06666 & 0.00825 & 0.00132 & 0.10383 & 0.00153 & 2.65167 & 0.05896 & 1.90914 & 0.06482 \\
\hline 10387 & 1.70260 & 0.13353 & -0.00494 & 0.00268 & 0.07419 & 0.00311 & 2.33884 & 0.11980 & 1.07864 & 0.13392 \\
\hline 1958 & & 0.12321 & & & & & & & 2.03251 & 0.11721 \\
\hline 921 & 5.62486 & 0.07594 & -0.01133 & 0.00175 & 0.03775 & 0.00203 & 0.80619 & 0.08143 & 1.25727 & 0.08861 \\
\hline
\end{tabular}


Table 4 - continued

\begin{tabular}{|c|c|c|c|c|c|c|c|c|c|c|}
\hline $\begin{array}{l}\text { ID } \\
(1)\end{array}$ & $\begin{array}{l}\mathrm{H}_{\beta} \\
\text { (2) }\end{array}$ & $\begin{array}{c}\sigma \mathrm{H}_{\beta} \\
(3)\end{array}$ & $\begin{array}{l}\mathrm{Mg}_{1} \\
(4)\end{array}$ & $\begin{array}{c}\sigma \mathrm{Mg}_{1} \\
(5)\end{array}$ & $\begin{array}{c}\mathrm{Mg}_{2} \\
(6)\end{array}$ & $\begin{array}{c}\sigma \mathrm{Mg}_{2} \\
(7)\end{array}$ & $\begin{array}{c}\text { Mgb } \\
(8)\end{array}$ & $\begin{array}{c}\sigma \mathrm{Mgb} \\
(9)\end{array}$ & $\begin{array}{c}\text { Fe5270 } \\
(10)\end{array}$ & $\begin{array}{c}\sigma \mathrm{Fe} 5270 \\
(11)\end{array}$ \\
\hline 526 & & & 0.07177 & 0.00035 & 0.28018 & 0.00041 & 6.61085 & 0.01426 & 6.36810 & 0.01505 \\
\hline 484 & 1.42297 & 0.03053 & -0.02152 & 0.00060 & 0.06394 & 0.00070 & 2.11313 & 0.02707 & 1.99763 & 0.02954 \\
\hline 6548 & 0.49610 & 0.74809 & 0.33930 & 0.01321 & 0.19814 & 0.01424 & 4.27093 & 0.53708 & 2.82585 & 0.53794 \\
\hline 1181 & 2.67965 & 0.15076 & -0.14580 & 0.00348 & -0.16468 & 0.00409 & 1.62608 & 0.14106 & 0.95591 & 0.15715 \\
\hline 1785 & 1.27569 & 0.01759 & 0.08821 & 0.00034 & 0.23752 & 0.00040 & 5.05040 & 0.01450 & 4.90434 & 0.01531 \\
\hline 11860 & 3.35735 & 0.18422 & 0.00218 & 0.00383 & 0.71677 & 0.00498 & & & 1.14870 & 0.18832 \\
\hline 5871 & 2.46747 & 0.21816 & -0.14391 & 0.00494 & -0.13159 & 0.00583 & 2.54280 & 0.19608 & -3.16630 & 0.27030 \\
\hline 6079 & 2.43809 & 0.12179 & 0.00421 & 0.00252 & 0.09106 & 0.00293 & 2.13766 & 0.11431 & 1.38027 & 0.12553 \\
\hline 7299 & 2.76794 & 0.28393 & 0.02429 & 0.00565 & 0.01862 & 0.00644 & 1.54703 & 0.24870 & 1.59366 & 0.27111 \\
\hline 7453 & 2.55815 & 0.25426 & 0.33351 & 0.00552 & 0.04884 & 0.00582 & 2.40941 & 0.22060 & 1.59301 & 0.24453 \\
\hline 1214 & 0.87293 & 0.39518 & 0.35244 & 0.00791 & 0.12368 & 0.00840 & 4.41888 & 0.30498 & 2.33893 & 0.33750 \\
\hline 951 & 2.63540 & 0.17575 & 0.37760 & 0.00394 & 0.03323 & 0.00411 & 1.96908 & 0.15781 & 1.04964 & 0.17669 \\
\hline 2154 & 2.37938 & 0.15105 & -0.01270 & 0.00307 & 0.04665 & 0.00356 & 1.68826 & 0.13859 & 1.57618 & 0.15162 \\
\hline 1219 & 2.30168 & 0.16977 & 0.00382 & 0.00335 & 0.10030 & 0.00390 & 2.08078 & 0.15269 & & \\
\hline 1716 & 5.05854 & 0.10029 & -0.14959 & 0.00249 & -0.18514 & 0.00293 & 0.75280 & 0.10358 & 0.69119 & 0.11499 \\
\hline 8009 & 6.75657 & 0.03381 & -0.03923 & 0.00087 & 1.03372 & 0.00000 & 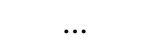 & $\ldots$ & 3.29142 & 0.04321 \\
\hline 654 & 1.30557 & 0.13419 & 0.09388 & 0.00254 & 0.87207 & 0.00328 & & & 3.71373 & 0.11508 \\
\hline 1926 & 1.55802 & 0.13123 & 0.00368 & 0.00259 & 0.09613 & 0.00301 & 2.85480 & 0.11438 & 1.85090 & 0.12644 \\
\hline 3 & 1.28607 & 0.11113 & 0.01817 & 0.00217 & 0.13638 & 0.00253 & 3.39220 & 0.09570 & 2.10816 & 0.10483 \\
\hline 338 & 2.01372 & 0.02289 & 0.00469 & 0.00046 & 0.13770 & 0.00054 & 4.06774 & 0.01992 & 2.36165 & 0.02247 \\
\hline 391 & & & -0.05499 & 0.00098 & -0.03216 & 0.00115 & -0.11196 & 0.04611 & -0.05713 & 0.05214 \\
\hline 223 & 1.32851 & 0.07405 & 0.01308 & 0.00146 & 0.12933 & 0.00170 & 2.92818 & 0.06521 & 1.99434 & 0.07117 \\
\hline 314 & 1.53876 & 0.04685 & 0.05839 & 0.00092 & 0.14398 & 0.00106 & 2.36277 & 0.04168 & 1.48794 & 0.04502 \\
\hline 1325 & 1.38286 & 0.03284 & 0.01911 & 0.00065 & 0.11760 & 0.00076 & 2.96613 & 0.02891 & 2.10983 & 0.03182 \\
\hline 294 & 3.66435 & 0.06909 & -0.16222 & 0.00166 & -0.16042 & 0.00196 & 1.62607 & 0.06790 & 1.63417 & 0.07465 \\
\hline 4448 & 3.05098 & 0.12844 & 0.00424 & 0.00264 & 0.10155 & 0.00308 & 2.33764 & 0.11967 & 2.45124 & 0.12829 \\
\hline 10218 & 1.31530 & 0.13068 & 0.00446 & 0.00254 & 0.11696 & 0.00296 & 3.15775 & 0.11213 & 1.56531 & 0.12445 \\
\hline 3915 & 3.57394 & 0.10651 & -0.00595 & 0.00227 & 0.07971 & 0.00264 & 2.14594 & 0.10230 & 2.04445 & 0.11183 \\
\hline 813 & 2.27763 & 0.13500 & -0.00951 & 0.00275 & 0.05576 & 0.00319 & 2.05247 & 0.12336 & 1.17302 & 0.13790 \\
\hline 266 & 2.09607 & 0.05256 & 0.02996 & 0.00108 & 0.16865 & 0.00126 & 4.16956 & 0.04674 & 2.90924 & 0.05173 \\
\hline 256 & 4.24373 & 0.03835 & -0.01407 & & & 0.00100 & 1.08078 & 0.03967 & 0.92942 & 0.04408 \\
\hline 1934 & 1.73745 & 0.16576 & 0.00724 & 0.00324 & 0.11142 & 0.00 & 2.74445 & 0.14501 & 1.51214 & 0.15914 \\
\hline 206 & 3.18473 & 0.09078 & -0.01018 & 0.00191 & 0.04615 & 0.00222 & 1.23735 & 0.08817 & 1.39074 & 0.09595 \\
\hline 407 & 1.15018 & 0.03032 & 0.03667 & 0.00059 & 0.15681 & 0.00069 & 3.28265 & 0.02631 & 2.81248 & 0.02832 \\
\hline 1693 & 3.42373 & 0.22621 & 0.04329 & 0.0 & 2734 & & 63 & 994 & 1. & 0.22970 \\
\hline 1818 & 2.65438 & 0.16302 & 0.17335 & 0.00351 & 0.03474 & 0.0 & 1.87656 & 0.14822 & 0.65747 & 0.16729 \\
\hline 6868 & 1.47979 & 0.07634 & 0.42762 & 0.00167 & 0.09404 & 0.00175 & 2.78518 & 0.06644 & 2.00677 & 0.07301 \\
\hline 1210 & 2.84151 & 0.23267 & 0.34705 & 0.00510 & 0.05421 & 0.00537 & 2.18355 & 0.20595 & 1.06898 & 0.22814 \\
\hline 2013 & 1131 & 0.22147 & 0.19284 & 0.00476 & 281 & $0 .($ & 3.10394 & 0.19683 & 253 & 0.21519 \\
\hline 1161 & 2.34482 & 0.15288 & 0.08055 & 0.00315 & 0.02436 & 0.00355 & & & 1.03649 & 0.15329 \\
\hline 6786 & 1.90330 & 0.13104 & -0.00564 & 0.00264 & 0.08141 & 0.00308 & 2.39554 & 0.11849 & 1.28457 & 0.13231 \\
\hline 12299 & 2.93148 & 0.17181 & -0.03094 & 0.00354 & 0.03488 & & 1.47326 & 0.16069 & 0.86268 & 0.17882 \\
\hline 888 & 1.75539 & 0.11167 & 0.01044 & & 8966 & & 87 & 323 & 1.68903 & 0.10945 \\
\hline 7505 & 2.04387 & 0.27810 & 0.01887 & 0.0 & 54 & 0.0 & 2.05155 & 0.24458 & & \\
\hline 7573 & 3.99887 & 0.11547 & -0.16686 & 0.00277 & -0.18082 & 0.00327 & 0.98339 & 0.11491 & 1.17812 & 0.12547 \\
\hline 452 & $\ldots$ & & 0.07600 & & & & 6.23868 & 0.01469 & & 0.01611 \\
\hline 10927 & 41246 & 03186 & & & & & & & 3.25964 & 0.03071 \\
\hline 5964 & 6188 & 1564 & 0033 & 39 & 25 & 0. & 1.85115 & 0.10823 & 1.20816 & 0.12015 \\
\hline 1897 & 1.13113 & 0.04106 & 0.02704 & 0.00080 & 0.13332 & 0.00093 & 2.97601 & 0.03582 & 2.22412 & 0.03898 \\
\hline 613 & 2.08808 & 0.14474 & -0.00111 & & & & 2.13041 & 0.12993 & 1.31938 & 0.14343 \\
\hline 641 & 1.19955 & 0.04389 & & & 013636 & 0.00 & 2.54522 & 0.03865 & & \\
\hline 651 & 1.21019 & 0.05873 & 0.46141 & 0.00128 & 0.12224 & 0.00133 & 2.87809 & 0.05105 & 2.13020 & 0.05557 \\
\hline 720 & 1.44506 & 0.05036 & 0.02969 & 0.00099 & 0.14578 & 0.00115 & 2.56061 & 0.04530 & 2.35925 & 0.04723 \\
\hline 4 & 1.93432 & 0.14130 & -0.01842 & 0.00281 & 0.07474 & 0.00327 & 2.43530 & 0.12516 & 1.32923 & 0.13935 \\
\hline 399 & 1.33173 & 0.02365 & & & & & 6.13691 & 0.01880 & 3.50330 & 0.02144 \\
\hline 1282 & 1.50194 & 8294 & -0.15261 & 184 & 3204 & 218 & 2.61034 & 0.07305 & -0.33876 & 0.09056 \\
\hline 1081 & 1.05207 & 0.11905 & 0.01921 & 0.00233 & 0.12112 & 0.00272 & 3.02187 & 0.10336 & 1.80271 & 0.11394 \\
\hline 829 & 1.06776 & 0.05433 & 0.01361 & 0.00106 & 0.10736 & 0.00123 & 2.52370 & 0.04758 & 2.10204 & 0.05178 \\
\hline 4482 & 3.01291 & 0.12842 & -0.00773 & 0.00272 & 0.05601 & 0.00316 & 1.71112 & 0.12339 & 0.79867 & 0.13770 \\
\hline
\end{tabular}


A. Alves-Brito et al.: Abundance variations in the globular cluster M71 (NGC 6838), Online Material p 10

Table 4 - continued

\begin{tabular}{|c|c|c|c|c|c|c|c|c|c|c|}
\hline $\begin{array}{l}\text { ID } \\
\text { (1) }\end{array}$ & $\begin{array}{l}\mathrm{H}_{\beta} \\
(2)\end{array}$ & $\begin{array}{c}\sigma \mathrm{H}_{\beta} \\
(3)\end{array}$ & $\begin{array}{l}\mathrm{Mg}_{1} \\
(4)\end{array}$ & $\begin{array}{c}\sigma \mathrm{Mg}_{1} \\
(5)\end{array}$ & $\begin{array}{c}\mathrm{Mg}_{2} \\
(6)\end{array}$ & $\begin{array}{c}\sigma \mathrm{Mg}_{2} \\
(7)\end{array}$ & $\begin{array}{c}\mathrm{Mgb} \\
(8)\end{array}$ & $\begin{array}{c}\sigma \mathrm{Mgb} \\
(9)\end{array}$ & $\begin{array}{c}\text { Fe5270 } \\
(10)\end{array}$ & $\begin{array}{c}\sigma \mathrm{Fe} 5270 \\
(11)\end{array}$ \\
\hline 1486 & 1.39487 & .08907 & 0.00919 & 0.00177 & 0.11589 & 0.00206 & 2.98442 & 0.07839 & 1.80873 & 0.08705 \\
\hline 3909 & 4953 & 13790 & 0.01219 & 0.00266 & 13415 & 0.00310 & 3.53451 & 0.11624 & 1.85187 & 0.12906 \\
\hline 1087 & 1.36366 & 0.11818 & 0.01492 & 0.00234 & 0.12819 & 0.00272 & 3.21511 & 0.10309 & 2.01140 & 0.11367 \\
\hline 387 & 2.43080 & 0.14175 & -0.01197 & 0.00286 & 0.05819 & 0.00333 & 1.65046 & 0.13020 & -5.06105 & 0.20487 \\
\hline 778 & 1.49698 & 0.10983 & 0.01853 & 0.00216 & 0.12598 & 0.00252 & 3.12756 & 0.09562 & 1.89121 & 0.10542 \\
\hline 2045 & 5734 & 0.12653 & 0.00135 & 0.00254 & 0.08299 & 0.00295 & 2.41215 & 0.11347 & 1.18041 & 0.12687 \\
\hline 1292 & 1.33699 & 0.12083 & 0.01398 & 0.00238 & 0.10434 & 0.00277 & 2.91980 & 0.10516 & 1.82446 & 0.11643 \\
\hline 242 & 1.79732 & 0.13878 & -0.00059 & 0.00276 & 0.09248 & 0.00321 & 2.54538 & 0.12281 & 1.67391 & 0.13511 \\
\hline 212 & 1.50184 & 0.04881 & 0.09768 & 0.00095 & 0.23621 & 0.00110 & 3.88277 & 0.04220 & 4.10027 & 0.04340 \\
\hline 5412 & 1.30644 & 0.06089 & 0.01611 & 0.00120 & 0.11015 & 0.00139 & 2.63092 & 0.05350 & 2.10637 & 0.05834 \\
\hline 574 & 2.79883 & 0.14897 & 0.36713 & 0.00337 & 0.02280 & 0.00352 & 1.55868 & 0.13625 & 1.08049 & 0.15132 \\
\hline 78 & 2.86741 & 0.17928 & 0.29300 & 0.00396 & 0.03263 & 0.00420 & 1.87402 & 0.16125 & 1.15810 & 0.18010 \\
\hline 1561 & 1.68997 & 0.13497 & 0.10795 & 0.00273 & 0.08656 & 0.00308 & -1.51759 & 0.13994 & 1.69391 & 0.12911 \\
\hline 1894 & 3.35560 & 0.18211 & -0.01367 & 0.00380 & 0.53794 & 0.00482 & 4.45043 & 0.22861 & 1.09506 & 0.18772 \\
\hline 881 & 3.78683 & 0.04534 & -0.02727 & 0.00099 & 0.04604 & 0.00115 & 1.74615 & 0.04467 & 1.79704 & 0.04923 \\
\hline 7014 & 2.37763 & 0.14366 & -0.02200 & 0.00292 & 0.05087 & 0.00340 & 1.73564 & 0.13203 & 1.29846 & 0.14622 \\
\hline 11907 & 2.84846 & 0.23225 & -0.14932 & 0.00526 & -0.14318 & 0.00620 & 2.03274 & 0.21047 & 1.19985 & 0.23761 \\
\hline 523 & 1.77719 & 0.08943 & -0.00010 & 0.00181 & 0.07916 & 0.00210 & 2.25041 & 0.08098 & 1.45859 & 0.08984 \\
\hline 2229 & 3.78836 & 0.26392 & 0.00760 & 0.00535 & 0.07581 & 0.00622 & 2.00141 & 0.24222 & 1.80245 & 0.26055 \\
\hline 2153 & 2.62474 & 0.15626 & -0.05211 & 0.00331 & -0.01073 & 0.00386 & 1.71805 & 0.14432 & 1.03627 & 0.15966 \\
\hline 513 & 1.11320 & 48 & -0.02054 & 0.00080 & 0.12460 & 0.00093 & 3.80636 & 0.03375 & 2.48247 & 0.03747 \\
\hline 5843 & 4.04459 & 0.03078 & -0.00287 & 0.00067 & 0.11807 & 0.00078 & 3.34937 & 0.02922 & 1.77796 & 0.03266 \\
\hline 11331 & 3.83852 & 0.16901 & -0.00427 & 0.00358 & 0.02945 & 0.00415 & 1.08484 & 0.16388 & 0.65439 & 0.18158 \\
\hline 1144 & 2.46969 & 0.09903 & -0.02428 & 0.00204 & 0.04797 & 0.00238 & 1.91467 & 0.09191 & 1.01999 & 0.10294 \\
\hline 1815 & 2.69190 & 0.13002 & -0.00206 & 0.00270 & 0.05693 & 0.00314 & 1.80936 & 0.12187 & 0.82827 & 0.13635 \\
\hline 616 & 2.14027 & 0.13974 & -0.01746 & 0.00280 & 0.05768 & 0.00325 & 2.37608 & 0.12406 & 1.20654 & 0.14004 \\
\hline 8076 & 2.26381 & 0.18873 & -0.14617 & 0.00428 & -0.14826 & 0.00505 & 1.96801 & 0.17150 & 0.92967 & 0.19099 \\
\hline 1409 & 2.29504 & 0.21093 & -0.07720 & 0.00448 & -0.01780 & 0.00527 & 2.83997 & 0.18622 & 1.11685 & 0.20817 \\
\hline
\end{tabular}


Table 5. Selected spectral indices and uncertainties.

\begin{tabular}{|c|c|c|c|c|c|c|c|c|}
\hline $\begin{array}{l}\text { ID } \\
(1)\end{array}$ & $\begin{array}{c}\mathrm{Fe} 5335 \\
(2)\end{array}$ & $\begin{array}{c}\sigma \mathrm{Fe} 5335 \\
(3)\end{array}$ & $\begin{array}{c}\text { Fe5406 } \\
(4)\end{array}$ & $\begin{array}{c}\sigma \mathrm{Fe} 5406 \\
(5)\end{array}$ & $\begin{array}{c}\mathrm{NaD} \\
(6)\end{array}$ & $\begin{array}{c}\sigma \mathrm{NaD} \\
(7)\end{array}$ & $\begin{array}{c}\mathrm{Al} 3953 \\
(8)\end{array}$ & $\begin{array}{c}\sigma \mathrm{Al} 3953 \\
(9)\end{array}$ \\
\hline 155 & 1.88008 & 0.05544 & 1.13882 & 0.04054 & 2.04970 & 0.03406 & & \\
\hline 138 & $\ldots$ & $\ldots$ & 0.81074 & 0.02593 & 4.12518 & 0.02094 & 4.13757 & 0.08959 \\
\hline 114 & 1.97289 & 0.04263 & 1.02490 & 0.03133 & $\ldots$ & $\ldots$ & $\ldots$ & $\ldots$ \\
\hline 253 & 1.51201 & 0.03747 & 0.69764 & 0.02730 & $\ldots$ & $\ldots$ & $\ldots$ & $\ldots$ \\
\hline 1468 & 0.84823 & 0.13686 & 0.69834 & 0.09912 & 1.86168 & 0.08544 & 2.70808 & 0.43285 \\
\hline 367 & 0.60807 & 0.08541 & 0.20029 & 0.06286 & 1.48435 & 0.05619 & 3.41298 & 0.14671 \\
\hline 327 & 1.95244 & 0.04120 & 1.13027 & 0.03021 & 3.26561 & 0.02444 & 3.25623 & 0.14144 \\
\hline 346 & 1.06836 & 0.05323 & 0.87886 & 0.03839 & 1.95114 & 0.03249 & 3.73815 & 0.15558 \\
\hline 356 & 4.72869 & 0.02187 & & & 5.82846 & 0.01238 & 2.10982 & 0.11406 \\
\hline 221 & 1.93333 & 0.04331 & 1.14638 & 0.03170 & 2.04300 & 0.02633 & 3.68824 & 0.14965 \\
\hline 207 & & $\ldots$ & 0.36262 & 0.08785 & 1.54693 & 0.07733 & 3.20823 & 0.26721 \\
\hline 291 & 4.29157 & 0.02001 & 1.40417 & 0.01533 & 6.36977 & 0.01129 & $\ldots$ & $\ldots$ \\
\hline 306 & $\ldots$ & $\ldots$ & 1.05979 & 0.03108 & 4.15998 & 0.02479 & -0.93592 & 0.29136 \\
\hline 751 & 1.27704 & 0.16750 & 0.59313 & 0.12306 & 1.80957 & 0.10448 & 3.97421 & 0.57499 \\
\hline 3791 & 1.66556 & 0.10151 & 0.88093 & 0.07444 & 1.97370 & 0.06277 & 2.11603 & 0.44516 \\
\hline 1936 & 0.81900 & 0.15765 & 0.66817 & 0.11403 & 1.47505 & 0.09792 & 3.34221 & 0.51237 \\
\hline 390 & 5.33949 & 0.01743 & 1.96846 & 0.01325 & 9.01046 & 0.00893 & 1.42806 & 0.10927 \\
\hline 1511 & 7.84740 & 0.01242 & 4.83822 & 0.00930 & 8.81875 & 0.00699 & 0.42836 & 0.13982 \\
\hline 1124 & 1.54715 & 0.03397 & 0.71771 & 0.02497 & $\ldots$ & $\ldots$ & $\ldots$ & $\ldots$ \\
\hline 69 & 1.85099 & 0.04955 & 1.02622 & 0.03604 & $\ldots$ & $\ldots$ & 3.03424 & 0.17479 \\
\hline 7677 & 0.96876 & 0.21559 & 0.82637 & 0.15647 & 1.10367 & 0.13828 & 0.76813 & 0.87924 \\
\hline 51 & 0.93517 & 0.10502 & 0.17910 & 0.07758 & 1.82498 & 0.06769 & 3.64415 & 0.18788 \\
\hline 488 & 0.47508 & 0.10135 & 0.48680 & 0.07362 & 1.59129 & 0.06554 & 3.05270 & 0.18440 \\
\hline 7277 & 1.79542 & 0.12151 & 0.82457 & 0.09015 & 1.97723 & 0.08238 & 2.73261 & 0.47105 \\
\hline 1351 & 5.78717 & 0.01269 & 1.88199 & 0.00983 & 8.36527 & 0.00651 & 0.02643 & 0.12503 \\
\hline 573 & $\ldots$ & $\ldots$ & 0.89615 & 0.04462 & 2.33871 & 0.03734 & 3.21746 & 0.22140 \\
\hline 505 & 1.56723 & 0.03514 & 0.76354 & 0.02595 & 1.98323 & 0.02190 & 3.43203 & 0.08805 \\
\hline 1556 & 7.22957 & 0.01210 & 3.66878 & 0.00924 & 9.31503 & 0.00636 & 1.00106 & 0.12246 \\
\hline 7498 & 7.49795 & 0.01150 & 2.03808 & 0.00946 & 7.66586 & 0.00651 & 0.14208 & 0.11679 \\
\hline 917 & 1.87019 & 0.05849 & 0.96000 & 0.04283 & 2.00605 & 0.03592 & 3.76283 & 0.20126 \\
\hline 1796 & 0.50466 & 0.27832 & 0.71101 & 0.19980 & 1.16686 & 0.17118 & 4.91702 & 1.00968 \\
\hline 458 & & & 0.69960 & 0.02445 & 3.61287 & 0.01986 & 3.20395 & 0.08887 \\
\hline 6761 & 1.64737 & 0.07901 & 1.04923 & 0.05763 & 2.14796 & 0.04823 & 3.03072 & 0.28683 \\
\hline 566 & 4.20148 & 0.08733 & 2.79188 & 0.06456 & 4.22998 & 0.05104 & 0.28492 & 0.82609 \\
\hline 439 & 3.70541 & 0.08057 & 2.10156 & 0.06051 & 3.70731 & 0.05016 & 0.76744 & 0.37679 \\
\hline 619 & 0.84795 & 0.18939 & 0.32044 & 0.13842 & 1.66702 & 0.11823 & 5.39553 & 0.49262 \\
\hline 1235 & 1.64902 & 0.10532 & 0.84878 & 0.07781 & 1.80787 & 0.06766 & 3.23324 & 0.29572 \\
\hline 640 & 1.73364 & 0.03488 & 0.68479 & 0.02576 & 3.43285 & 0.02100 & 4.10011 & 0.08782 \\
\hline 122 & 1.92711 & 0.07596 & 0.97030 & 0.05689 & 2.10646 & 0.04857 & 3.21900 & 0.20280 \\
\hline 1035 & 1.29244 & 0.16604 & 0.70795 & 0.12118 & 1.81988 & 0.10179 & 4.49992 & 0.57375 \\
\hline 787 & 2.18442 & 0.03773 & 1.14165 & 0.02770 & 3.78922 & 0.02172 & 3.56031 & 0.15401 \\
\hline 292 & 1.58101 & 0.03606 & 0.75698 & 0.02647 & 5.34830 & 0.02072 & $\ldots$ & $\ldots$ \\
\hline 258 & 1.78686 & 0.04892 & $\ldots$ & $\ldots$ & 3.11649 & 0.02908 & $\ldots$ & $\ldots$ \\
\hline 2984 & 0.67412 & 0.12070 & 0.27678 & 0.08908 & 1.34410 & 0.07828 & 2.59936 & 0.25309 \\
\hline 328 & 0.44214 & 0.09579 & 0.19050 & 0.07038 & 1.63522 & 0.06421 & $\ldots$ & $\ldots$ \\
\hline 1060 & 2.22165 & 0.10880 & 1.16092 & 0.08134 & 2.07268 & 0.06969 & 3.35157 & 0.34487 \\
\hline 1294 & 1.75503 & 0.11571 & 0.99874 & 0.08530 & 1.74806 & 0.07398 & 3.74682 & 0.32144 \\
\hline 792 & 1.66604 & 0.09366 & 0.80134 & 0.06898 & 2.06663 & 0.05800 & 1.96757 & 0.40522 \\
\hline 13 & 4.91128 & 0.02737 & 2.84901 & 0.02038 & 7.95423 & 0.01467 & 2.30609 & 0.16380 \\
\hline 232 & 1.48008 & 0.10735 & 0.67056 & 0.07913 & 1.99062 & 0.06577 & 3.48433 & 0.40631 \\
\hline 402 & 1.61127 & 0.03515 & 0.72657 & 0.02594 & $\ldots$ & $\ldots$ & $\ldots$ & $\ldots$ \\
\hline 4126 & 1.51639 & 0.14848 & 0.79867 & 0.10869 & 1.97674 & 0.09164 & 4.21065 & 0.54356 \\
\hline 1633 & 2.39855 & 0.08345 & $\ldots$ & $\ldots$ & 2.67346 & 0.05035 & 2.69732 & 0.36287 \\
\hline 2001 & 1.42637 & 0.03466 & 0.73745 & 0.02559 & 2.94943 & 0.02116 & 4.62421 & 0.07610 \\
\hline 1873 & 1.71704 & 0.07313 & 0.99498 & 0.05355 & 2.24143 & 0.04484 & 2.87170 & 0.26732 \\
\hline 10387 & 1.17871 & 0.15119 & 0.58279 & 0.11081 & 1.57460 & 0.09422 & 6.02303 & 0.36726 \\
\hline 1958 & 1.51552 & 0.13346 & 0.90350 & 0.09758 & 1.94411 & 0.08170 & 3.02844 & 0.60193 \\
\hline 921 & 1.27145 & 0.10090 & 0.52541 & 0.07521 & 1.87059 & 0.06604 & 3.02401 & 0.19063 \\
\hline
\end{tabular}


Table 5 - continued

\begin{tabular}{|c|c|c|c|c|c|c|c|c|}
\hline $\begin{array}{l}\text { ID } \\
\text { (1) }\end{array}$ & $\begin{array}{c}\overline{F e 5335} \\
\text { (2) }\end{array}$ & $\begin{array}{c}\sigma \mathrm{Fe} 5335 \\
\text { (3) }\end{array}$ & $\begin{array}{c}\text { Fe5406 } \\
(4)\end{array}$ & $\begin{array}{c}\sigma \mathrm{Fe} 5406 \\
(5)\end{array}$ & $\begin{array}{c}\mathrm{NaD} \\
(6)\end{array}$ & $\begin{array}{c}\sigma \mathrm{NaD} \\
(7)\end{array}$ & $\begin{array}{c}\mathrm{A} 13953 \\
(8)\end{array}$ & $\begin{array}{c}\sigma \mathrm{A} 13953 \\
(9)\end{array}$ \\
\hline 526 & 4.96871 & 0.01711 & 3.11902 & 0.01238 & & & 0.99159 & 0.13327 \\
\hline 484 & 1.68761 & 0.03344 & 1.05350 & 0.02438 & 1.83346 & 0.02050 & 4.30435 & 0.09241 \\
\hline 6548 & 2.70095 & 0.59014 & 2.37708 & 0.42203 & 2.56727 & 0.34309 & & \\
\hline 1181 & $\cdots$ & & 0.66861 & 0.12690 & 1.74240 & 0.11132 & 3.03023 & 0.46108 \\
\hline 1785 & 3.13278 & 0.01758 & 1.78792 & 0.01291 & 2.57412 & 0.01040 & 2.11845 & 0.09314 \\
\hline 11860 & 0.84356 & 0.21571 & 0.09819 & 0.15961 & 1.37398 & 0.13655 & 3.62595 & 0.71557 \\
\hline 5871 & 12.32339 & 0.27252 & -0.16567 & 0.18345 & 1.67359 & 0.15338 & 2.56151 & 0.98518 \\
\hline 6079 & 1.01860 & 0.14303 & 0.74467 & 0.10416 & 1.81616 & 0.08961 & 4.73762 & 0.35331 \\
\hline 7299 & 0.55601 & 0.31312 & 0.67329 & 0.22237 & 1.48273 & 0.18879 & 6.10641 & 0.96179 \\
\hline 7453 & 0.59866 & 0.28284 & -0.09022 & 0.20780 & 1.90269 & 0.17100 & 3.71238 & 1.13530 \\
\hline 1214 & 1.44650 & 0.38574 & 1.28500 & 0.27374 & 2.13300 & 0.22363 & 2.91973 & 1.82234 \\
\hline 951 & 1.12423 & 0.19938 & 0.34240 & 0.14689 & 1.45882 & 0.12586 & 4.41565 & 57983 \\
\hline 2154 & 1.05292 & 0.17371 & 0.29589 & 0.12803 & 1.61639 & 0.10815 & 4.87071 & 0.43522 \\
\hline 1219 & 1.60980 & 0.18361 & 0.84906 & 0.13545 & 2.39961 & 0.11474 & 4.76836 & 0.58302 \\
\hline 1716 & & & 0.17035 & 0.09490 & 1.56270 & 0.08467 & 3.15587 & 0.24504 \\
\hline 8009 & 24613 & 0.04609 & 2.94921 & 0.03593 & & & 4.02323 & 0.09952 \\
\hline 654 & 3.27638 & 0.12831 & 2.33312 & 0.09376 & 2.96788 & 0.07752 & 5.02895 & 0.79250 \\
\hline 1926 & 1.40006 & 0.14373 & & & 2.29584 & 0.08678 & 2.97128 & 0.57746 \\
\hline 3 & 1.63310 & 0.11896 & 0.90890 & 0.08769 & 2.06072 & 0.07176 & 4.51402 & 0.44895 \\
\hline 338 & 2.61543 & 0.025 & 1.10601 & 0.01865 & 2.71342 & 0.01536 & 3.59507 & 0.07471 \\
\hline 391 & -0.03744 & 6012 & 00765 & 04419 & 1.39905 & 0.04257 & & \\
\hline 223 & 1.73680 & 0.08037 & 0.97835 & 0.05897 & 1.86579 & 0.04919 & 3.68973 & 0.28871 \\
\hline 314 & 2.70134 & 0.04824 & 84 & 3574 & 3.18568 & 30 & 3.37 & 496 \\
\hline 1325 & 1.68266 & 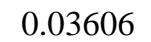 & 57 & 2656 & 3.29840 & 38 & 3.12 & 315 \\
\hline 294 & & & 0.59059 & 225 & 1.54293 & 0.05534 & 3.12744 & 0.19310 \\
\hline 4448 & 2.48048 & 5 & 0.98286 & 0.10841 & 2.88919 & 0.08917 & 4.32998 & 0.52777 \\
\hline 10218 & 1.61451 & & 0.7 & 0.10246 & .01120 & 0.08477 & 4.54057 & 617 \\
\hline 3915 & 1.91833 & & 82 & 9418 & 1.99952 & 0.08046 & 2.67857 & 378 \\
\hline 813 & 0.87306 & 0.15 & 0.66021 & 0.11404 & 1.93974 & 0.09731 & 3.47166 & 0.49736 \\
\hline 266 & 2.58337 & & 1.84446 & & 2.84290 & 3667 & 3.43362 & 0.17819 \\
\hline 256 & 3201 & 0. & 88 & 0 & 1.29847 & 3322 & 3.6 & 159 \\
\hline 1934 & 6685 & 0.10 & 56 & 3000 & 2.08951 & 0.10892 & -0.28106 & 1.27920 \\
\hline 206 & & 0.10937 & 0.41655 & 0.08117 & 1.60935 & 0.06918 & 3.64951 & 0.26288 \\
\hline 407 & & & & & & & & 3003 \\
\hline 1693 & 0.53781 & 0 & 0.72 & 27 & 1.53842 & 21 & 4.80290 & 0.74823 \\
\hline 1818 & & & & & 1.63487 & 87 & 3.46074 & 0.53511 \\
\hline 6868 & & 0.083 & & & 2.01688 & 0.05101 & 3.70292 & 0.28231 \\
\hline 1210 & & & & & & & & 1.03946 \\
\hline 2013 & 9 & & & & 288 & & 4.9 & 1.01110 \\
\hline 1161 & 1 & & 70 & & 1.89938 & 0.10848 & 4.05533 & 0.47317 \\
\hline 6786 & & & & & 1.91228 & & & \\
\hline 1229 & & & & & & & & 55 \\
\hline 888 & & & & & 2.10037 & & 4.78 & 5893 \\
\hline 7505 & 0.90818 & 0 & & 45 & 1.68895 & 0.18433 & 6.79087 & 0.80568 \\
\hline 7573 & & & & & & & & 0.32946 \\
\hline 452 & & & & & & & & 0.07812 \\
\hline 10927 & & & & & 10.72231 & & 3.88 & 0.10960 \\
\hline 5964 & 0.87000 & & 14 & 0.10055 & 1.49708 & 0.08654 & 4.76196 & 0.31327 \\
\hline 1897 & & & & & & & & 0.14693 \\
\hline 13 & & & & & 71 & & 3.5 & 0.53072 \\
\hline 64 & 1637 & & & 0.03428 & 4.24248 & 0.02708 & 2.90108 & 0.17047 \\
\hline 651 & 1.67528 & 0.06286 & 1.04275 & 0.04599 & 2.21284 & 0.03838 & & \\
\hline 720 & & & & & & & & \\
\hline 1 & & & & & 2.06199 & 0.09575 & 4.77959 & 0.51265 \\
\hline 399 & 3.38575 & 0.02374 & & 0.01762 & 7.78670 & 1240 & 2.55373 & 0.13061 \\
\hline 1282 & & & 0.85223 & 0.06550 & 2.08299 & 0.05516 & 3.16112 & 0.35116 \\
\hline 1081 & rT & & 1.03263 & 0.09397 & 1.97172 & 0.07904 & 3.44093 & 0.59470 \\
\hline 829 & & & 0.96855 & 0.04300 & & & 3.09130 & 0.21529 \\
\hline 4482 & 0.82764 & 0.15675 & $\ldots$ & $\ldots$ & 1.79999 & 0.09794 & 4.19127 & 0.40209 \\
\hline
\end{tabular}


A. Alves-Brito et al.: Abundance variations in the globular cluster M71 (NGC 6838), Online Material p 13

Table 5 - continued

\begin{tabular}{|c|c|c|c|c|c|c|c|c|}
\hline $\begin{array}{l}\text { ID } \\
\text { (1) }\end{array}$ & $\begin{array}{c}\text { Fe5335 } \\
\text { (2) }\end{array}$ & $\begin{array}{c}\sigma \mathrm{Fe} 5335 \\
\text { (3) }\end{array}$ & $\begin{array}{c}\text { Fe5406 } \\
\text { (4) }\end{array}$ & $\begin{array}{c}\sigma \mathrm{Fe} 5406 \\
(5)\end{array}$ & $\begin{array}{c}\mathrm{NaD} \\
(6)\end{array}$ & $\begin{array}{c}\sigma \mathrm{NaD} \\
(7)\end{array}$ & $\begin{array}{c}\mathrm{Al} 3953 \\
(8)\end{array}$ & $\begin{array}{c}\sigma \mathrm{Al} 13953 \\
(9)\end{array}$ \\
\hline 1486 & 1.79260 & 0.09804 & 1.10070 & 0.07184 & 1.62756 & 0.06126 & 2.37508 & 0.39374 \\
\hline 3909 & 1.55553 & 0.14598 & & & 1.78727 & 0.08849 & 3.77577 & 0.74441 \\
\hline 1087 & 1.56550 & 0.12960 & 0.98579 & 0.09431 & 2.00786 & 0.07938 & 3.51205 & 0.49106 \\
\hline 387 & 0.82944 & 0.16243 & 0.79228 & 0.11748 & 1.62529 & 0.10130 & 3.79242 & 0.48981 \\
\hline 778 & 1.74358 & 0.11887 & 1.00316 & 0.08732 & 1.74430 & 0.07325 & 2.93407 & 0.53113 \\
\hline 2045 & 1.09128 & 0.14326 & 0.61309 & 0.10526 & 1.86543 & 0.08843 & 3.23094 & 0.50473 \\
\hline 1292 & 1.47703 & 0.13244 & 0.73218 & 0.09733 & 2.14589 & 0.08061 & 2.48720 & 0.59800 \\
\hline 242 & 1.22167 & 0.15383 & 0.38858 & 0.11451 & 1.87789 & 0.09458 & 6.53663 & 0.28232 \\
\hline 212 & 3.73995 & 0.04812 & & & 5.92878 & 0.02682 & 2.71097 & 0.34024 \\
\hline 5412 & 1.68524 & 0.06605 & 0.96588 & 0.04844 & 2.36532 & 0.04005 & 3.03503 & 0.25712 \\
\hline 574 & 0.77934 & 0.17349 & 0.37815 & 0.12625 & 1.48217 & 0.10809 & 3.75212 & 0.48791 \\
\hline 78 & 0.63643 & 0.20610 & 0.63973 & 0.14822 & 1.80273 & 0.12771 & 3.05079 & 0.64166 \\
\hline 1561 & 1.47053 & 0.14637 & 0.51445 & 0.10777 & 1.77911 & 0.09100 & 0.18369 & 0.79269 \\
\hline 1894 & 0.39047 & 0.21706 & 0.55319 & 0.15640 & 1.60446 & 0.13524 & 3.93562 & 0.64747 \\
\hline 881 & 0.92866 & 0.05714 & 0.77508 & 0.04178 & 1.70466 & 0.03691 & 3.64786 & 0.11143 \\
\hline 7014 & 1.05350 & 0.16653 & 0.62449 & 0.12075 & 1.72585 & 0.10407 & 4.24166 & 0.46861 \\
\hline 11907 & $\cdots$ & & 0.21974 & 0.19226 & 1.72373 & 0.16724 & 3.96968 & 0.89711 \\
\hline 523 & 1.27628 & 0.10225 & 0.63888 & 0.07516 & 1.66726 & 0.06379 & 2.70793 & 0.32215 \\
\hline 2229 & 1.48455 & 0.30012 & 0.09952 & 0.22388 & 1.84882 & 0.18548 & 4.19124 & 1.13152 \\
\hline 2153 & & & & & 1.54874 & 0.11257 & 4.85807 & 0.44442 \\
\hline 513 & 2.05710 & 0.04221 & 1.49305 & 0.03065 & -0.77358 & 0.02760 & & \\
\hline 5843 & 2.25559 & 0.03652 & 1.42794 & 0.02663 & 2.75761 & 0.02204 & 3.79642 & 0.09944 \\
\hline 11331 & 0.25566 & 0.20857 & 0.17199 & 0.15184 & 1.42899 & 0.13115 & 3.50476 & 0.53636 \\
\hline 1144 & 1.00494 & 0.11726 & & & 1.65590 & 0.07363 & 4.00095 & 0.27559 \\
\hline 1815 & 0.81040 & 0.15481 & 0.42560 & 0.11344 & 1.55366 & 0.09775 & 3.42074 & 0.42193 \\
\hline 616 & 1.06674 & 0.15872 & 0.51563 & 0.11617 & 1.98283 & 0.09716 & 3.63461 & 0.49448 \\
\hline 8076 & ... & $\cdots$ & 0.19108 & 0.15584 & 1.45762 & 0.13649 & 4.66239 & 0.69923 \\
\hline 1409 & $\ldots$ & 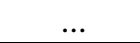 & 0.79311 & 0.16702 & 1.63869 & 0.14313 & 1.58806 & 1.00579 \\
\hline
\end{tabular}

